\title{
TRANSINSTITUTIONALIZATION: A CASE STUDY OF TWO RESIDENTIAL CARE FACILITIES IN RURAL MIDWEST NORTH AMERICA
}

\author{
A Dissertation \\ Presented to \\ The Faculty of the Graduate School \\ At the University of Missouri
}

In Partial Fulfillment

Of the Requirements for the Degree

Doctor of Philosophy

\section{By}

RENEE DESNEIGE CHRISTENSEN

Dr. Benyamin Schwarz, Dissertation Supervisor

May 2015 
The undersigned, appointed by the dean of the Graduate School, have examined the

dissertation entitled

\section{Transinstitutionalization: A Case Study of Two Residential Care Facilities in Rural Midwest North America}

presented by Renee Christensen, a candidate for the degree of Doctor of Philosophy, and hereby certify that, in their opinion, it is worthy of acceptance.

Professor Benyamin Schwarz

Professor Ruth Tofle

Professor Coleen Galambos

Professor Newton D’Souza 


\section{DEDICATION}

Dedicated to my brother, Michael Samuel Hoffman (February 9, 1963-February 17, 2011), who found no shelter in this world from the storms of life. 


\section{ACKNOWLEDGEMENTS}

I would like to thank the faculty and staff of the Department of Architectural Studies at the University of Missouri for providing me with the knowledge and skills required to complete this process. Dr. Benyamin Schwarz, a simple "thank you" does not seem sufficient for the support, guidance, and encouragement you provided throughout my studies. Dr. Ruth Tofle, thank you for being a positive role model and seeing my abilities which I had not yet realized. Dr. Newton D'Souza, thank you for challenging me to become an efficient researcher and giving me the tools for achievement. Dr. Colleen Galambos, thank you for mentoring me and encouraging me to incorporate areas of study that I would not have considered on my own.

I would also like to thank my family: parents, Liliane and Dennis Hargiss; children, Amber, Christie, Tyler, Jordan, Luke, and Eli; sisters, Michelle, Nancy, and Laurie; and brothers, Michael and Rick, for their unending support and understanding through this difficult but rewarding process.

Thank you to my friends for reminding me to stay grounded, especially Shannon, who continually reminded me of the value of humor in difficult times.

Last, but not least, thank you for all the participants in this study for sharing insights into their lives and reminding me of the importance of this project. 


\section{TABLE OF CONTENTS}

$\begin{array}{ll}\text { Acknowledgement Page } & \text { ii }\end{array}$

List of Figures

$\begin{array}{lll}\text { Abstract } & \text { vii }\end{array}$

Chapter One: Introduction $\quad 1$

Statement of the Problem $\quad 4$

Purpose of the Study 4

Research Questions $\quad 5$

Limitations $\quad 6$

Motivation for Study 6

$\begin{array}{ll}\text { Chapter Two: Methods } & 7\end{array}$

Grounded Theory 9

Case Study 10

Study Sites $\quad 10$

Data Collection 16

Data Analysis 18

Ethical Standards $\quad 20$

Validity $\quad 21$

$\begin{array}{ll}\text { Chapter Three: Conceptual Framework } & 22\end{array}$

Institutionalization 34

Normalization $\quad 35$

Social Role Valorization $\quad 37$

Civil Rights Movement 38

Deinstitutionalization 38

Civil Rights Movement 41

Recent Legislation 41

Community Mental Health Centers $\quad 41$

Residential Care Facility 45

$\begin{array}{ll}\text { Chapter Four: Findings } & 51\end{array}$

The Places 52

Bridgemont $\quad 52$

$\begin{array}{ll}\text { Stoneybrook } & 63\end{array}$

The People $\quad 74$

Public Administrators (Guardians) $\quad 75$

$\begin{array}{ll}\text { Government Officials } & 81\end{array}$

Facility Administrators $\quad 82$ 
Facility Staff Members $\quad 84$

Visitors $\quad 86$

$\begin{array}{lr}\text { Family } & 87\end{array}$

The Community $\quad 89$

Residents $\quad 90$

$\begin{array}{lr}\text { Public Policy } & 105\end{array}$

Chapter Five: Discussion $\quad 116$

Daily Rounds 116

Eating 118

Bath and Body Care $\quad 122$

Ostracism

126

Built Environment Contributions 130

Conclusions $\quad 141$

Transinstitutionalization 143

Implications for Research 144

$\begin{array}{lr}\text { Exhibit A } & 146\end{array}$

$\begin{array}{lr}\text { References } & 149\end{array}$

$\begin{array}{ll}\text { Vita } & 153\end{array}$ 


\section{LIST OF FIGURES}

Figure 1: Bridgemont, Floor Plan, first floor $\quad 11$

Figure 2. Bridgemont, Floor Plan, second floor 12

Figure 3. Stoneybrook, Floor Plan, third floor $\quad 13$

Figure 4. Stoneybrook, Floor Plan, first floor 14

Figure 5. Stoneybrook, Floor Plan, second floor 15

Figure 6. Brownes Hospital $\quad 23$

Figure 7: Beamsley Almshouse $\quad 24$

Figure 8: Pennsylvania Hospital $\quad 26$

Figure 9: Paterson General Hospital $\quad 27$

Figure 10: Paterson General Hospital $\quad 27$

Figure 11: Eastern State Hospital $\quad 30$

Figure 12: Kirkbride Plan $\quad 32$

Figure 13: Nevada State Hospital $\quad 32$

Figure 14: Fairfield State Hospital 33

Figure 15: Deinstitutionalization graph 39

Figure 16: Large facility with 206 beds in a metropolitan area $\quad 47$

Figure 17: RCF operated by Christian organization $\quad 48$

Figure 18: Resident bedroom at RCF operated by Christian organization 48

Figure 19: Institutional building converted into a RCF 46

Figure 20: RCF with home-like appearance $\quad 50$

Figure 21: RCF with apartment/duplex appearance $\quad 50$

Figure 22: Bridgemont, west façade $\quad 53$

Figure 23: Bridgemont, west façade $\quad 49$

Figure 24: Bridgemont, east façade $\quad 53$

Figure 25: Bridgemont, axon drawing, Main entrance 54

Figure 26: Bridgemont, axon drawing, first floor $\quad 55$

Figure 27: Bridgemont, kitchen $\quad 56$

Figure 28: Bridgemont, first floor corridor $\quad 58$

Figure 29: Bridgemont, first floor corridor $\quad 58$

Figure 30: Bridgemont, axon drawing, second floor $\quad 60$

Figure 31: Bridgemont, second floor corridor $\quad 61$

Figure 32: Bridgemont, axon drawing, third floor $\quad 62$

Figure 33: Bridgemont, Third Floor, skylight $\quad 62$

Figure 34: Bridgemont, third Floor, skylight $\quad 62$

Figure 35: Bridgemont, stairwell $\quad 62$

Figure 36: Bridgemont, elevator $\quad 62$

Figure 37: Vernacular architecture, Broadway Street ca.1900 63

Figure 38: Vernacular architecture Broadway Street ca. $1900 \quad 63$

Figure 39: Broadway Street, 2014

Figure 40: Broadway Street, 2014 
Figure 41: Stoneybrook, north façade $\quad 64$

Figure 42: Stoneybrook, north façade $\quad 64$

Figure 43: Stoneybrook, axon drawing, first floor, main entrance 65

Figure 44: Stoneybrook, south façade $\quad 66$

Figure 45: Stoneybrook, smoking porch 66

Figure 46: Stoneybrook, Floor Plan, first floor 67

Figure 47: Stoneybrook, interior front door, view from inside the sitting room 68

Figure 48: Stoneybrook, female bedroom $\quad 69$

Figure 49: Stoneybrook, female bedroom $\quad 69$

Figure 50: Stoneybrook, dining/living/recreation room 70

Figure 51: Stoneybrook, kitchen $\quad 71$

Figure 52: Stoneybrook, kitchen $\quad 61$

Figure 53: Stoneybrook, laundry area leading to bathroom $\quad 72$

Figure 54: Stoneybrook, bathroom $\quad 72$

Figure 55: Stoneybrook, Floor Plan, second floor $\quad 73$

Figure 56: Bridgemont, axon drawing, second floor 119

Figure 57: Stoneybrook, axon drawing, dining area $\quad 122$

Figure 58: Bridgemont, axon drawing, shower room and bathroom 122

Figure 59: Stoneybrook, axon drawing, first floor bathroom 123

Figure 60: Bridgemont, axon drawing dining area 133

Figure 61: Stoneybrook, axon drawing, first floor 134

Figure 62: Bridgemont, axon drawing, second floor 135

$\begin{array}{ll}\text { Figure 63: Stoneybrook, axon drawing, first floor } & 138\end{array}$ 


\title{
Transinstitutionalization: A Case Study of Two Residential Care Facilities in Rural Midwest North America
}

\author{
Renee Desneige Christensen \\ Dr. Benyamin Schwarz, Dissertation Supervisor
}

ABSTRACT

Since deinstitutionalization began during the 1950's in North America, thousands of individuals with a Severe and Persistent Mental Illness were forced out of large, state run, institutions. While society may have seen deinstitutionalization as a positive direction for society, the outcome of this grand plan is obscure because the plan made no provision for new living environments for this population and funding issues prevented adequate community support services. Therefore, many individuals with a mental illness became homeless, makeshift living environments were developed without prior understanding of the specific housing needs, and funding issues prevented adequate community-based support services for this vulnerable population. In addition, current public policy prohibits a full range of activities of daily living which ensure the continued institutionalization of this population.

In this qualitative case study I interviewed residents living in Residential Care Facilities (RCFs) and participants in their lives in an effort to understand the interaction between the residents and their environment. The findings from this study illuminated the daily struggles of individuals with a mental illness and the substantial effects of the interaction between the residents and their social and physical environments. The results show that the individuals living in Residential Care Facilities exhibit institutionalized behaviors and the program of deinstitutionalization was never realized for these individuals.

The program of deinstitutionalization was supposed to ensure more freedom and choices for individuals with a mental illness. Instead, these individuals were transinstitutionalized as opposed to deinstitutionalized. 


\section{CHAPTER ONE}

Introduction

The Centers for Disease Control and Prevention (CDC) reports that the World Health Organization (2013) published studies which reported as many as twenty-five percent of all United States adults have a mental illness and that nearly fifty percent of U.S. adults will develop at least one mental illness during their lifetime. In addition, according to the World Health Organization (WHO), mental illness results in more disability in developed countries than any other group of illnesses, including cancer and heart disease, and created an economic burden of about $\$ 300$ billion in 2002 (CDC, 2013).

Although not all individuals who develop a mental illness will become incapacitated to the point where they are unable to care for themselves, some will require assistance with day-to-day living activities. Those individuals who are unable to live independently are often appointed a legal guardian and live in some type of facility at some point in their lives.

The total number of individuals with a mental illness living in any type of living facility in the United States is difficult to obtain due to a lack of consistency among the states regarding the definition of "living facility." The National Center for Health Statistics (NCHS) first conducted the National Master Facility Inventory (NMFI) survey in 1963 and continued it in 1967, 1969, 1971, 1973, 1976, 1978, 1980 and 1982 (Vital and Health Statistics of the National Center for Health Statistics, 1985). However they had difficulty obtaining accurate data due to lack of response and definition of living facilities and have not release any additional information since 1982. A report by the CDC in 2009 estimates almost one million mentally ill residents living in 
nursing homes (Centers for Disease Control and Prevention, 2008). Again, because of the problems with definitions, the total number of mentally ill residents in living facilities remains unclear.

Prior to the 1800's mental illness was considered a spiritual issues and the Protestant Reformers remained the primary influence of Early American society and the care of the mentally ill in private homes reflected the importance they place on the family system. Early American thinkers believed the family failed to teach the child good moral character and therefore it made sense to them that their embattled community members could be cared for together in a building that reflected proper values. They intended not only to reform those ignorant of proper moral behavior but also, to set an example for the rest of the community. They not only purchased pre-existing homes, converting them only slightly, but they also built new structures which reflected their ideas regarding morality, spirituality and mental illness. The Enlightenment ideas that swept across North America brought with it ideas that resulted in the advancement of medicine into an organization and socially powerful profession (Forty, 1986). The medicalization of mental illness during the mid-1800's dramatically changed the face of mental illness in the United States. Mental illness was no longer seen as a spiritual issue but a medical one. These ideas resulted in the construction of large, state-run, asylums.

Physicians, Pilippe Pinel and William Tuke's development, during the late $18^{\text {th }}$ century, of a nonviolent and nonmedical treatment known as Moral Treatment affected the design of asylums during that time. 
Several social movements during the first part of the $20^{\text {th }}$ century provoked a revolution in the way mental illness would be viewed. Theories of Normalization and Social Role Valorization attempted to reverse the exclusionary and discriminatory practices against individuals with a mental illness. These theories affected American laws during the 1950's and led to the deinstitutionalization of hundreds of thousands of Americans with a mental illness.

According to psychiatrist and author Thomas Szasz (2007), "deinstitutionalization is the policy and practice of transferring homeless, involuntarily hospitalized mental patients from state mental hospitals into many different kinds of de facto psychiatric institutions funded largely by the federal government" ( $p$. 34). Once a refuge from the unrelenting demands of a rapidly changing and complex world, the shelter sought by millions of people for more than a century would no longer be available. While society may have seen deinstitutionalization as a positive direction for society, the outcome of this grand plan is obscure because the plan had no provision for new living environments for this population.

The social response to deinstitutionalization was the development of ad-hoc living facilities for individuals with a mental illness called Residential Care Facilities (RCFs). These facilities were not based on research regarding specific social and environmental needs of individuals with a mental illness and, as a result, many individuals live in make-shift facilities throughout the country. This study attempted to gain an understanding of how these individuals are managing their illness within the confines of a RCF by illuminating their day-to-day experiences. 


\section{Statement of Problem}

Little is known about the daily lives of individuals living in a RCF. There have been minimal efforts to understand their daily lives and the substantial effect of the interaction between the individuals and their environment. There continues to be insufficient understanding of how the physical and social environment is responding to the needs of this vulnerable population. The perpetuation of poor design of long-term care facilities for the mentally ill is the result of a lack of understanding regarding the specific housing needs of this population. Without research to inform design, individuals with a mental illness are forced to live in institutional settings and conform their behavior to an environment that does not meet their needs.

\section{Purpose of Study}

Jaber Gubrium (1975) conducted an ethnographic study which examined the social organization of care in a single nursing home in his landmark book Living and Dying in Murray Manor. In his effort to bring the "complicated meanings of living and dying in an institution" to light through the participants' perspectives (Gubrium, 1975, p. xiii). Little is known about how individuals living in an RCF are managing their day-today-activities and how their basic needs for food clothing and shelter are being met.

The purpose of this study is to increase the understanding of the unique social organization of individuals living in a RCF. This study inquired into the daily routines of participants- residents, guardians, RCF staff members, administrators, family and visitors in two RCFs in rural Midwest United States in an effort to gain insight about how these individuals are managing their daily lives within the confines of a RCF. 


\section{Research Questions}

The research questions revolved around this unique situation where individuals with a mental illness are involved in developing a unique world in which each participant struggles to negotiate their roles, develop goals, and strive to get their needs met within the specified setting. This study specifically asks:

1. Who are the individuals living in Residential Care Facilities (RCFs)?

2. What is the everyday life like for these individuals?

3. How do staff members, the Administrator, guardians, and program representatives affect the everyday lives of the residents?

4. What is the interaction between the residents and the physical environment?

5. What are the architectural elements that either assist or impede in the goals of the participants.

\section{Limitations of Research}

This study is not meant to be a generalization of all facilities throughout the country abstracted from time and place. There is a wide array of facility forms and sizes throughout the United States. The facilities chosen to be representational of other facilities in rural Midwest United States and the experience of the participants in this study to be common among other individuals at the time.

\section{Motivation for the Study}

Deinstitutionalization was a grand plan to toward the humane treatment of individuals with a mental illness. Before the demolition of the large asylums throughout the country individuals with a mental illness has a place to go that provided them with shelter from the storms of life. 
While it is true that these asylums had many issues that needed to be resolved, tearing them down eliminated an important safety net for individuals with a mental illness because they were not replaced with an adequate substitute. Current inpatient psychiatric facilities are few and far between and are not readily accessible to these individuals.

In addition, in the past, when individuals would enter asylums they would often do it voluntarily. A majority of them maintained their rights to enter and leave the facility. However, today's society often robs these individuals of their decision making rights by appointment of a legal guardian. Therefore, many individuals with a mental illness are reluctant to engage in mental health services due to the threat that their rights may be taken away from them. They live on the fringe of society in an effort to protect themselves from the legal system.

Individuals with a mental illness suffer from homelessness, insufficient income, and lack of proper food and clothing. Many lose control over their lives. This was not the intention of the plan of deinstitutionalization.

As more and more individuals are being diagnosed with a mental illness every year.as budgets for mental health services dwindle. Resources for individuals with a severe and persistent mental illness are becoming obsolete and housing for these individuals are developed on antiquated models of care. 


\section{CHAPTER TWO \\ Methods}

In an effort to understand how individuals are managing individuals with a mental illness are managing their lives in today's care landscape. A qualitative approach helped to uncover complex meanings through lived experience of residents in Residential Care Facilities.

A qualitative research design lends itself to the understanding of the complexities of the realworld conditions through an inductive approach which emphasizes the development of thick descriptions (Yin, 2011). John Creswell (2013) defines qualitative research as beginning with

assumptions and the use of interpretive/theoretical frameworks that inform the study of research problems addressing the meaning individuals or group ascribed to a social or human problem. To study this problem, qualitative researchers use an emerging qualitative approach to inquiry, the collection of data in a natural setting sensitive to the people and places under study, and data analysis that is both inductive and deductive and establishes patterns or themes. The final written report or presentation includes the voices of participants, the reflexivity of the researcher, a complex description and interpretation of the problem, and its contribution to the literature or a call for change (p. 44).

Furthermore, qualitative studies allow for a better understanding of particular environments in which participants act and the influence of this context on their actions. Focusing on the processes by which individuals make meaning out of their lives within the confines of a facility lends itself to a qualitative study. In addition, a qualitative study provides a degree of flexibility as new developments emerge from the data.

The province of qualitative research is the world of lived experience- where individual belief and action intersect with culture (Denzin \& Lincoln, 2011). Jaber Gubrium's study highlighted "the complex worlds of caregiving...provides perspectives on the everyday meaning of those 
worlds" through his role as a participant observer" $(1975$, p. xiv). He was able to illustrate how the residents of a nursing home develop an organized social entity through the participants' negotiation of roles, goals, and needs.

Additionally, Erving Goffman's “immediate object in doing field work...was to try to learn about the social world of the hospital inmate, as this world is subjectively experienced by him" (1961, p. ix). Goffman further contended

it was then....my belief that any group of persons-prisoners, primitives, pilots, or patientsdevelop a life of their own that becomes meaningful, reasonable, and normal once you get close to it, and that a good way to learn about any of these worlds is to submit oneself in the company of members to the daily round of petty contingencies to which they are subject 1961, p. x).

Furthermore, epic author of mid- to-late-twenty-first-century North American countercultures, Hunter S. Thompson spent more than a year immersing himself in the lives of his participants. Although he was considered a journalist he experimented with a style where reporters immerse themselves in the lives of their subjects to such a degree that they also become figures in their stories.

Gubrium, Goffman, and Thompson immersed themselves in the setting as much as possible and used observations and participants' statements as data. In an effort to understand the daily lives of individuals living in a RCF I found the ethnographic approach used by Goffman, Gubrium, and Thompson to be fundamental as I attempted to uncover how the residents of RCFs spent their days and the meaning they make out of their world-as they experience it.

I was not a foreigner to either of the two facilities. My employment at the local Community Mental Health Center that provided mental health services to some of the residents allowed 
me to spend numerous hours in each of the facilities (among several others) prior to this study. I was familiar with the facility Administrator, the staff members, residents, and the daily schedules of the two facilities. I had built up a trust that allowed me access to these facilities. Perhaps because of my past frequent presence in the facilities, my presence during the study did not arouse too much suspicion. I sat quietly in the hallway of Bridgemont and in the small sitting room of Stoneybrook. I explained to the residents who inquired that I was no longer an employee of the local Community Mental Health Center but was now "studying architecture."

My frequent presence in various seating areas in both facilities initially gained the attention of a majority of the residents, however, after a few times, they barely noticed and went through their days oblivious to my presence. The rate at which my presence was no more notable than the vending machine in the corridor was surprising. The residents and staff members went through their day as if I was not there. Therefore, I was able to witness the daily life of these individuals as they went about their day, like any other day. I recorded as many interactions as possible. However, since there was constant activity at both facilities recording every interaction was impossible.

\section{Grounded Theory}

Grounded Theory requires a minimization of pre-conceived notions and theories. In lieu of beginning with a hypothesis the researcher must keep her "eyes open and look carefully at individual cases-not in the hope of proving anything, but rather in the hope of learning something" (Eysenck, 1976 as cited in Flyvbjerg, 2011, p. 303). By using Grounded Theory methods I was able to allow the participants to tell their own story instead of attempting to mold their responses into preconceived ideas about their experiences. 
Kathy Charmaz notes that "Grounded Theory methods consist of systematic, yet flexible guidelines for collecting and analyzing qualitative data to construct theories grounded in the data themselves" $(2006$, p. 2). Throughout the study I challenged perceptions of what I thought was going on at the facilities with actual observations and the participants' statements from interviews. All data was constantly adjusted as data revealed the complexity of the situation and formed themes.

\section{Case Study}

Conducting a case study was appropriate for this project because a RCF is a setting that has specific, concrete, environmental boundaries which constitute an individual unit in which many individuals live their daily lives. By focusing on two RCFs I was able to spend a considerable amount of time in the setting and obtain multiple forms of data which allowed an in-depth

analysis, which contains more "detail, richness, completeness, and variance" (Flyvbjerg, 2011, p. 303). The case studies were conducted in two RCFs in the Midwest United States during 2013 and 2014.

\section{Study Sites}

Bridgemont is located in a small town with a population under 1,000 . It was originally built as a small community hospital in 1929. It operated as such until costly repairs were required to comply with federal government regulations. It was forced to close in 1977 and the city sold it to a private organization which converted it to private medical and dental offices. After suffering from extensive water damage from a broken pipe in 1983 it was sold back to the city but remained empty for 4 years. In 1987 it was sold to private owners and used as an alcohol 
and drug treatment center. It operated as such until it was sold to its current owner in 2001.

Since 2001 it has operated as a Residential Care Facility.

\begin{tabular}{|r|c|}
\hline \multicolumn{1}{|c|}{} & LEGEND \\
\hline 1 & Kitchen \\
\hline 2 & Pantry \\
\hline 3 & Medication \\
\hline 4 & Dining \\
\hline 5 & Living \\
\hline 6 & Resident Bedroom \\
\hline 7 & Bathroom \\
\hline 8 & Closet \\
\hline 9 & Recreation \\
\hline 10 & Porch \\
\hline 11 & Shower \\
\hline 12 & Lounge \\
\hline 13 & Office \\
\hline 14 & Storage \\
\hline
\end{tabular}

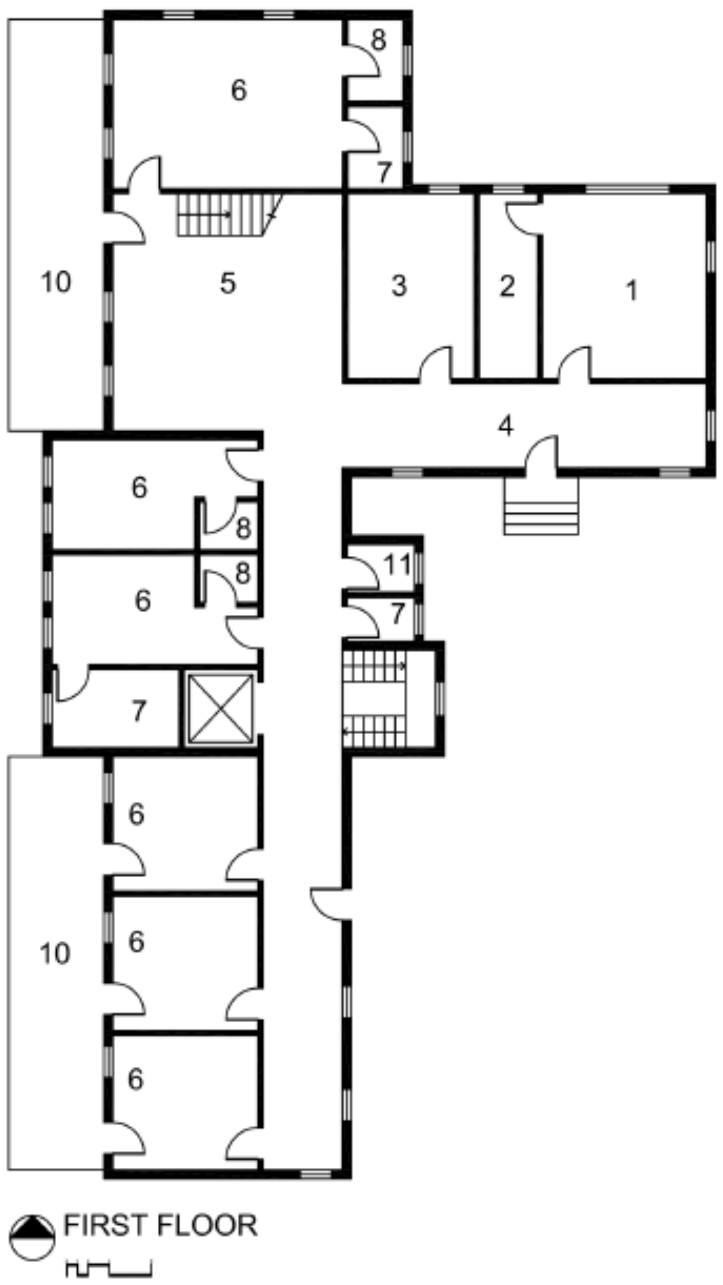

Figure 1. Bridgemont, Floor Plan, first floor.

The floor plan has only minor changes since its original construction. The first floor features an entrance from the street side of the building and an entrance in the rear of the building. There is also a living room, kitchen, medication room, dining area, recreation room, shower room, bathroom (toilet and sink), and several male and female resident bedrooms on the first floor. 
Some of these bedrooms have access to the front porch directly from their room. A $63 \times 8$ foot corridor runs along the spine of the facility on the first and second floor.

The second floor has nine bedrooms accommodating 23 male and female residents.

\begin{tabular}{|r|c|}
\hline \multicolumn{2}{|c|}{ LEGEND } \\
\hline 1 & Kitchen \\
\hline 2 & Pantry \\
\hline 3 & Mecication \\
\hline 4 & Dining \\
\hline 5 & Living \\
\hline 6 & Resident Bedroom \\
\hline 7 & Bathroom \\
\hline 8 & Closet \\
\hline 9 & Recreation \\
\hline 10 & Porch \\
\hline 11 & Shower \\
\hline 12 & Lounge \\
\hline 13 & Office \\
\hline 14 & Storage \\
\hline
\end{tabular}

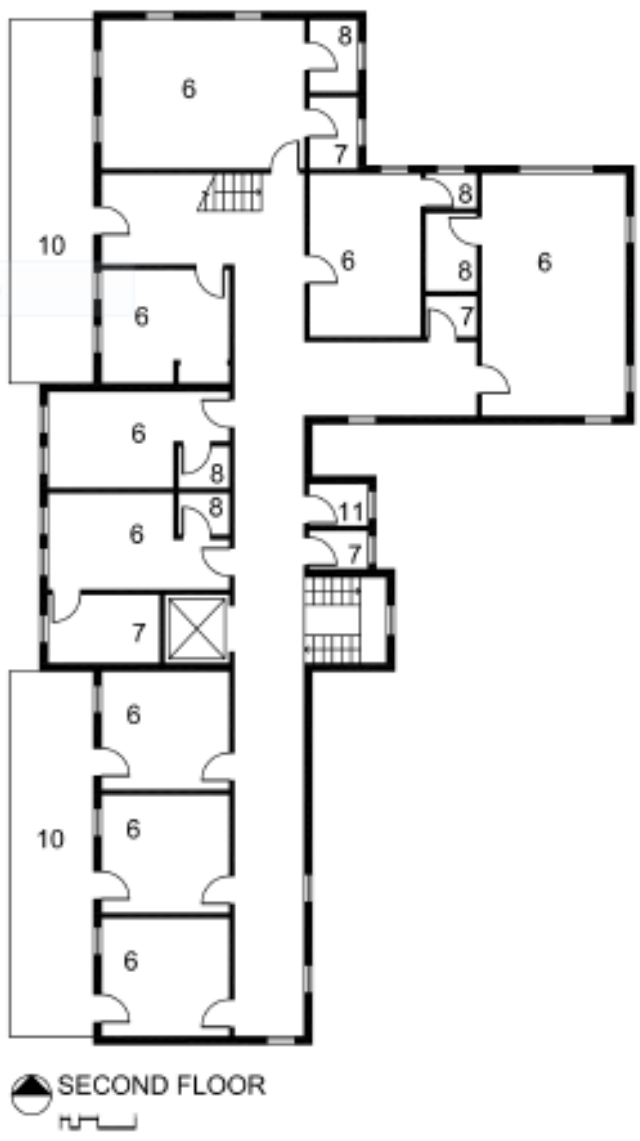

Figure 2. Bridgemont, Floor Plan, second floor

The bathroom, shower room, stairwell and elevator shaft are in the same location as those on the first floor. Also like the first floor, none of the original bathrooms in the rooms are functioning and are now used either for storage or are sealed shut. All of the residents must 
use the bathroom and shower room located off the corridor. However, on this floor there is also a small bathroom with a toilet and sink.

The third floor is accesses through the stairwell at the rear of the building. This floor is off limits to residents and the door leading to these spaces is locked.

\begin{tabular}{|r|c|}
\hline & LEGEND \\
\hline 1 & Kitchen \\
\hline 2 & Pantry \\
\hline 3 & Medication \\
\hline 4 & Dining \\
\hline 5 & Living \\
\hline 6 & Resident Bedroom \\
\hline 7 & Bathroom \\
\hline 8 & Closet \\
\hline 9 & Recreation \\
\hline 10 & Porch \\
\hline 11 & Shower \\
\hline 12 & Lounge \\
\hline 13 & Office \\
\hline 14 & Storage \\
\hline
\end{tabular}
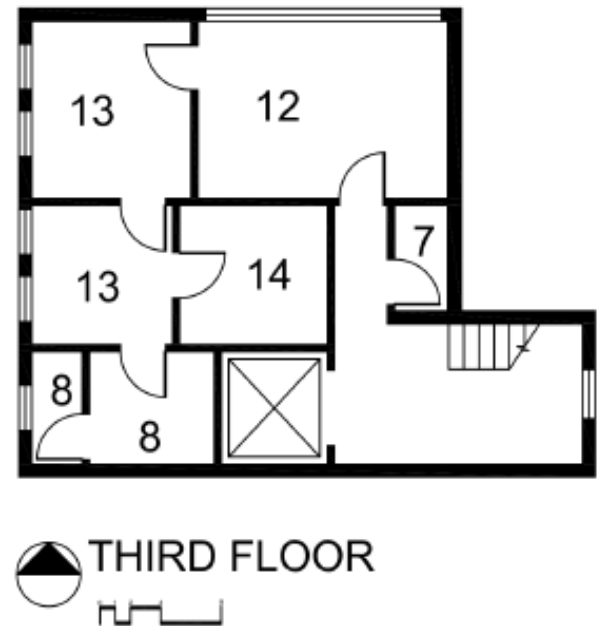

Figure 3. Bridgemont, Floor Plan, third floor.

The third floor is used for the facility Administrators office and storage. There is also a small bathroom on this floor for use by the facility Administrator and other staff.

Stoneybrook is located about 20 miles from Bridgemont in a town with a population of about 10,000 . The facility is located on one of the main street about two blocks from the town's historic town square. 
This facility was built as a private home around the turn of the $20^{\text {th }}$ century. It was used as a private home until the 1980's when it was converted to a Residential Care Facility. It has undergone minor renovations since initially built. Renovations included applying aluminum siding to the exterior, resurfacing wall textures, creating a pantry space in the kitchen, and installing a toilet and sink in a downstairs bedroom.

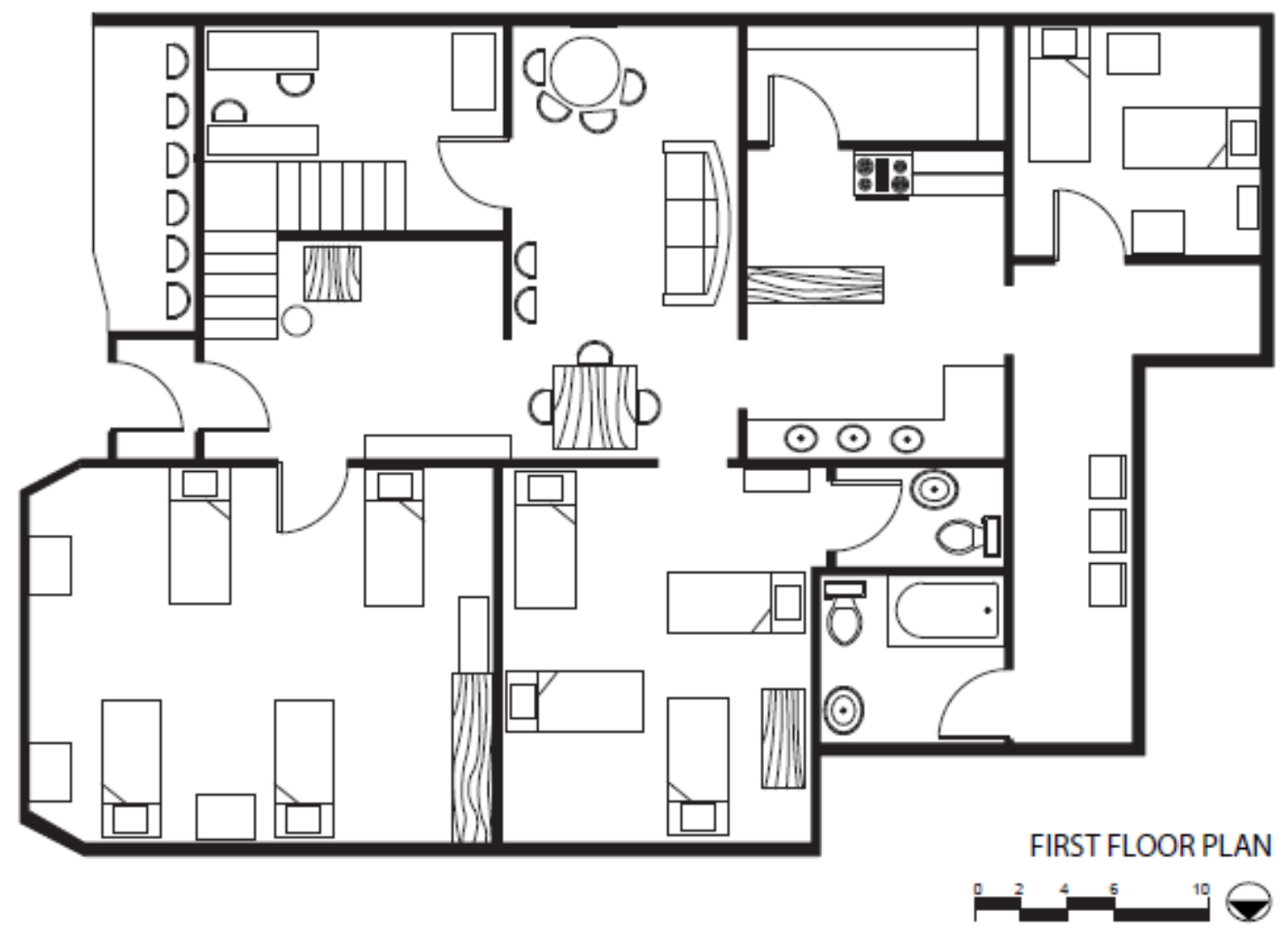

Figure 4 . Stoneybrook, Floor Plan, first floor

This facility has a smoking porch, a small sitting room, living/dining area, medication room/office, kitchen, laundry area, bathroom and three bedrooms on the first floor. One of the bedrooms on this floor has a small bathroom with a toilet and sink. 
The second floor has four more bedrooms and a bathroom. Both male and female residents occupy these bedrooms. Although the all other rooms are at least double occupancy, one room is single occupancy. The residents with bedrooms on this floor are expected to use the bathroom on this floor however, the bathroom on the first floor is used by all residents throughout the day due to its convenient location near the living/dining room.

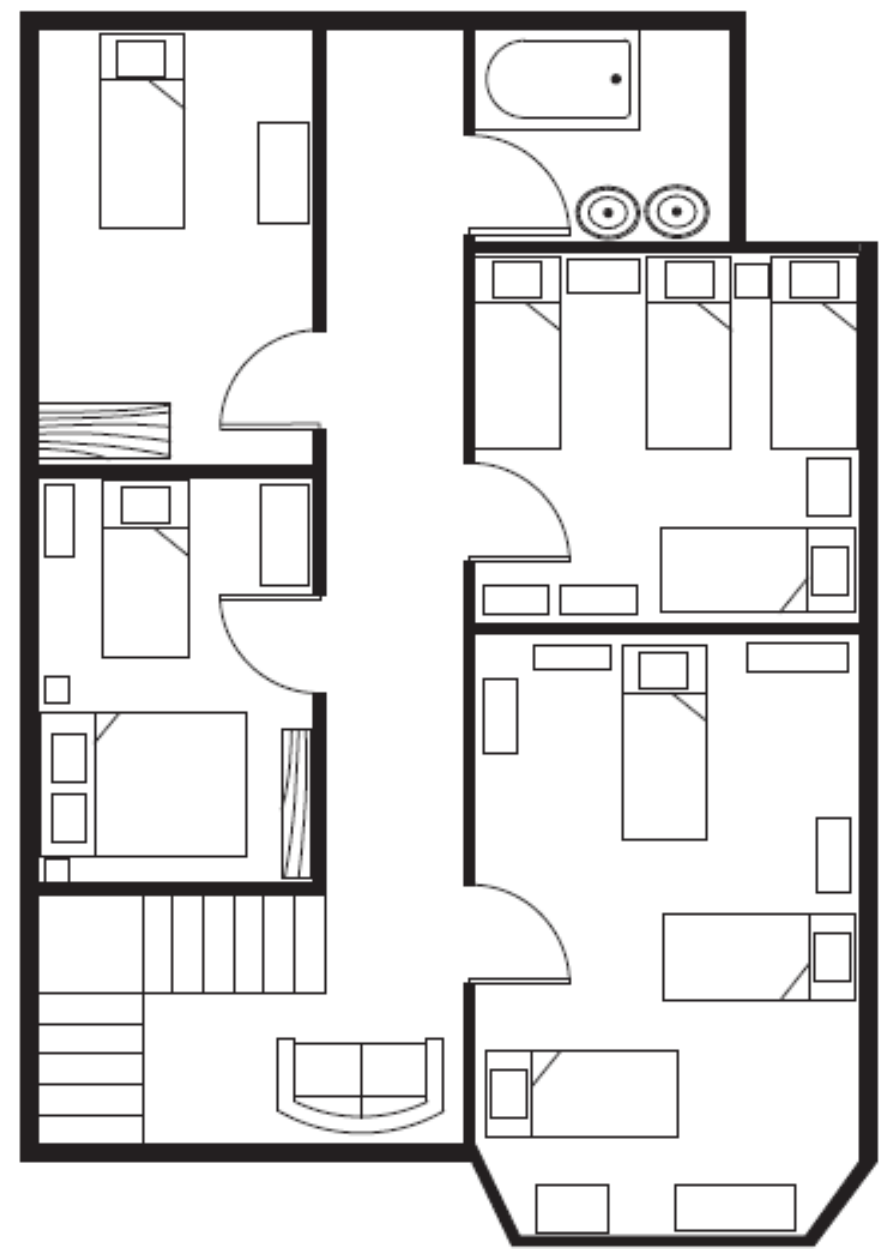

Figure 5. Stoneybrook, floor plan, second floor 


\section{Data Collection}

This study obtained data through interviews with a variety of participants and observations of the staff members and residents' behaviors in each facility. In addition, I drew upon documentation, archival records and photographs.

People are meaning makers and interviews are the most direct way of accessing their experiences. Interviews were conducted with seventeen participants during a 12-month period between 2013 and 2014. Snowball sampling was employed to obtain names for other participants. Initially, interviews were conducted with facility Administrators. Facility Administrators then gave the names of several Public Administrators throughout the state who acted as guardians for their residents. Those Public Administrators signed a Consent to Participate to allow their wards to participate in the study. Those wards were then asked for their Consent to Participate.

Interviews were scheduled for one hour however the times were adjusted to fit the comfort and desire of the participant. Richards \& Morse state "researchers should beware of attempting grounded theory research with structure data records, which preemptively limit what they will hear in response to their preconceived questions" $(2013$, p. 25$)$. In this study I felt it was best to begin by allowing the participants of the study to generate the data without any imposed constrictions. I did not want to limit the range of responses through previously developed protocols for interviews. Therefore the interviews were highly unstructured. I began by asking the facility Administrators, Public Administrators, and program officials how they came to work in their respective fields. I asked the residents questions such as "Could you 
tell me how you came to live in a facility?" and "Can you tell me how you spend your day here?" Follow-up questions were used only to clarify a statement or encourage the participant to elaborate on their previously made statement. Each interview was scheduled for one hour however, the times were adjusted to fit the comfort level of the resident.

Interviews were conducted with six residents. Although the interviews revealed varying individual details, the substance of the answers from the interviews was remarkably similar and provided rich and thick data. After the sixth resident interviewed I felt the study reached saturation and I felt that more interviews would not reveal new directions or information.

Creswell (2013) considers observations to be one of the key tools for collecting data in qualitative research. Richards \& Morse (2013) consider observation as the most natural of all the ways of making data. Observations must take place in the subject's venue that surrounds them in everyday life to highlight trends imbedded in the context (Groat \& Wang, 2002).

In addition, observations also allow the researcher the opportunity to balance the understanding of the phenomenon from the point of view of the participants with an outsider's observations (Groat \& Wang, 2002). As an outsider, the researcher is able to see cultural assumptions, beliefs, values, practices, and behaviors embedded within a cultural group. When the researcher remains open to the phenomenon and allows it to show itself in its fullness and complexity through her own direct involvement and understanding unforeseen meanings and themes could emerge (Seamon, 2000).

Permission was granted from the facility Administrators to observe the activities within the facility. More than 100 hours were spent in the facilities observing the residents' and staff 
members' behaviors, conversations and activities. Observations focused on interactions between the residents and other residents, residents and staff members, residents and extraneous participants (i.e. facility Administrator, visitors, family, pets, etc.). Observations also intently focused on the interaction between the participants and the physical environment.

Observations were recorded as field notes during the observation times and recorded the actual words of participants' conversations and their actions. Field notes also recorded to show movements of the participants from one space to another and their activity within that space.

Observations were made during different days of the week and varying times of the day. Observations were concluded after I felt the interactions were being replicated despite the difference in day or time of the observation and that continued observations would reveal no new informative data.

\section{Data Analysis}

Glaser and Strauss (2006) refer to their method of data analysis as a constant comparison. The participants' statements, observations, field notes, etc. became the data and my role as the researcher was to link the statements together with the observations and other data in an effort to understand the process by which the residents made meaning out of their lives through interactions with others and their physical environment.

Charmaz states "the first analytic turn in our grounded theory journey brings us to coding.... (and) requires us to stop and ask analytic questions of the data we have gathered" (2006, p.

42). Charmaz (2006) describes coding as the critical link between data collection and 
explanation of meaning. Johnny Saldaña defines a code as "a word or short phrase that symbolically assigns a summative, salient, essence-capturing, and/or evocative attribute for a portion of the language-based or visual data" $(2013$, p. 3).

All interviews were audio-recorded, transcribed and coded. An open-coding system was used to capture new insights emerging from the data (Corbin \& Strauss, 2007). Initially, In vivo coding was used to "preserve participant's meanings of their views and actions... and serve as symbolic markers of participants' meanings" (Charmaz, 2006, p. 55).

Observations were coded similar to interview transcriptions with the exception of an initial attribute coding to provide basic description of the setting, time frame and other similar variables of interest.

Johnny Saldaña (2013) notes that the "best approach to analyzing visual data is a holistic, interpretive lens guided by intuitive inquiry and strategic questions" (p. 52). Visual datadrawings, photographs, floor plans, etc. were repeatedly reviewed and analyzed to develop sub-codes for the purpose of allowing a more detailed analysis of the phenomenon. An analysis of photographs, floor plans and other physical characteristics of the setting were conducted with a focus on how the participants in this setting interact with each other and use the spaces within the facility. Theoretical categories were then developed to organize coded data into a more general or abstract framework. 


\section{Ethical Standards}

Access for research purposes to vulnerable populations can be difficult due to their vulnerability to exploitation. Special care was taken to ensure confidentiality was preserved for all the participants in this study.

Application to the University of Missouri Institutional Review Board had been sought and granted for the study. No medical records were accessed. Information regarding residents' medical conditions or medications taken was provided by the residents or staff members.

Participation in this study was voluntary, and the design was such as to provide for the maximum information with as little intrusion into the normal daily events as possible. $\mathrm{A}$ Consent to Participate was signed by each participant. A Consent to Participate was initially signed by the residents' guardians prior to approaching the resident. At no time was the participant personal information used as part of this study's final report.

\section{Validity}

Validity was obtained through triangulation-obtaining multiple sources of data. Throughout the study I constantly compared data gained from various sources-statements made by residents and other participants, observations of behavior, and analysis of the physical setting.

Additionally, I obtained insight from dissertation committee members who ranged in expertise from social work to architecture. 


\section{Reflexivity}

Reflexivity was practiced to expose researcher's epistemological assumptions, their influence on the framing of the research questions and any changes in perspective that might emerge during the course of the study. Charmaz contends,

theorists background assumptions and disciplinary perspectives alert them to certain possibilities...sensitizing concepts and disciplinary perspectives provide a place to start not end. Grounded theorists use sensitizing concepts as tentative tools for developing their ideas about processes that they define in their data (2006, p. 68).

Practicing reflexivity allowed me to make transparent preconceived notions and biases regarding the experience being investigated. This was important for me because I had spent many years working within the system. Throughout my years working with private and public agencies I began to acknowledge my bias against the current treatment of the mentally ill, Residential Care Facilities, and the agencies that are content with the current practices. I approached this study not in an attempt to prove or disprove any existing theory but to allow the participants to tell their story. The use of Grounded Theory provided me with tools for collecting and analyzing data the preserves the participants voice in a way other methods would not allow.

The two study sites allowed me to provide a detailed description of the facilities, the programs and the services offered to the residents. The facilities chosen for this study were similar demographically and geographically, the physical environment and operations of the facilities were representational of the social policy at the time, and the daily operations within the facility reflected current social policy. 


\section{Chapter Three Conceptual Framework}

The development of RCFs after deinstitutionalization began in the 1960's. It was meant to be the solution to the problems associated with the large, state-run asylums. However, the development of the RCF had a long history and evolved from earlier forms of institutions.

Erving Goffman, in his seminal work Asylums, defines a total institution as a "place of residence and work where a large number of like-situated individuals, cut off from the wider society for an appreciable period of time, together lead an enclosed, formally administered round of life" (1961, p. xi ). Thomas Markus wrote, in Buildings \& Power: Freedom \& control in the origin of modern building types, "society's ideological expression not only exists in popular discourse; they also appear in the built environment" (1993, p. 12). The rise of institutions in North America during the 1800's was not a response to a problem that only had one solution (Rothman, 1971). The creation of the institution was a solution to a problem that displaced or resisted other solutions. The social response could have taken shape in diverse ways but the erection of the institution was a product of the forces that reflected societal values.

Institutions reflected society's way of attempting to stabilize their community and alleviate fears in the most economical way. These ideas were reflected in early institutional architecture and was the beginning of a wider and long-term process toward commercialization which, one initiated, was powerful and inexorable (Dalglish, 2005). However, institutions did not resolve societies' anxiety but created its own tensions and conflicts that were instrumental in provoking further change. 
The first institutions were constructed in Europe for the "unproductive poor" who were a threat to property and stability of the community. The increase of indigent individuals in the communities caused an economic strain and attempts to prevent strangers from endangering the town's peace and stability was the main impetus for the establishment of the almshouse. Almshouses were built to limit the mobility of vagrants from one community to another and provide them with a "master" for domestic production.

Although not a hospital by todays definition, Browne's Hospital (1493), Stamford, England, was one of the first houses for the poor. It had partitioned dormitory rooms on both sides of an open central hall and double height chapel at the end.

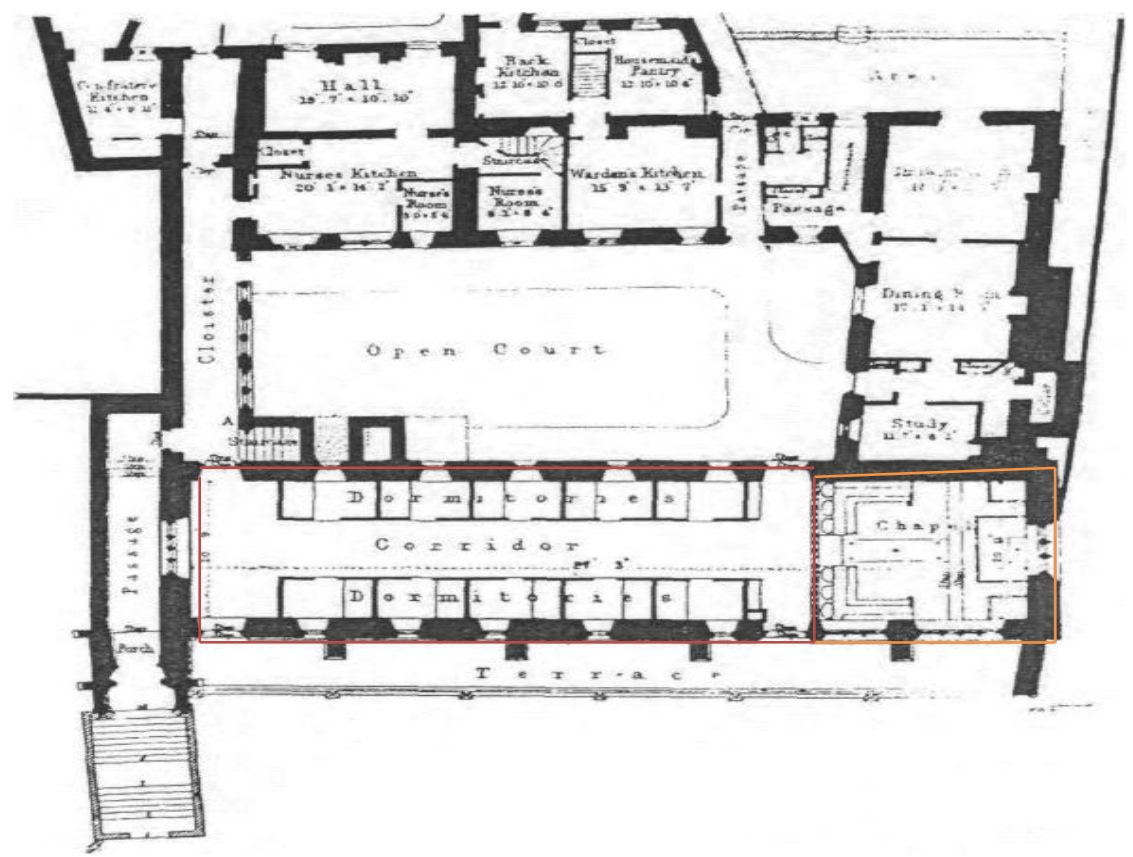

Figure 6. Browne's Hospital, Stamford England, 1493

Another example is Beamsley Hospital in Yorkshire-built to house thirteen women. 


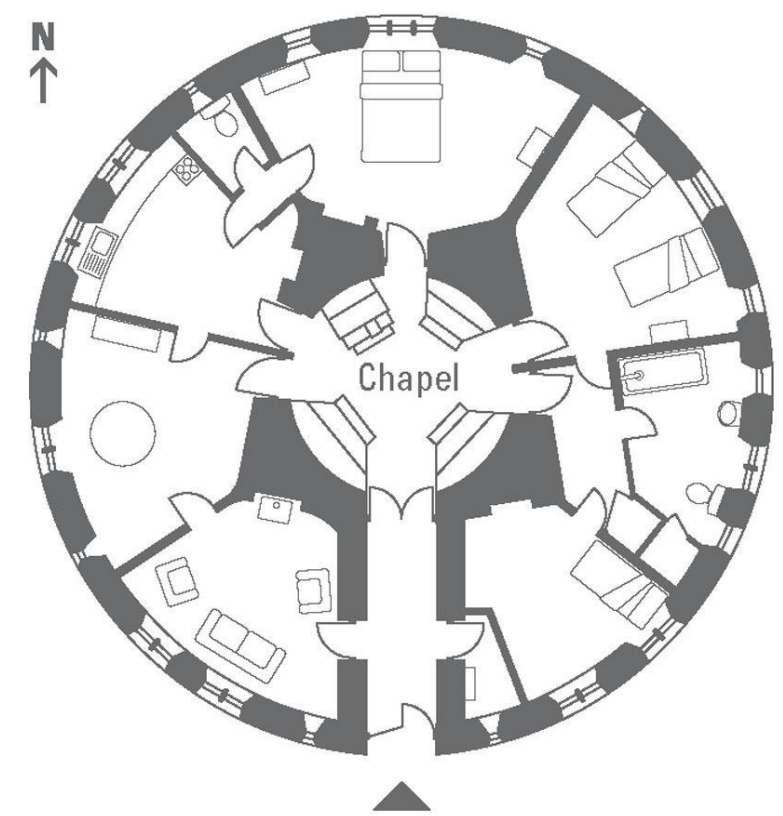

Figure 7. Beamsley Almshouse for women, Yorkshire England, 1593

Markus notes that what lies at the center-the focus and placement of authority figures in institutions is a reflection of society's ideology (1993). The focal point of the design "is an expression of the social, political and economic values which is then translated into space" (Markus, 1993, p. 198). At Beamsley almshouse (Figure 7) the chapel is situated at the center then at Browne's (Figure 6) it is at the far end. Both allow for the perpetual gaze inward, assuring residents that Providence was present. Markus added that it also made them aware of the presence of others gazing at the same point (1993).

In North America, during colonial times, the Protestant Church was the governing authority and the mentally ill were not so much a threat the security of the community but a monetary inconvenience. The church was responsible for providing financial support for the households that cared for this population. Their attitude toward people in need of assistance was that the 
poor would always be with us and the presence of the needy was a God-given opportunity for other men to do good. The Protestant Church considered the poor as the pawns in a divine game where the better sort made the moves and there was no reason to fear a pawn or to alter the rules of the game. The Protestant Church did not distinguish between delinquency and dependency but considered it their moral obligation to care for the indigent. They also saw no reason to penalize or separate the poor. Although policy makers during this enacted laws to care for the poor, the laws focused more on who should administer aid-not who should receive it. The Protestant colonists believed they could not rely on ideas brought from Europe, but instead, wanted to develop systems of care that reflected their religious beliefs.

In North America the colonists attempted to create a social organization that was different from where they came. Early North American colonists considered mental illness a spiritual issue and the Protestant Reformers remained the primary influence of Early American society. The care of the mentally ill in private homes reflected the importance they placed on the family system. Early American thinkers believed the family failed to teach the child good moral character and they intended not only to reform those ignorant of proper moral behavior but also, to set an example for the rest of the community. It made sense to them that their embattled community members could best be cared for together in a building that reflected proper values. They not only purchased pre-existing homes, converting them only slightly, however they also built new structures which reflected their ideas regarding morality and spirituality. However, they were ill prepared for the issues they would be confronted with during the next century. 
During the $18^{\text {th }}$ century the church began to lose its authority and Enlightenment thought affected the power of religious policy makers. The Enlightenment was an intellectual movement that embraced scientific inquiry, encyclopedic development, the inventive spirit, optimistic worldview, and the belief in progress. The belief that the exercise of reason could solve all political, social, religious, and personal problems gained prominence. There was a dramatic shift from the religious to the secular and this was reflected in ideas about the etiology of sickness, vice, and mental illness. Thereafter, these issues were no longer viewed as spiritual issues but could be understood through man's intellectual reasoning. The emerging ideology was both and attempt to understand human behavior and an impetus for the medicalization of mental illness. Questions regarding the etiology of mental illness caused a dramatic effect on the treatment of the mentally ill and affected institutional architecture.

The first hospital erected in North America was Pennsylvania Hospital, established in 1751, and was founded by Benjamin Franklin and Dr. Thomas Bond to "care for the sick-poor and insane of Philadelphia" (Pennsylvania Hospital, 2014a).

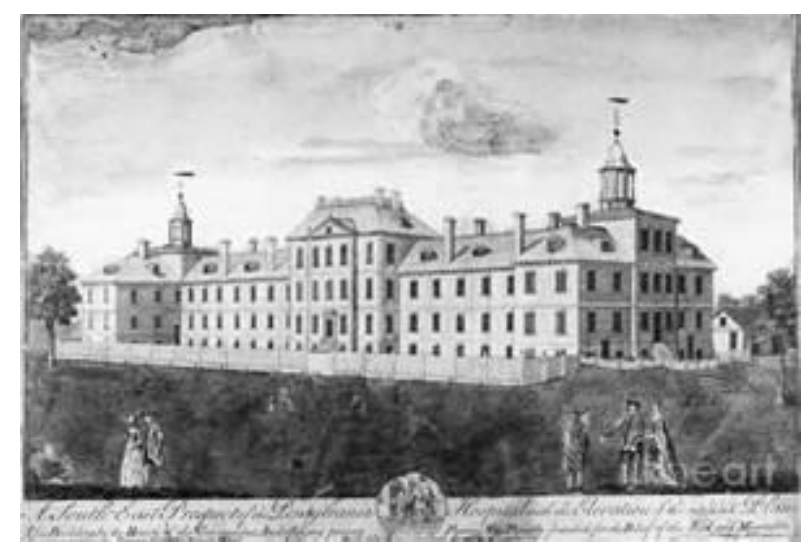

Figure 8. Pennsylvania Hospital, 1755 photograph Source: Bing (2014a)

There remained no distinction between the sick-poor and the insane during this time. 
The Paterson General Hospital (circa 1867), founded by the Sisters of Charity, exemplified the increasingly specialization and dominance of the socially powerful medical organization.

Historians William Nelson and Charles Shriner (1920) note

the sisters were heartily welcomed to Paterson, as the city stood in sad need of a place where the indigent sick could be properly taken care of...The hospital was formally opened, with religious services, on Monday, April 10, 1871, with two patients, in a two-story frame building on Dickerson street, known as the Fifield house, the rent of which, with thirteen lots, for the first year was donated by the landlord, Mr. James Crooks. Forty patients were treated the first year (p. 1.)

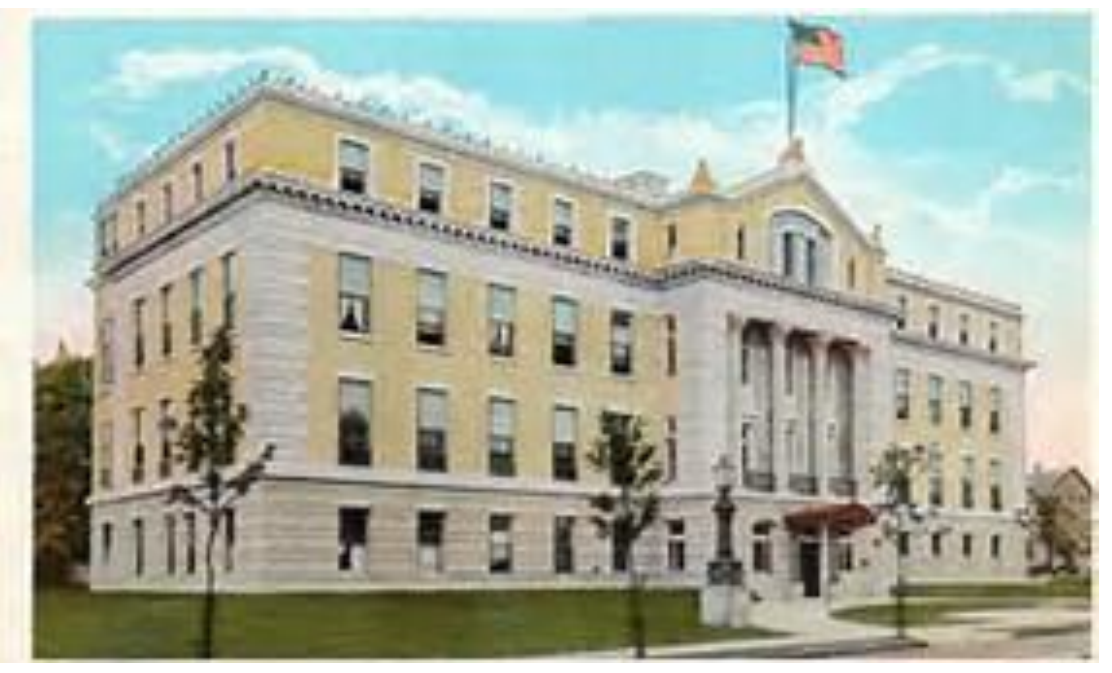

Figure 9. Paterson General Hospital, Paterson, N.J., (circa 1867) Source: Bing (2014b).

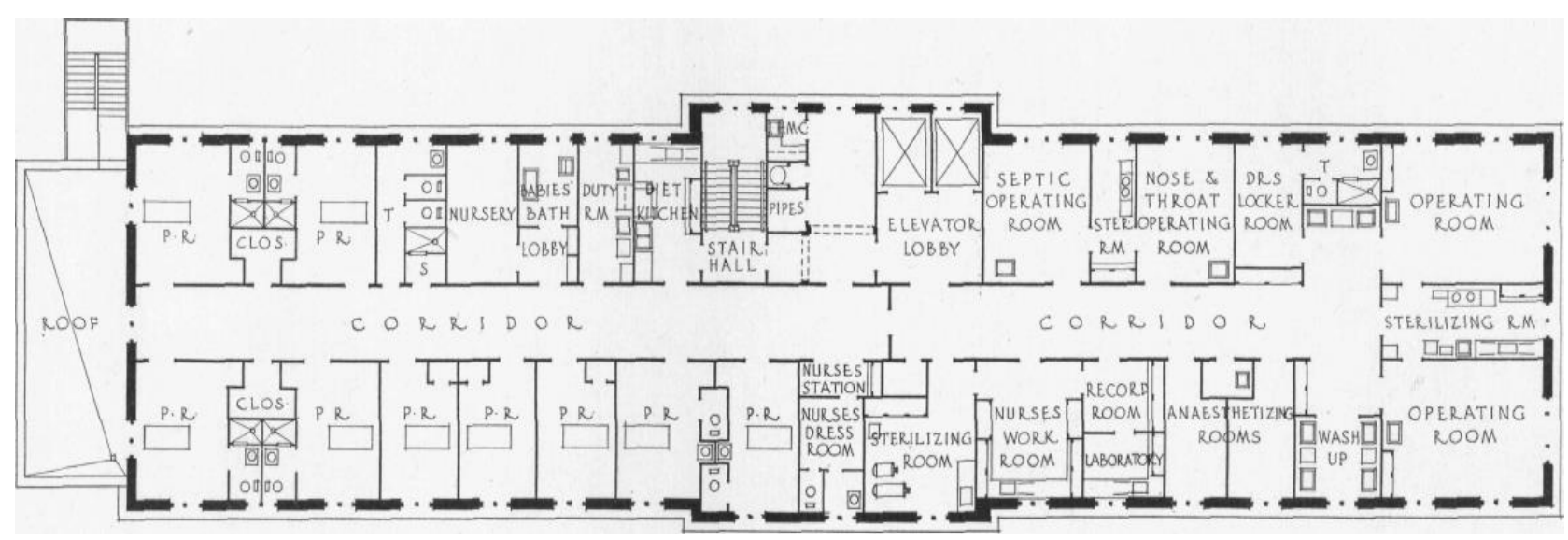

Figure 10. Paterson General Hospital, Paterson, N.J., (circa 1867) Source: Clute 
The Paterson General Hospital created rooms for separate rooms for specialized practices and replaces the chapel at the end of the corridor with the operating room.

As the Industrial Revolution began to take shape and communities began to grow, the care for the mentally ill increased social anxiety about the financial burden they would place on the community. Every man, woman, and child was required to participate in the workforce to keep up with this fast-paced transformation of American society. Policy makers attempted to resolve the problem of caring for vulnerable populations that threatened this growth and reduce the anxiety of growing communities.

Sidney Heath (1910) makes an important distinction between the almshouse and the so-called 'hospital' of the Middle Ages-"a different kind of house for the same kind of inmate" (as quoted in Markus, 1993, p. 97). Sixteenth century European society had a difficult time distinguishing between the impotent poor and idle, study and disorderly beggars. However, as the distinction between the sick, poor, insane and criminal began to emerge society began to attempt to separate the various populations.

As Michel Foucault (1977) notes:

during the 150 or 200 years that Europe has been setting up its new penal systems, the judges have gradually, by means of a process that goes back very far indeed, taken to judging something other than crimes, namely, the 'soul' of the criminal. (And), it is no longer simply: 'What law punishes this offence?' But: 'What would be the most appropriate measures to take? How do we see the future development of the offender? What would be the best way of rehabilitating him?' A whole set of assessing, diagnostic, prognostic, normative judgments concerning the criminal have become lodged in the framework of the penal judgment (p. 19). 
Initially, the prison system grew out of attempts to create a place to wait until the individual was convicted and punished. However, the first prisons were highly permeable: goods, persons and information passed freely in and out. In addition, the early prison system did not have a way of fitting the crime with the punishment.

Italian philosopher and politician Cesare Marquis Beccaria-Bonesana (1738-1794) brought Enlightenment ideas to this chaos. His celebrated treatise Crimes and Punishments (1764) put forth some of the first arguments against the death penalty and advocated for the reform of the criminal justice system. Beccaria's aim to bring to an end to idle chaos and unmeasured punishment would have been impossible to realize had it not been for two pressing issues. The first was the scourge of goal fever which took a heavy toll of prisoners and all in contact with them. The second was related-if goal fever was contagious, Enlightenment society reasoned, vice could be spread like the disease.

Eighteenth-century European society could not determine the cause of goal fever (typhus) and associated it with poor ventilation. Eighteenth century society also believed that if disease could be contagious so could morality. If morality was spread like disease then isolation was the cure. Ideas regarding the contagion persisted throughout the nineteenth century and affected the design of all institutional architecture throughout the world.

Eastern State Penitentiary in Pennsylvania designed by John Haviland encompasses all the features previously discussed and demonstrates the evolution of ideas from the Colonial Period through Enlightenment in the United States. Markus (1993) notes that the perpetual cell- 
bound solitude kept prison inmates segregated and reflected a progression of ideas regarding the prison system-from reformative to punitive.

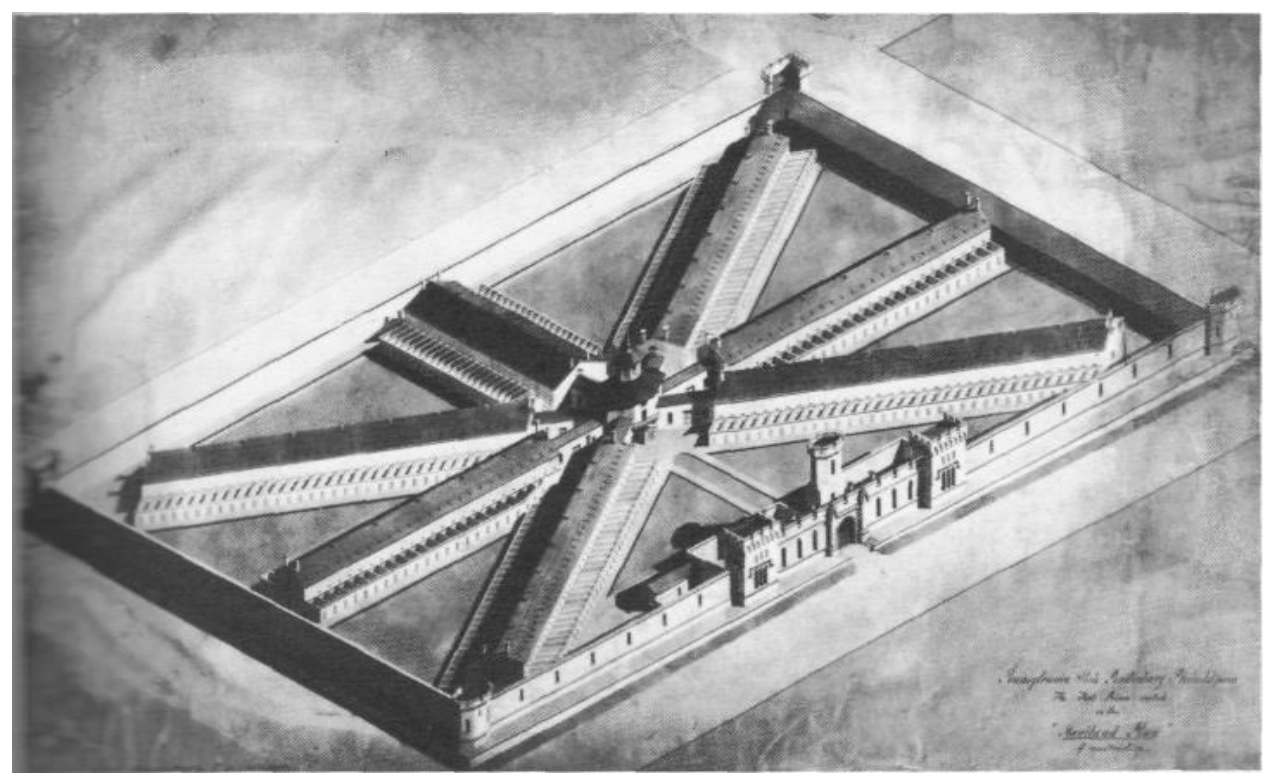

Figure 11. Eastern State Penitentiary, Philadelphia (1821-9). Source: Markus (1993).

Modeled after early panopticon design of Jeremy Bentham, it provided the crucial cellular segregation, insulation from the community, and central surveillance.

Dorothea Lynde Dix (1802-1887) pioneered a movement separate the mentally ill from criminals. She disputed the practice of keeping mentally ill persons in jail because of their burden on society. She appealed to lawmakers to establish facilities for these individuals where they could receive proper care. Her appeals to state legislatures regarding the horrendous treatment of individuals with a mental illness inside prisons and almshouses were the driving force behind the founding of asylums throughout the country. She was instrumental in founding the first public asylum in Pennsylvania, The Harrisburg State Hospital, in 1853. The culmination of her work was the Bill for the Benefit of the Indigent Insane. This legislation set aside $12,225,000$ acres of federal land for the benefit of the insane, blind, deaf and dumb with 
proceeds from the sale of the land distributed to the states to build and maintain asylums. Dix's land bill passed both houses of Congress, but in 1854 President Franklin Pierce vetoed it, arguing that the federal government should not commit itself to social welfare, which was properly the responsibility of the states. Throughout her life she devoted her time and energy to crusade to improve the care of prisoners, the disabled, and the mentally ill. In 1881, Dix moved into the New Jersey State Hospital, Morris Plains, where the state legislature designated a suite for her private use as long as she lived. Although an invalid, she still managed to advocate for the sick poor until her death on July 17, 1887.

Although the form of mental institutions progressed in a similar fashion as other institutions over time, theories regarding moral treatment and the curative powers of sculptured landscape guided the design of mental institutions during the nineteenth-century. Nineteenth-century psychiatrists considered the architecture of their hospitals to be one of the most powerful tools in the treatment of the insane and architects struggled to translate the theories of psychiatrists into a design form. The novel building type that emerged was a result of compromises in the "tensions between home and institution, benevolence and surveillance, medical progress and social control, nature and culture" (Yanni, 2007, p. 1).

Both the Cottage Plan and Thomas S. Kirkbride's Plan agreed upon the curative powers of the landscape. In Kirkbride's Plan, the building form itself was meant to have a curative effect: "a special apparatus for the care of lunacy, [whose grounds should be] highly improved and tastefully ornamented" (Yanni, 2007, p. 14). The idea of institutionalization was thus central to Kirkbride's plan for effectively treating patients with mental illnesses. 
The floor plan was elegant and simple with the administration area in the center with wings on each side stepping back to form a shallow $\mathrm{V}$.

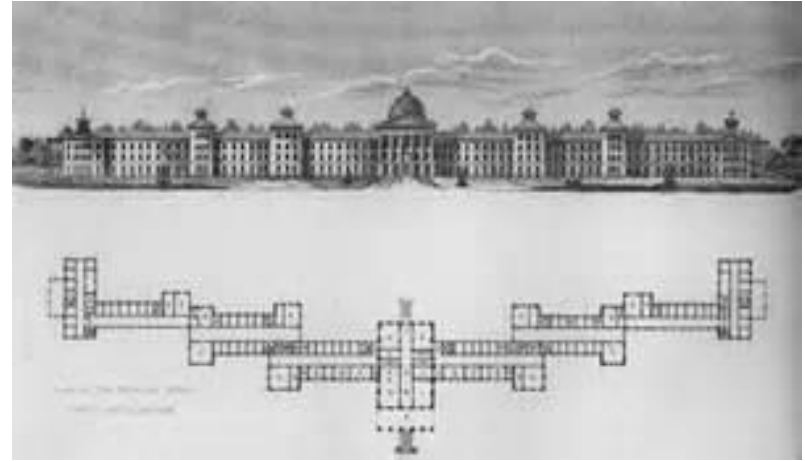

Figure 12. Kirkbride Plan

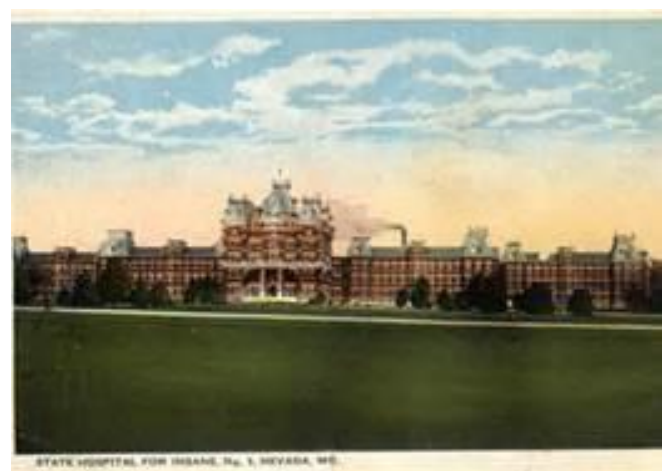

Figure 13. Nevada (Missouri) State Hospital

The most disturbed patients were placed at the wing tips-furthest from the administration area.

The patient's goal was to progress closer to the central area where the superintendent, chapel, (and, metaphorically, God) resided.

The most significant departure from the Kirkbride plan was that the Cottage Plan placed the most violent patients closest to the administration, a complete reversal from the Kirkbride plan. The Cottage Plan allowed for the segregation of noisy and violent patients and situation them closer to the administrative staff to allow for closer supervision. The Cottage Plan such as those developed by Shepley, Rutan and Coolidge for McLean Hospital in Belmont, Massachusetts provided that institution with an "atmosphere of a prep school or well-endowed college" (Beam, 2001, p. 1). The buildings were designed in styles that reflected the high culture of the time and were intended to create a residential, rather than an institutional, effect for patients. The buildings were normally two stories tall or less and connected through a series of underground tunnels. One example of this is the Fairfield Hospital in Connecticut. 
The Honorable Mr. Eddy noted, about Fairfield hospital in Connecticut:

The laying of the cornerstone of the building from which will be administered the conduct of an institution for the care....the cure of those unfortunate people whose minds have become deranged with strange fancies and who have lost control over their thoughts and emotions. Here we hope that the pure air and sunshine and the cheerful outlook on nature so abundantly available on this beautiful hillside, combined with modern equipment and skillful treatment, may make it possible to restore to mental health many who have been groping in the fogs of despondency or hallucinations, and that at least some of the gloom and suffering may be driven from the mind of the incurable (Fairfield State Hospital, 2013, p. 1).

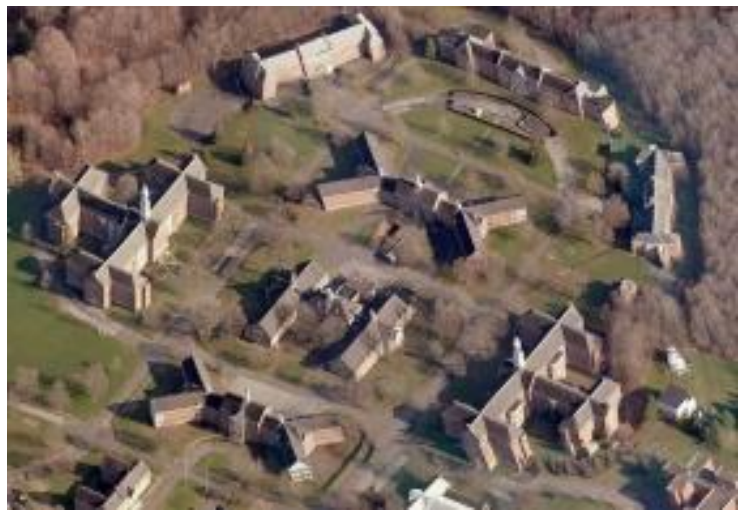

Figure 14. Fairfield State Hospital, Connecticut (established 1929).

Typically an administration building was located at the front of the campus and patient buildings would encircle the campus with communal buildings such as a kitchen, chapel, or auditorium in the center. The placement of the administration building, kitchen and chapel in the center exemplify the utopian ideas regarding reforming the deviant and dependent in the Jacksonian Era in North America..

The mental institutions of the nineteenth century began with good intentions but over the course of a hundred years social critics began to publicize accounts of severe abuse and neglect throughout the hundreds of asylums built across North America. 
However, the medicalization of mental illness had a greater, and more lasting effect, on the treatment of mental illness. As physicians gained greater influence over many areas of social life, they proclaimed authority in mental illness and affected the way mental illness would be portrayed during the next century. Mental illness would no longer considered to be a combination of a variety of social and biological factors but treatment would be focused on medications. Based Canter and Canter's therapeutic environment models, the asylum (and RCF) is a combination of the Medical Model and where the individual with a mental illness is seen "as a patient who has an illness which is to be cured" and the Custodial Model where "individuals are separated and protected from the community at large with a corollary that the community at large is separated and protected from them" (1978, p. 15 and p. 13 respectively).

Despite the many changes throughout the nineteenth century several elements in institutional architecture remain in the twenty-first century. Fears of contagion and insecurities about the economic burden the mentally ill might pose persisted. Individuals with a mental illness continue to be housed in large numbers under one roof for economic purposes. Additionally, institutions continued to be built in rural areas-separate from the community.

\section{Institutionalization}

Despite the closure of most state-run asylums many individuals with a mental illness continue to be confined to institutions. Erving Goffman states the purpose of his work on the process and effects of institutionalization in his seminal book Asylums (1961) was to "learn about the social world of the hospital inmate, as this world is subjectively experienced by him" (p. ix). Goffman (1961) developed a theory about how institutionalized individuals "develop a life of 
their own that becomes meaningful, reasonable, and normal" (p. x). Later, in Stigma (1963), Goffman explores how individuals are disqualified from full social acceptance and how an individual attempts to manage his identity and present himself in a favorable light. While confined, these individuals struggle to make their lives meaningful and gain social acceptance.

Simply dispersing previously institutionalized individuals did not resolve the problems associated with the large state-run asylums. Individuals living in RCFs continue to experience detrimental effects of current public policies that dictate practices and programs within the RCF.

\section{Normalization}

A significant obstacle in developing community supports for individuals with a mental illness has been ignorance and resistance on the part of "normal" community members who have been taught by our society that individuals with a mental illness are somehow fundamentally flawed and it is in society's best interest if they are segregated from other members of society (this developing out of the nineteenth-century ideas about health, morality and contagion).

The sociopolitical concept of normalization can be traced back to Scandinavia during the 1940's (Ericsson, 1985). In the 1940's Sweden's Government Committee developed an early version of the normalization principle and took the position regarding

the handicapped person's relationship to the welfare state. The Committee advocated the handicapped person's right to participating in and availing of, instead of being excluded from the welfare state. This viewpoint also implied a repudiation of institutional life and an institutional system of services. The Normalization principle expressed thereby a socio-political position and the 
handicapped person's right to participation in society. It became consequentially the starting point for the development of services in society for handicapped persons which took place in the 1950's (Ericsson, 1985, p. 2).

Swedish activist Bengt Nirje is internationally known for his work in promoting selfdetermination among people with intellectual disabilities. Critical to his theory of normalization is the inclusion of people with disabilities in all aspects of society-schools, careers, homes, relationships and leisure. Nirje's ideas regarding Community Integration (Cl) were the antithesis of the exclusionary practices during the time.

The work of Nirje affected American politics as well. Title VIII of the Civil Rights Act of 1968 is commonly known as the Fair Housing Act and was meant as a follow-up to the Civil Rights Act of 1964. The 1968 act expanded previous acts and prohibited discrimination concerning the sale, rental, and financing of housing based on race, religion, national origin, and since 1974, gender. Since 1988 the act protects people with disabilities and families with children.

Normalization has had a significant effect on the way services for people with disabilities have been structured throughout the North America, UK, Europe, Australasia and increasingly, other parts of the world. It has led to a new conceptualisation of disability as not simply being a medical issue (the medical model which saw the person as indistinguishable from the disorder), but as a social situation. It is the environment that must be normalized, not the individual. The philosophy of Normalization and Social Role Valorization was apparent in Bridgemont's mission statement: "to promote an individual home environment in all areas of human concern through support, understanding, and opportunity" (facility brochure, 2010). The organization's facility brochure further notes that their management and staff members 
are dedicated to enhancing individual self-esteem and providing opportunities for each individual in areas such as: physical and mental growth, community integration, participating and membership, daily habilitative programming and life skills, and promoting responsibility and independence (2010).

The organization's Mission Statement also reflects ideas regarding normalization

It is our belief that in a Democratic Society, we must assist each individual in realizing his or her own worth and should lead him or her toward becoming the most worthy and productive member of society possible, operating with the least restrictions. It is our responsibility to assist an individual in choosing and maintaining a living environment that will foster and accelerate their intellectual, physical, social and career development (facility brochure, 2010).

\section{Social Role Valorisation}

The principle was further developed during the 1970's, especially by Wolf Wolfensberger in Canada through the National Institute on Mental Retardation (NIMR). Wolfe Wolfensberger coined the term Social Role Valorisation (SRV) to describe his theory about why individuals with disabilities need to participate in socially valuable roles.

Joe Osburn describes the goal of SRV as creating or supporting socially valued roles for people in society,

because if a person holds valued social roles, that person is highly likely to receive from society those good things in life that are available to that society, and that can be conveyed by it, or at least the opportunities for obtaining these. In other words, all sorts of good things that other people are able to convey are almost automatically apt to be accorded to a person who holds societally valued roles, at least within the resources and norms of his/her society $(1998$, p. 9).

Much of Wolfensberger's work has been concerned with ideologies, structures and planning patterns of human service systems especially concerning persons with intellectual disabilities and their families. 


\section{Civil Rights Movement}

Another social movement was also responsible for the future treatment of the mentally ill. The Civil Rights movement during the 1950's and 1960's illuminated prejudicial attitudes not only toward black Americans. This social movement attempted to secure legal recognition and protection of civil rights enumerated in the Constitution of the United Sates. The link is strong between this movement and civil rights for Americans with mental illnesses. Both groups sought relief from segregation and discriminatory practices in education, housing, the workplace, and access to public services.

\section{Deinstitutionalization}

Although Deinstitutionalization existed as a social goal in the United States since the 1950's, it became law on Oct. 31, 1963-just weeks before President John F. Kennedy was assassinated. Known as the Community Mental Center Act, it attempted to bestow full benefits of our society to individuals with a mental illness.

The following graph shows the rate at which deinstitutionalization took place in the United States. 
Figure 1. Mental Patients in State Hospitals, 1959-1990

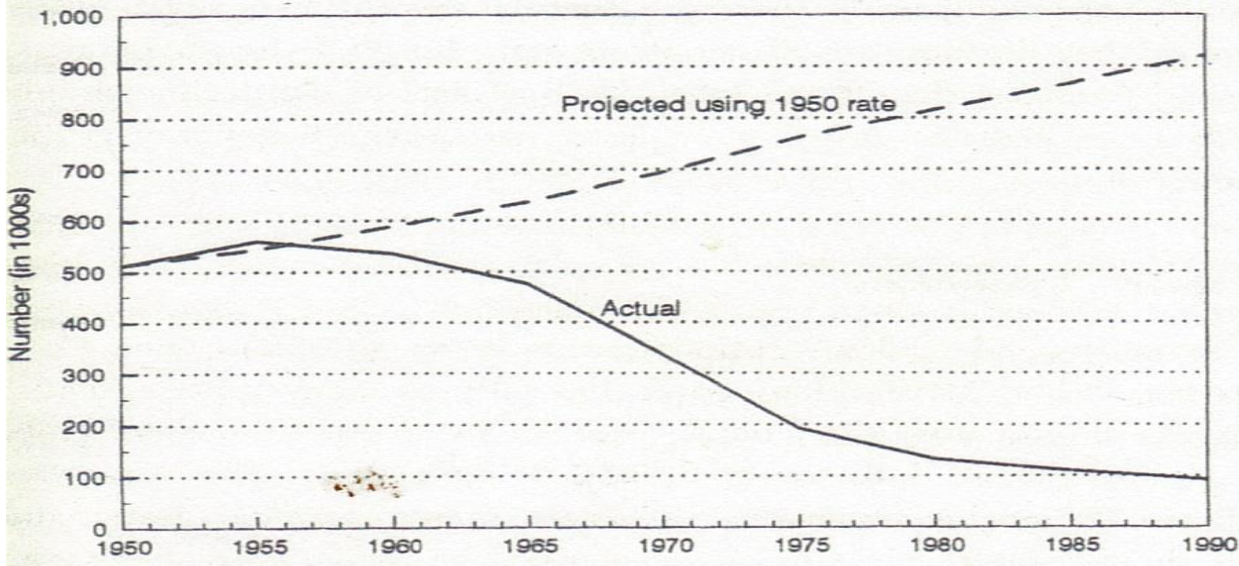

Source: Projections are based on the rate of growth in the civilian, noninstitutional population aged 14 and over. Actual counts for 1950-1985 are taken from David Mechanic and David Rochefort, "Deinstitutionalization: An Appraisal of Reform," Annual Review of Sociology: 16 (1990), 307. The 1990 estimate was provided by NIMH.

Figure 15. Deinstitutionalization graph

This graph shows that in 1955 there were more than 500,000 individuals living in state-run mental hospitals. A little more than 30 years later, the number dropped to under 100,000 . However, another study estimated that there were just over 57,000 individuals living in staterun hospitals by the end of 1998 (Lamb \& Bachrach, 2001).

The Community Mental Health Act (also known as Mental Retardation and Community Mental Health Centers Construction Act of 1963) aimed to build mental health centers accessible to all Americans so that those with mental illnesses could be treated while working and living at home, rather than being kept in neglectful, and often, abusive state institutions, sometimes for years on end. When President Kennedy signed the bill to build 1,500 centers, the population of those living in state mental hospitals -at that time more than 500,000 people-could be cut in half. 
In a special message to Congress earlier that year President Kennedy said the idea was to successfully and quickly treat patients in their own communities and then return them to a useful place in society (Community Mental Health Act: Kennedy's vision never realized, 2014).

While society may have seen deinstitutionalization as a positive direction for society, the outcome of this grand plan is obscure. Deinstitutionalization resulted in the closure of hundreds of large, state-run asylums for the mentally ill, mentally retarded or developmentally disabled. Once a refuge from the unrelenting demands of a rapidly changing and complex world, the shelter sought by millions of people for more than a century would no longer be available.

The program of deinstitutionalization could have led to more opportunities for a variety of living situations for the mentally ill. However, the plan made no provision for the construction of any type of living facilities for individuals with mental illness. Instead, communities grappled with the complex needs of these individuals as they attempted to provide housing and services for them. The result is that hundreds of thousands of individuals were forced out onto the streets in makeshift structures that were poorly equipped to meet their needs.

Although many patients formerly living in institutions were released into the community, not all communities had the funding, facilities, or expertise to deal with them. The failure to develop adequate community-based services resulted in shortages of housing and services. Since the Community Mental Health Act was enacted $90 \%$ of beds have been cut at state hospitals and only half of proposed Community Mental Health Centers were ever built, and those were never fully funded (Community Mental Health Act: Kennedy's vision never realized, 2014). Although 
Kennedy's legislation "provided for $\$ 329$ million to build mental health centers the problem with the legislation is that it didn't provide money to operate the centers long-term. In many cases, this has left the sickest people nowhere to turn, so they end up homeless, abusing substances or in prison. The three largest mental health providers in the nation today are jails: Cook County in Illinois, Los Angeles County and Rikers Island in New York (Community Mental Health Act: Kennedy's vision never realized, 2014). In addition, it is estimated that between one-third and one-half of all homeless were individuals with a mental illness (NIMH, 2000).

In the 1970's and 1980's mental health services increasingly shifted from the federal government to state and local levels. Meanwhile, the federal government continued to reduce financial support. These cutbacks for states, counties and individuals with a mental illness had significant consequences in community-based services.

\section{Recent Legislation}

In the 1990's two women living in a state hospital in Georgia wanted to live in the community. They believed their lives would be better and their treatment team agreed. Despite being voluntarily committed, they were not permitted to leave. The two women filed suit under that Americans with Disabilities Act for release from the hospital. On June 22, 1999 the United States Supreme Court held in Olmstead vs L.C. that unjustified segregation of persons with disabilities constitutes discrimination in violation of Title II of the Americans with Disabilities Act. The court held that public entities must provide community-based services to persons with disabilities. 
The Supreme Court explained that its holding reflects two evident judgments:

Institutional placement of persons who can handle and benefit from community settings perpetuates unwarranted assumptions that persons so isolated are incapable of or unworthy of participating in community life; (2) Confinement in an institution severely diminishes the everyday life activities of individuals, including family relationships, social contacts, work options, economic independence, educational advancement, and cultural enrichment (Olmstead vs. L.C. 2014, p. 1).

Basically, all states must make community living options available to people with disabilities when

the state's treating professionals have determined that a community placement is appropriate; the transfer from an institution to a more integrated setting is not not opposed by the affected individual; and, the placement can be reasonably accommodated, taking into account the resources available to the state and the needs of other person with disabilities (Olmstead vs. L.C., 2014, p. 1).

In an egalitarian society respect for human dignity demands that basic human needs, such as food, clothing, and shelter be accessible to all people. However, as deinstitutionalization proceeded, little thought was given to housing needs of this fragile population. Perhaps policy makers misunderstood the theory of normalization to mean the mentally ill, mentally retarded or developmentally disabled population would be able to go out into the community, be provided with the basic human needs and live as close to a normal life as possible. Here, the pressure is on the individual to adjust their behavior to meet the needs of society instead of on society to provide all members equal opportunities. Equal opportunities does not mean that everyone is treated the same. It requires an understanding of unique needs relative to issues of empowerment of this population. 
Despite the initial goals of deinstitutionalization inadequate planning, a lack of understanding

of the specific housing needs, and poorly understood demands on the community-based

mental health services resulted in the failure of this program.

\section{Community Mental Health Centers}

The program of deinstitutionalization included the development of support services. The support services were to be developed by private organizations with oversight and funding to be provided by the state and federal governments. Community Mental Health Centers

(CMHC's) are private organizations that manage and deliver mental health services to a specified geographical area. The purpose of the CMHC's is to provide community-based care, as an alternative to institutionalization. According to the Centers for Medicare and Medicaid

Services (2014), a CMHC is

an entity that meets applicable licensing or certification requirements for CMHCs in the State in which it is located; and must provide all of the following core services to meet the statutory definition of a CMHC. However, effective March 1, 2001, in the case of an entity operating in a State that by law precludes the entity from providing the screening services. The entity may provide for such service by contract with an approved organization or entity (as determined by the Secretary) that, among other things, meets applicable licensure or certification requirements for $\mathrm{CMHCs}$ in the State in which it is located. A CMHC may receive Medicare reimbursement for partial hospitalization services only if it demonstrates that it provides such services. The core services include: Outpatient services, including specialized outpatient services for children, the elderly, individuals who are chronically mentally ill, and residents of the CMHC's mental health service area who have been discharged from inpatient treatment at a mental health facility; 24 hour-a-day emergency care services; Day treatment, or other partial hospitalization services, or psychosocial rehabilitation services; and screening for patients being considered for admission to State mental health facilities to determine the appropriateness of such admission. (p. 1).

However, as Erving Goffman (1961) has noted that "mental patients can find themselves crushed by the weight of a service ideal that eases the life for the rest of us" (p. 386). 
Furthermore, Eric Sundstrom (1986) contends that the organizations effectiveness, defined as the extent to which an organization efficiently accomplishes its mission while maintaining continued viability, relies heavily upon the effectiveness of the roles played by all users of the structure. For institutions to remain viable they must place order based on a stable category of people, objects and activities, together with a set of rules which govern interactions.

Support services through $\mathrm{CMHC}$ can range from case managers to therapists to psychiatrists. $\mathrm{CMHC}^{\prime}$ s have psychiatrists on staff along with many therapists. Their community support services will often include a case manager. The case managers can help them with a variety of issues from balancing their bank accounts, getting their bills paid, assisting with medical appointments (including transportation arrangements) developing, practicing social skills and managing social interactions assisting them with accessing and maintaining other community services and program (Food Stamps, HUD, Medicaid/Medicare, Social Security, etc.). These services are imperative for the success of individuals with a mental illness living independently but less necessary for the individuals living in an RCF because the staff members at the RCF assume these responsibilities.

The local CMHC also

provides psychosocial rehabilitation services PSR. The goals of PSR to restore an individual's ability for independent living, socialization and effective life management. With psychosocial rehabilitation, clients are provided with numerous opportunities for social, recreational and vocational activities. Participants learn and improve skills needed to succeed in these activities (Burrell Behavioral Health, Services, 2014, p. 1).

In 2010 The Affordable Care Act provided a variety of approaches to improving the healthcare system in the United States. Section 2703 of the Act allows to states to amend their Medicaid 
state plan to provide Healthcare Homes for enrollees with chronic conditions. A Healthcare Home is a place where individuals can go to have their healthcare needs identified and receive medical, behavioral and related social service support they need. For individuals with a Severe and Persistent Mental IIIness (SPMI) the CMHC became their Healthcare Home.

The Centers for Medicare and Medicaid Services (CMS) expect Healthcare Homes to achieve a variety of outcomes. Two of these outcomes are: decrease reliance on long-term care facilities; and, improve experience of care, quality of life and consumer satisfaction through their support services.

In spite of the lofty expectations of CMHCs to provide desperately needed support services to this vulnerable population it is estimated that deinstitutionalization resulted in 2.2 million without the services they desperately need (Torrey, 1997).

\section{Residential Care Facility}

Residential Care Facilities are an offshoot of nineteenth-century asylums. The development of Residential Care Facilities was intended to be a humanitarian response to the "hellish... atrocious...inhumane" living conditions in asylums (Taylor, 2010, p. 1). Despite asylums failures regarding their therapeutic aims, they continue to be replicated, only in smaller versions. No new type of living facility has been developed for them that "support and promote the values, social relationships, and patterns of activities that are dominant in the society at that time" (Franck, 1994 as quoted in Schwarz, 1996, p. 255) and provides them with a personally meaningful place. 
Although nursing homes used for psychiatric care proliferated during the 1980 's, Residential

Care Facilities (RCFs) are the state and local response to the housing needs for individuals with a mental illness. The definition provided by the state says a Residential Care Facility is a facility

which provides 24-hour accommodation, board, and care to three or more residents who need or are provided with supervision of diets, assistance in personal care, storage, distribution or administration of medications, supervision of health care under the direction of a licensed physician, and protective oversight, including care during short-term illness or recuperation (Missouri Department of Health and Senior Services, 2013a, p. 1).

There are about 398 licensed RCF's in the state where this study took place with more being licensed every year (DHSS, 2013a). Licensure allows the facility to contract through various state agencies and receive federal and state funds for the care they provide to their residents.

Throughout the state there exists a wide variety of sizes and types of RCFs. The maximum number of residents was 206 while the minimum was two. However, the minimum number was misleading because, while a facility listed " 2 " as their bed capacity, they were actually a nursing home which designated two of their beds for RCF beds. The larger facilities were located in metropolitan areas (Figure 10) while the smaller were located in very rural areas. 


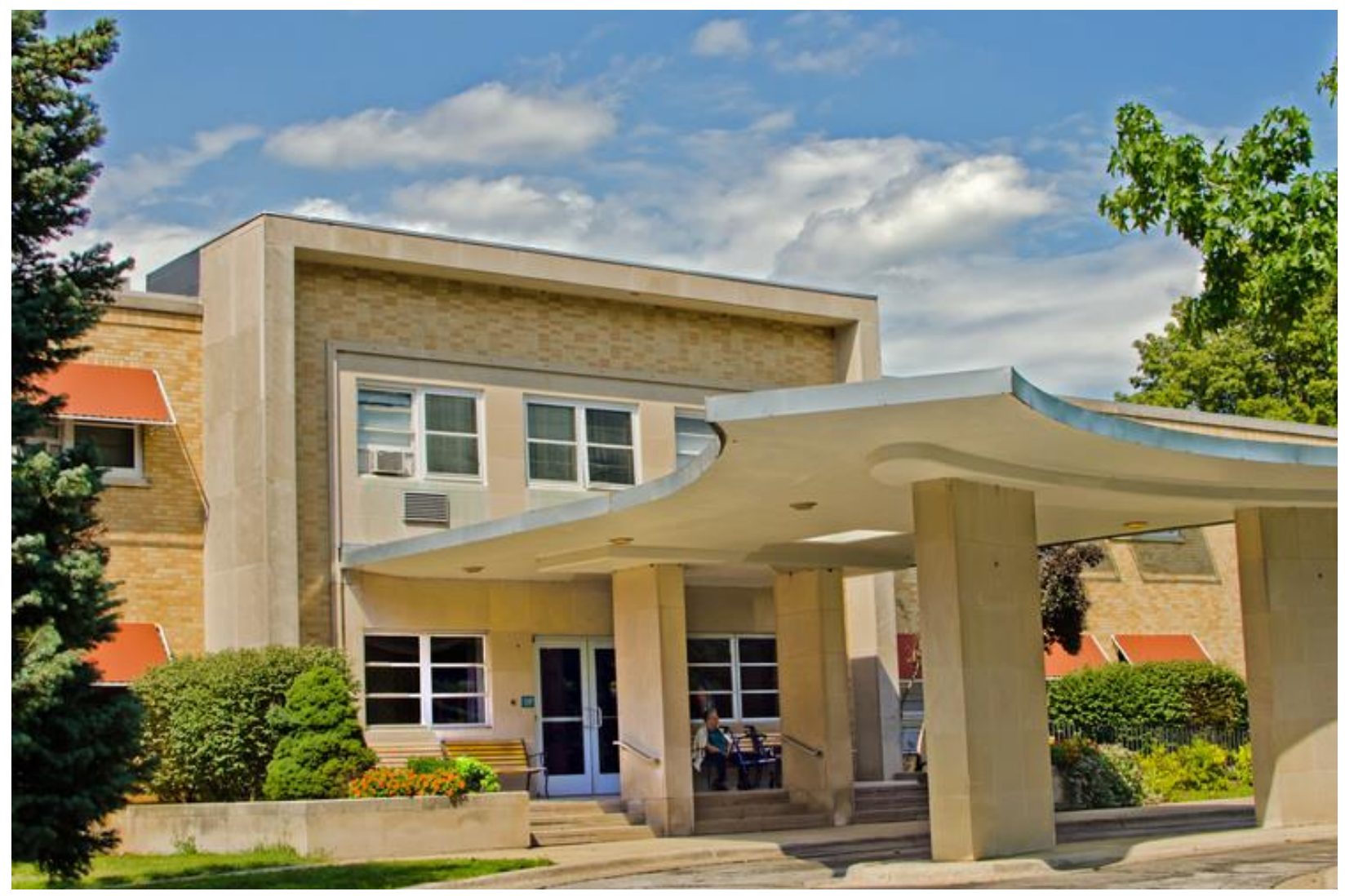

Figure 16. Large facility with 206 beds in a metropolitan area.

Larger facilities, such as the one in Figure 10 offer more on-site services than the smaller ones.

The facility in Figure offers services which include a Licensed Administrator, Licensed Director of Nursing, Consulting Certified Dietitian, Activity Director, Consulting Pharmacist, Psychologist, Psychiatrist, Home Health, Wound Care, Eye Doctor, Podiatrist, and Diabetic Services. This facility also offers the following: Physical freedom in a large, spacious community; Full activity and recreational programs; Beautiful acreage close to nature; Quality meals with choice of entrée; Planned physical activity and exercise; Daily housekeeping from friendly staff; Library area; Recreation room for games, tv, and billiards; Beauty shop and barber services; 300 -seat chapel with services each week; Additional physical care when able and appropriate; Outdoor places to walk, with wildlife all around; Full maintenance staff ready to help; Personal laundry 
available (Sunnyside Manor, 2014). While the basic services are covered by Medicaid, Medicare, or VA payments, many services require out-of-pocket or private insurance payments.

The smaller facilities limited their services to ones required by the state: a licensed Administrator; twenty-four hour staff; medication management; reminders or assistance with bathing; three meals per day; daily housekeeping, weekly linen laundry and a calendar of activities.

Although one company owned more than 50 RCFs, a majority of them are either owned or operated by small companies that own 2-4 facilities. Several are owned by a single or a few individuals (usually family members). There were also a few that were run by religious organizations. One Christian, not for profit, organization operates the facility in Figures 11 \& 12.

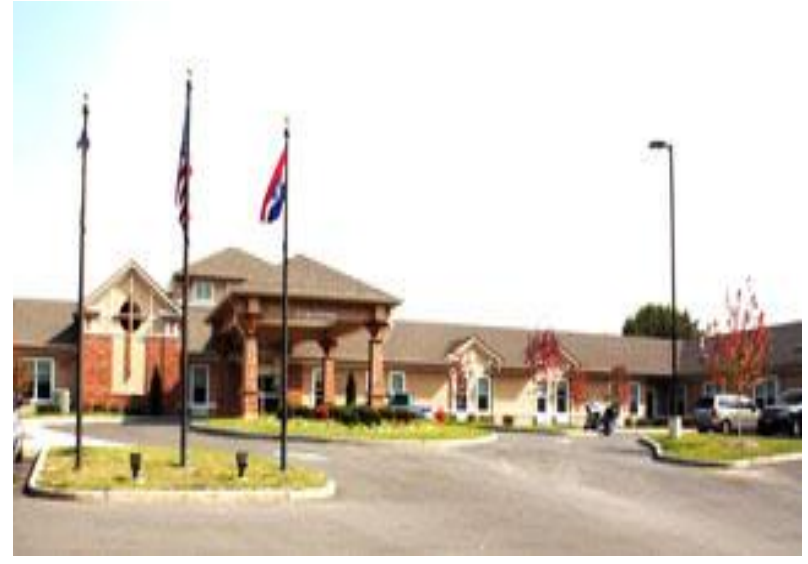

Figure 17. RCF operated by Christian organization

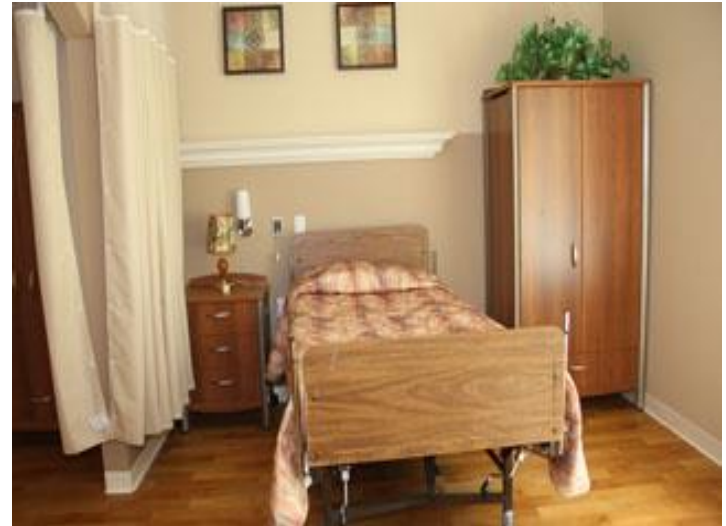

Figure 18. Resident bedroom at RCF operated by Christian organization

The facility ran by the Christian organization in Figures $17 \& 18$ posted the following scripture as their mission statement: "...Inasmuch as ye have done it unto one of the least of these my brethren, ye have done it unto me. Matt 25:40 KJV." (quoted by Christian Care, 2014). 
The type of buildings used for RCFs also varied greatly. Several RCFs have been converted from abandoned storefronts, hotels, and other institutional buildings and converted into a RCF.

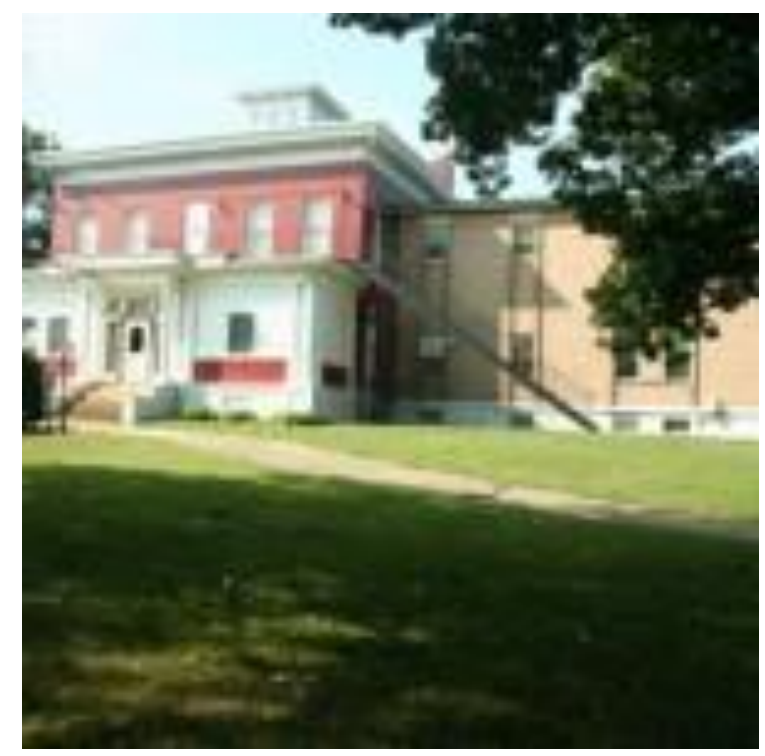

Figure 19. Institutional building converted into a RCF.

The conversion would be inexpensive and relatively easy for a facility of similar type, such as a nursing home, however it can be costly for older buildings to meet current fire and safety codes. Therefore, many newly licensed facilities are built for the specific purpose of a RCF. The exterior appearance of newly built RCFs range from resembling nursing homes (Figure 11) to single-family home-like structures (Figure 14) or apartment/duplex style appearance (Figure 15). 


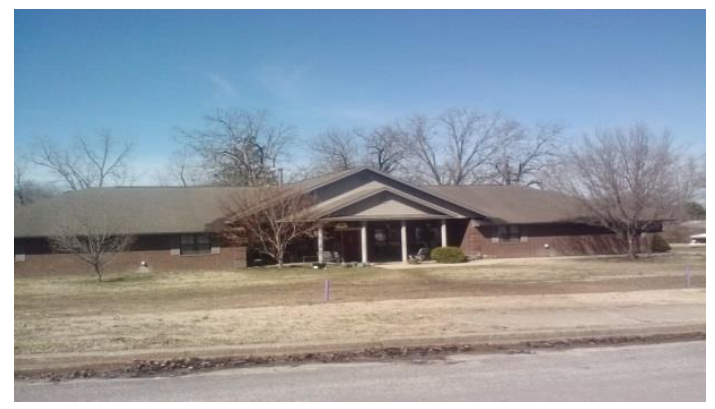

Figure 20 . RCF with home-like appearance.

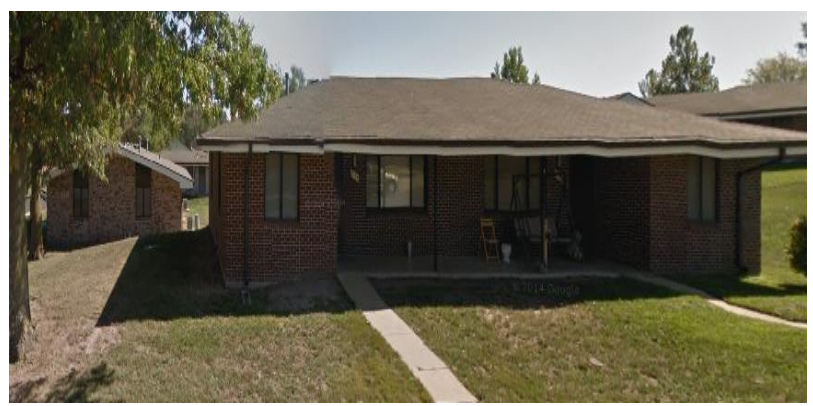

Figure 21.RCF with apartment/duplex style appearance

The development of the RCF was based on a long history of building types and programmatic and economic considerations. Theories of Normalization and Social Role Valorization could have resulted in a variety of negative outcomes. While the type of building became more varied (ranging from more institutional types to residential types) programmatic considerations remain unchanged. The programmatic consideration dominated the daily lives of individuals living in a RCF and perpetuated their institutionalization.

Fears and anxieties regarding contagion and threats to the security of community members linger. Despite theories of Normalization and Social Role Valorization the lives of individuals with a mental illness continue to be segregated from society. The RCFs that have been developed embody the practices of housing large numbers of individuals under one roof and concerns of safety and security over an individual need of competency in transactions with one's environment (Parmelee \& Lawton, 1990). 


\section{CHAPTER FOUR \\ Findings}

The data collected from the participant interviews, observations, and analyses of features of the built environment provided me with valuable information to answer my research questions. This section is organized into four categories: the two study sites; the people within the facilities; public polies that affected the daily lives of the individuals, and; the interaction between the facilities, public policies and the people.

\section{The Places}

Both Residential Care Facilities are located in the same county, in Midwest United States. Both facilities were built for other purposes and then converted into a Residential Care Facility (RCF). I felt these Residential Care Facilities were representational of many Residential Care Facilities in the area.

Both facilities had access to similar services within their community such as a public library, grocery store, convenience store and small department store. Both facilities provide similar walking, park space, and green space. Both facilities primarily use the same hospital and medical professionals and both are within the same catchment area for the Community Mental Health Center.

Both facilities primarily depend on State and Federal Aid for payment for the residents' care. The facilities become the payee for monthly Social Security checks and bill Medicaid and Medicare for the services the facility provides to the residents (i.e. bath and body care). Both facilities primarily accept individuals who have a guardian. 
Although the number of residents within a RCF can vary from more than one hundred to as little as six, the average bed capacity of RCF's in the area is around 20. Both facilities have within the average range of residents. Bridgemont has 30 bed capacity and Stoneybrook has a 20 bed capacity. Both RCFs maintain near capacity rates throughout the year.

Both facilities accept people with a range of mental illness diagnoses. The diagnoses include Bipolar Disorder, Schizophrenia, Schizoaffective Disorder and Major Depression. These diagnoses are considered a Severe and Persistent Mental Illness (SPMI) and qualify the individual for disability payments from Social Security Administration.

The variety of diagnoses housed within one facility is typical of other facilities in the area at the time. Some of the residents also have a dual-diagnosis: a major mental illness combined with another diagnosis such as a developmental disability or substance abuse problem.

Additionally, while there are some RCFs that are designated as only male or female, both facilities in this study accepted both males and females and made similar efforts to keep the spaces for each gender separated. However, in spite of their efforts, both facilities ended up with mixed spaces.

\section{Bridgemont}

The two-story brick portion of the north end of the building was constructed ca. 1876 as a single family residence. It was the first house built of brick in the town. The house was then incorporated into the hospital which was built in 1929 through philanthropic efforts of a prominent community member as a memorial to his recently deceased son. 

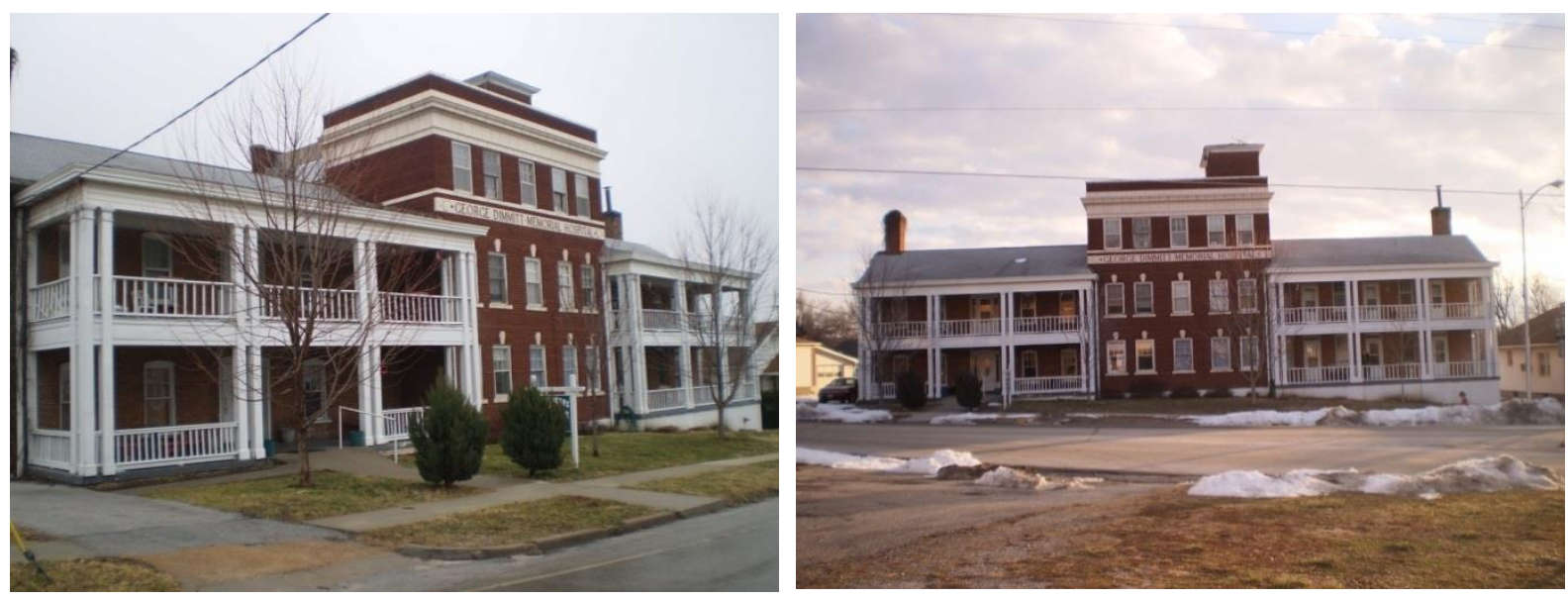

Figures 22 \& 23. Bridgemont, west façade.

The north wing, with the main entrance, is a few inches above grade with a gently sloping ramp for us by wheelchairs users and pedestrians. Four small trees and a couple of evergreen bushes are arranged across the narrow front lawn.

The center portion of the west elevation with the projecting elevator shaft has a flat roof. This cube-like segment contains most of the building's Colonial Revival stylistic features. The façade is highlighted by precast terra cotta design elements such as a wide cornice, original name tiles, belt courses, window sills and keystones. The low profile, shallow-molded, unadorned terra cotta cornice contributes to the overall simplicity of the style by minimizing exterior ornamentation.

The east (rear) elevation is irregular, with minimal ornamentation. Two metal staircases serve as emergency exits from the second and third floors. This elevation contains the expansion of the two-story gabled ell. 


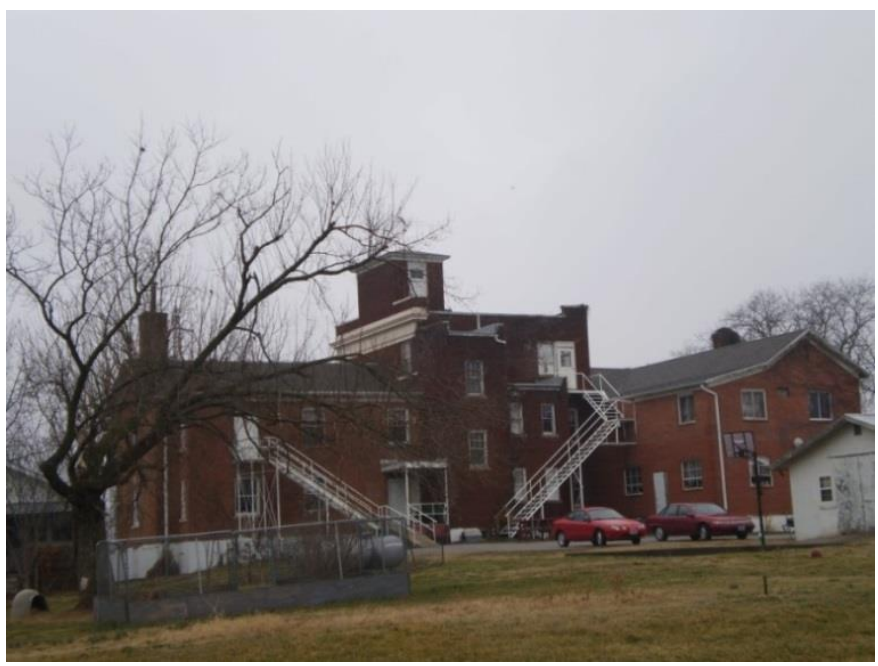

Figure 24: Bridgemont, east façade

The grounds include a parking area, storage building and a basketball half-court, and two entrances in the rear of the building.

The interior spaces exist today much as when the building was constructed. Over the years only minor adjustments to the floor plan have been made. There were also additions made at intervals when the property was taken over by various owners-addition of kitchen and dining area and closure of private bathrooms in resident rooms (ca. 1980). 


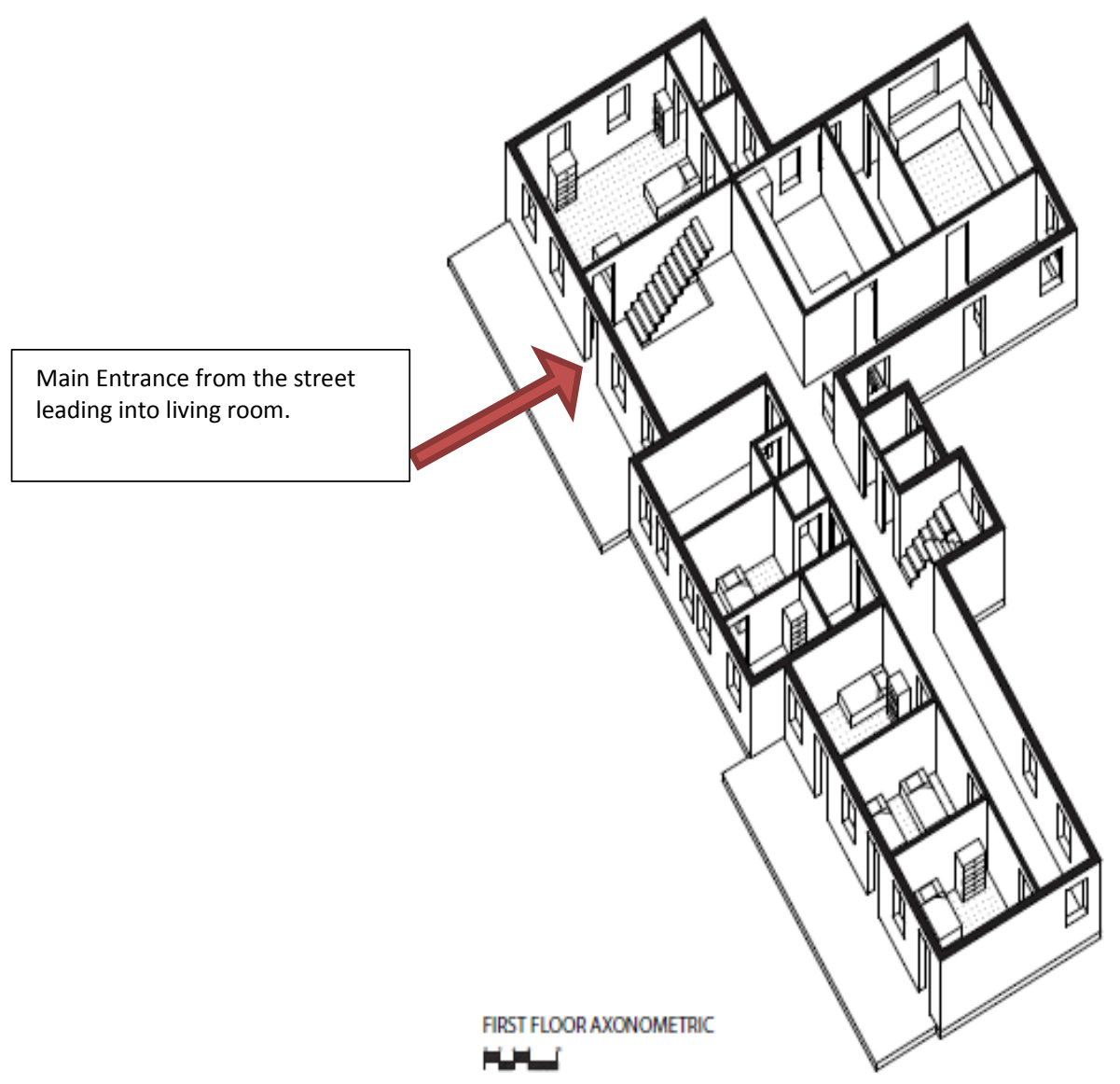

Figure 25. Bridgemont, axon drawing, Main Entrance

Inside the main entrance on the main floor is the living room. Residents enter through the front door to gain access to many of the interior spaces. There exists the original (circa 1876) staircase leading upstairs immediately inside the front door. 


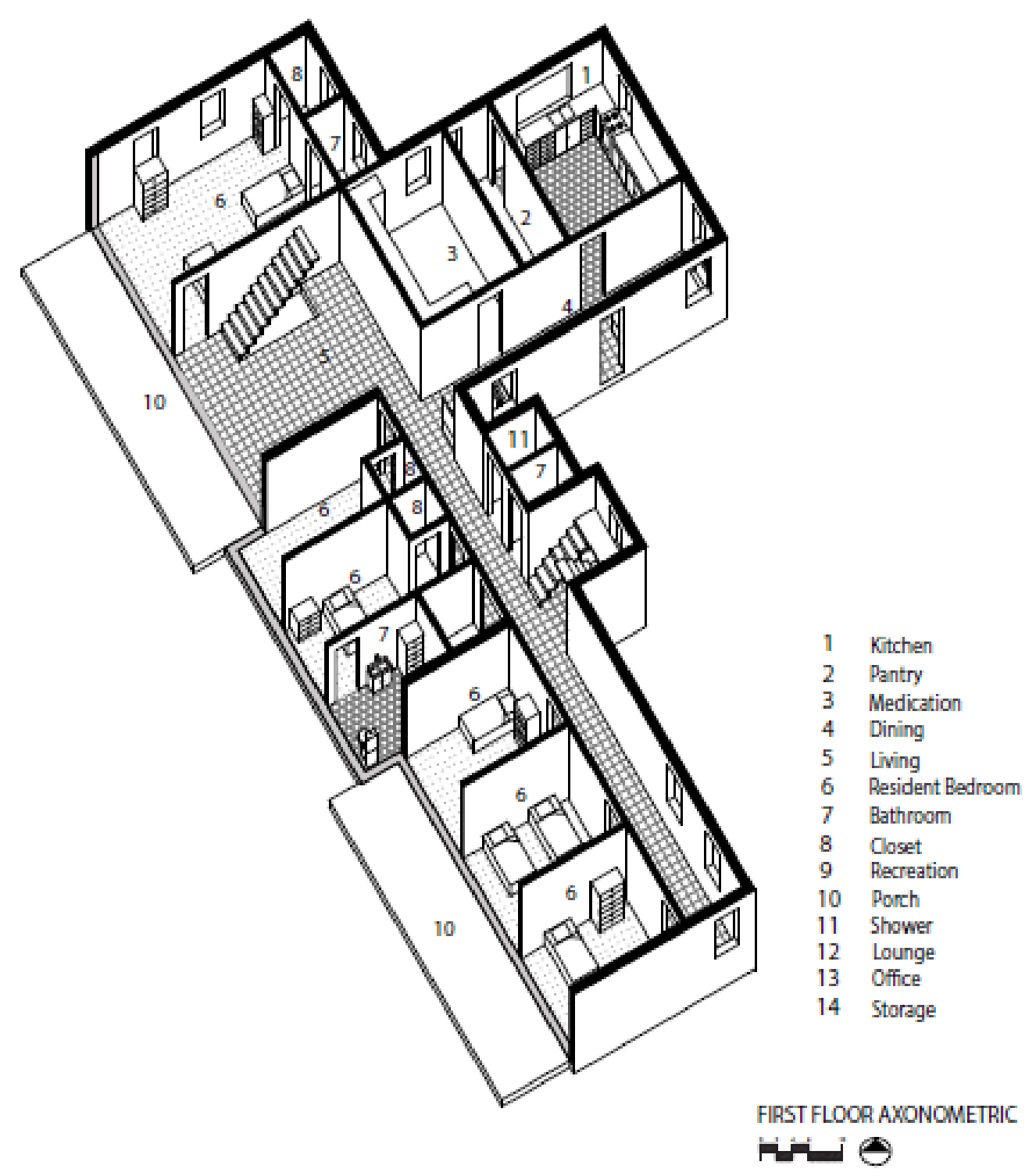

Figure 26. Bridgemont. axon drawing, first floor.

The living room is furnished with an upholstered sofa, loveseat, and armchair. There is also a flat-screen television mounted on the wall opposite of the sofas. Like a majority of the interior spaces the flooring covering is vinyl, tile or terrazzo. The walls are painted with monotonous neutral colors throughout the facility. To the left of the main entrance is a female residents' bedroom. This bedroom accommodates three female residents. The room is crowed with 
beds, dressers, nightstands and entertainment centers which contain televisions, radios and other storage areas.

Beyond the living room are the medication room, dining and kitchen spaces. Aside from the living room this is the most extensively used area in the building. The appeal of this space is due to the proximity of the medication room which can only be accessed from this area and the kitchen area (shown below). The kitchen area is closed off to prevent residents from accessing it. When I asked the facility Administrator why the metal partition was present she explained that it was added when the facility was a drug and alcohol rehabilitation center but she was not sure if there was a current policy requiring the partition and so they have not removed the partition.

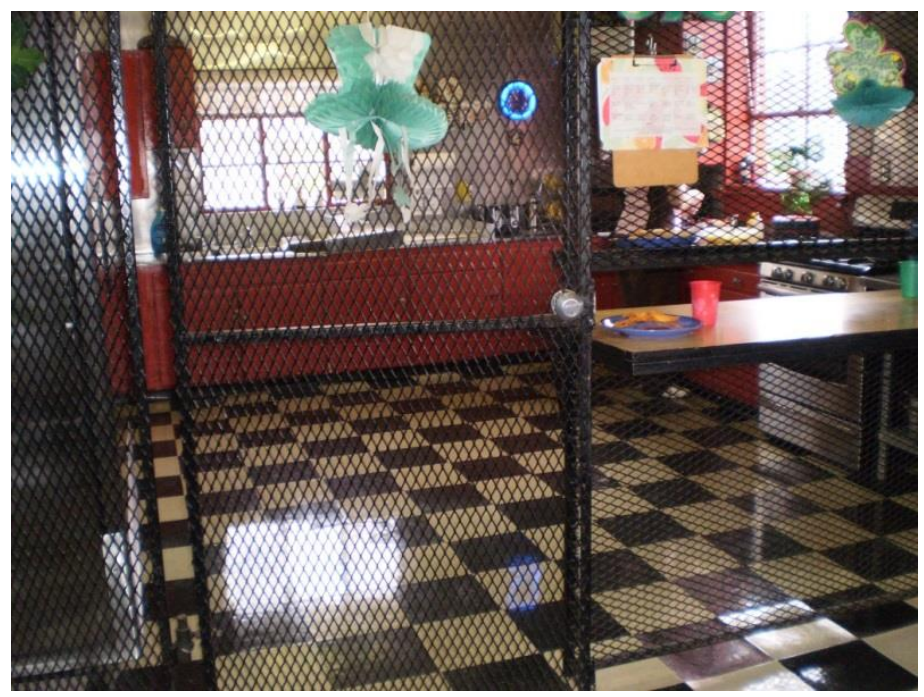

Figure 27. Bridgemont, kitchen

The kitchen is closed off from the rest of the facility a majority of the day. The staff members prepare the meals and slide the cafeteria style trays through the opening (Figure 27). The 
facility Administrator explained that "it is against policy" to allow residents access to the kitchen area. However, she commented, that they do allow some residents access during meal preparation and cleaning up after meals.

The medication room has a "Dutch" style-door which prevents residents from entering yet allows residents to interact with staff from the upper half. This is where the staff spends a majority of their day attending to facility business and "setting up meds."

To the south of the living room is a $63 \times 8$ corridor that provides access points to many other indoor and outdoor spaces. There is a small seating area (two armchairs) about halfway down the corridor, a drink vending machine, several live and artificial plants, and several large windows overlooking the rear of the building.
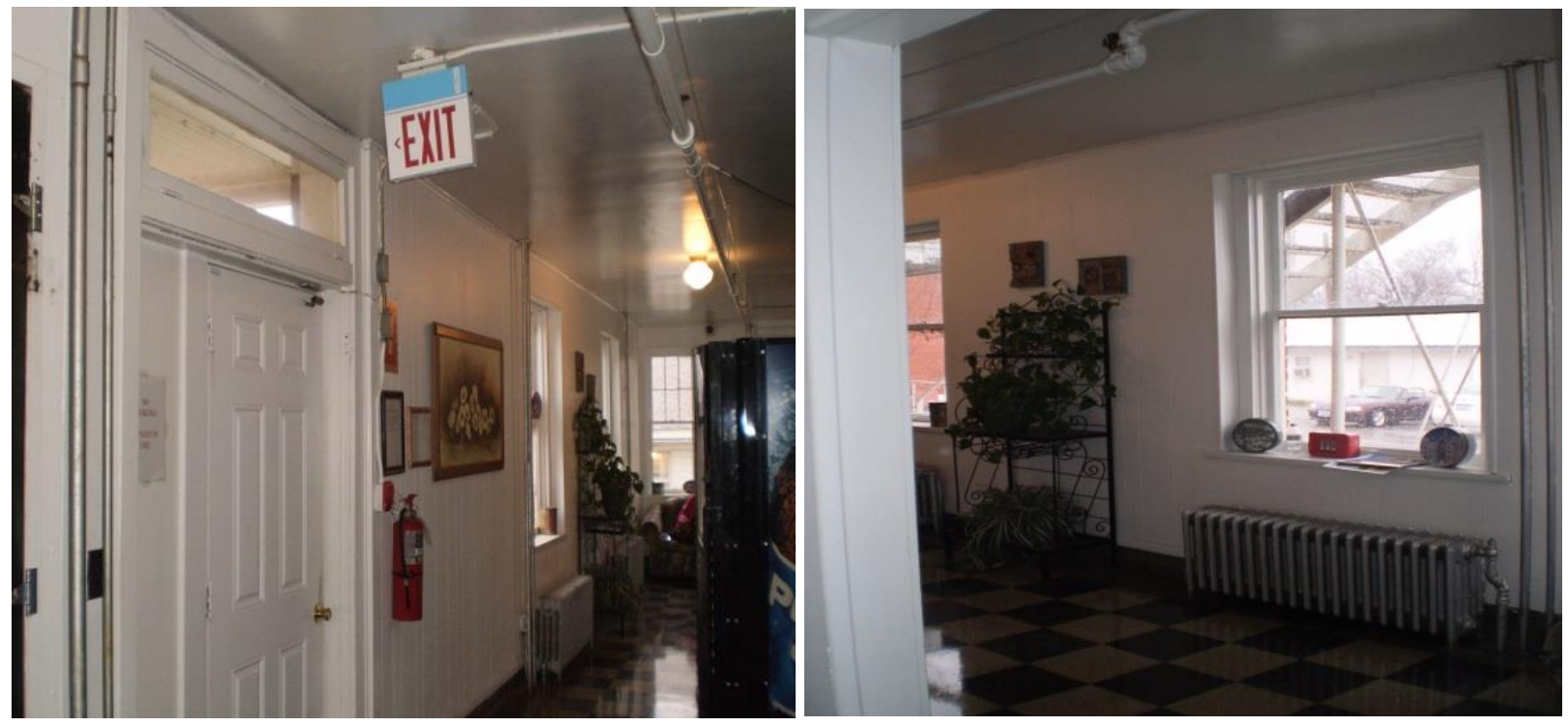

Figures 28 \& 29. Bridgemont, first floor corridor 
A recreation room is to the immediate right upon entering the corridor from the living room.

This area is rarely utilized by any of the residents. It is scarcely furnished with a well-worn vinyl upholstered sofa, some bookshelves containing books, magazines, and puzzles. The appeal of this room is a coffee pot. Residents who contribute to the "coffee fund" can get coffee throughout the day in the recreation room.

A shower room and bathroom is adjacent to the recreation room. These rooms were also part of the original construction of the building in 1929 and appear unchanged since that time. The shower room consists of a large shower, a chair, and a small cabinet. The bathroom consists of a toilet, sink and a small cabinet. The Policy prevents the doors from locking so privacy is tenuous. All residents use this first floor bathroom throughout the day.

The second floor contains nine multi resident bedrooms, a bathroom, a shower room plus an additional half-bathroom containing a toilet and sink. The rooms are shared by either two to three residents per room. The residents on this floor are considered more trustworthy by the RCF staff members than the ones on the lower floor. The residents who have bedrooms on this floor consider it a priviledge to have a bedroom on this floor because there is less surveillance by staff. There is considerably less activity on this floor throughout the day as residents are strongly encouraged not to stay in their bedrooms during the day. 


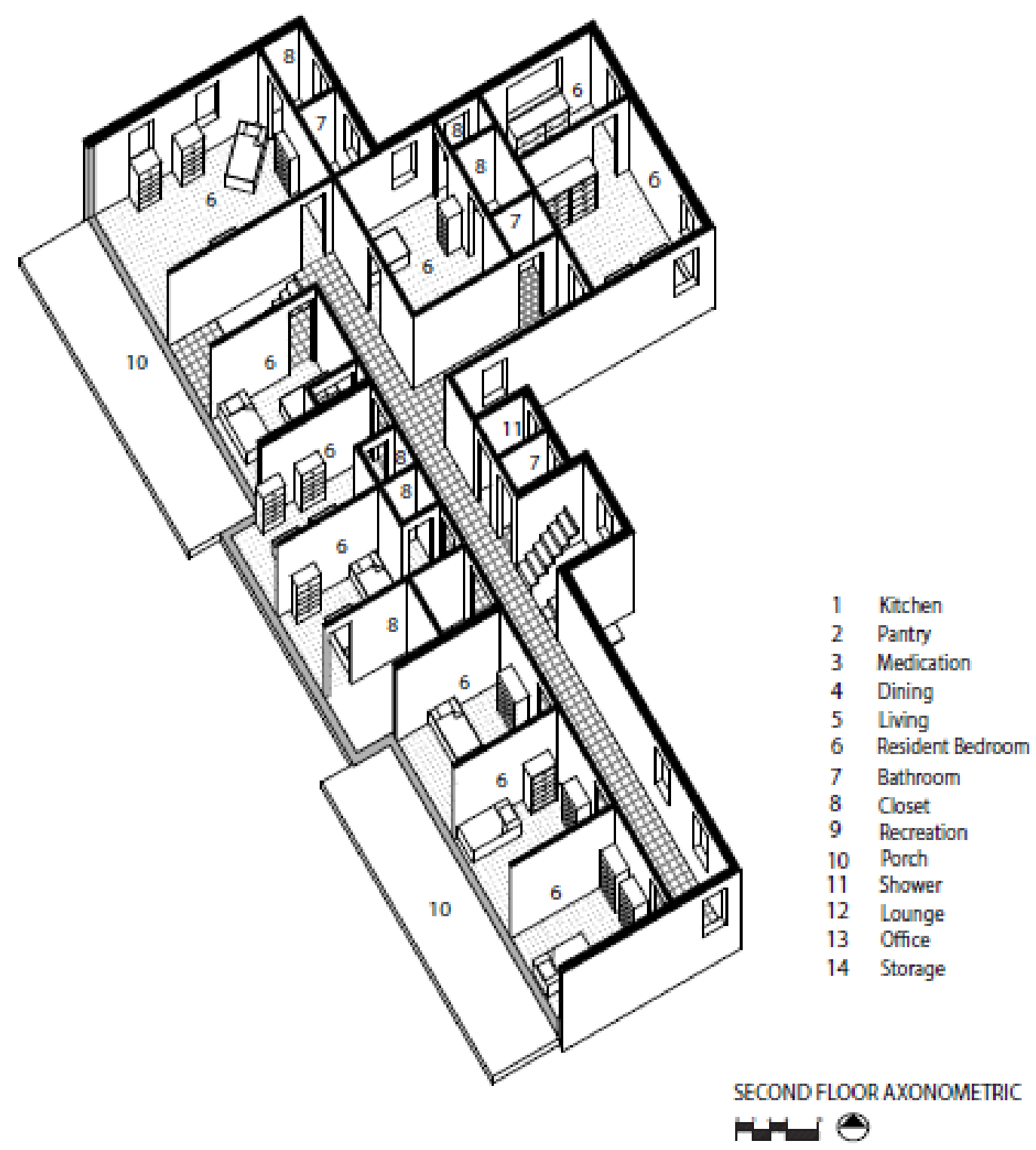

Figure 30. Bridgemont, axon drawing, second floor 


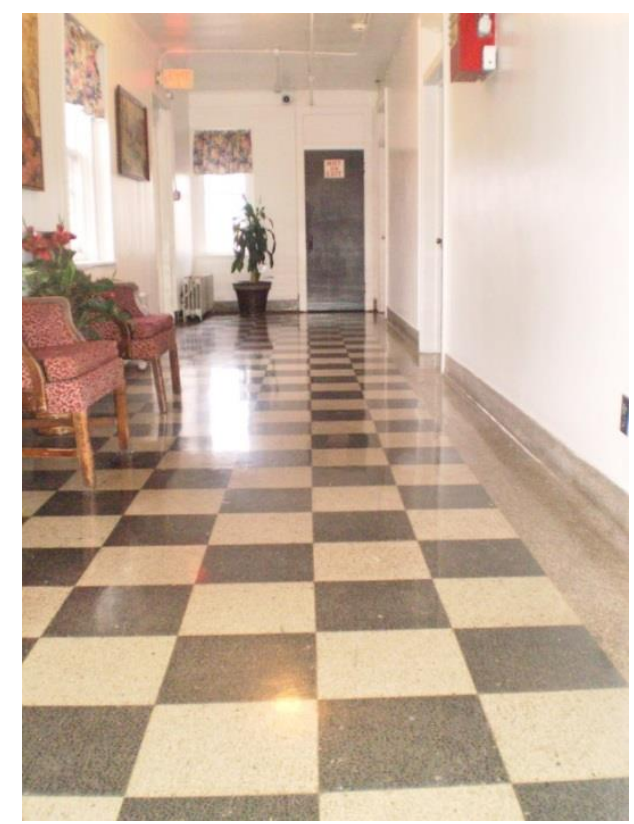

Figure 31. Bridgemont, second floor corridor

The third floor of the building is now being used as the Administrator's office (space 13 in the floor plan below) and storage spaces.
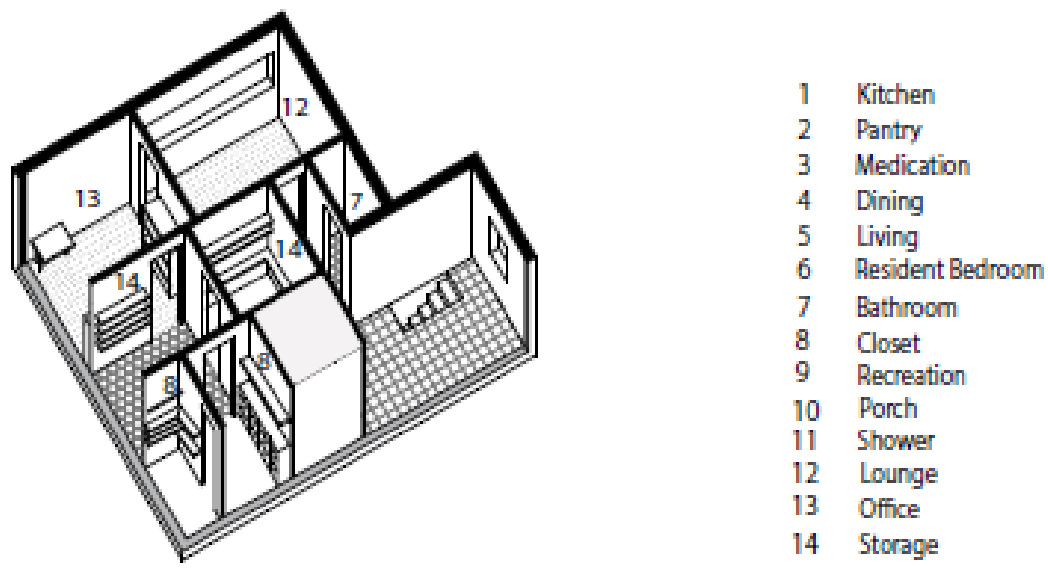

THIRD FLOOR AXONOMETRIC

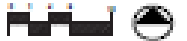

Figure 32. Bridgemont, axon drawing, third floor 
This space features a plate glass skylight (north wall in space 12 above) and many other architectural elements of this original operating room.
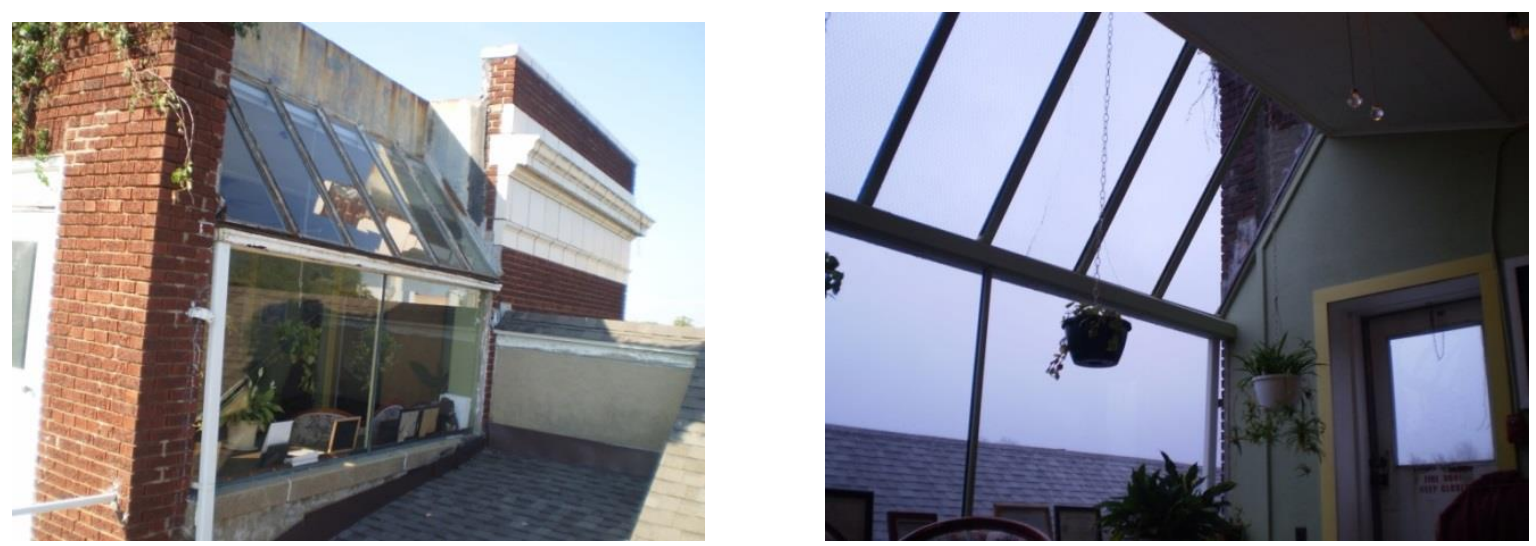

Figures $33 \& 34$. Bridgemont, third floor skylight

The facility Administrator spends a majority of her time in her office on this floor when she is in the building. Her office is small and contains a desk, file cabinets and piles of papers covering nearly every surface, including the floor space.

Increased fire and safety codes required the stairwell to be enclosing and the elevator doors to be sealed shut (however the elevator car remains preserved inside).

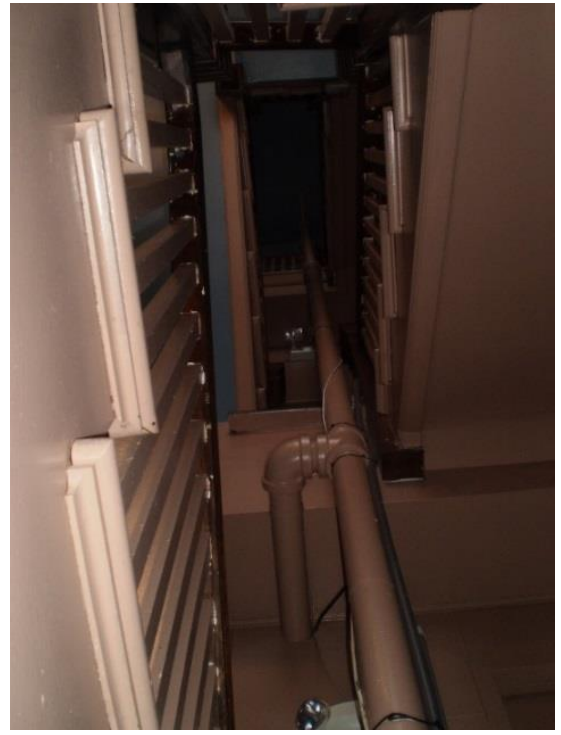

Figure 35. Bridgemont, stairwell, looking up

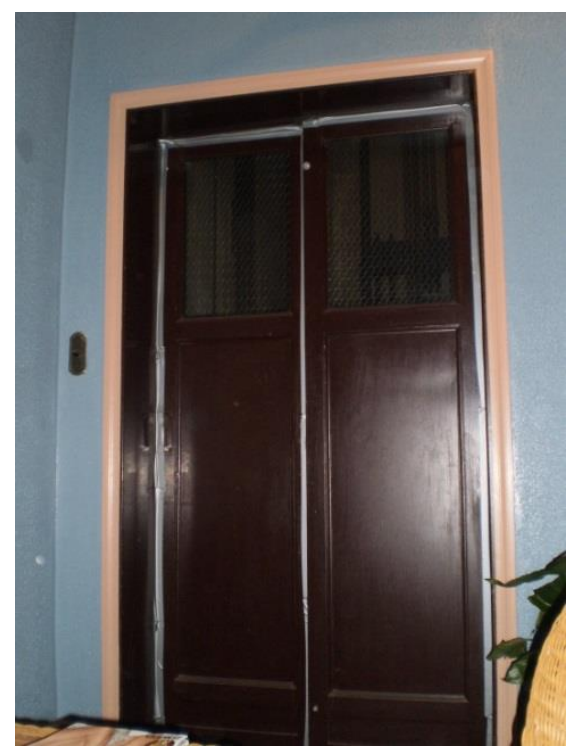

Figure 36. Bridgemont, elevator 


\section{$\underline{\text { Stoneybrook }}$}

Stoneybrook is located within 20 miles of Bridgemont in a town with a population of 9,143.

This city has six other RCF's within the city limits. Stoneybrook is located on one of the main streets about two blocks from the town's historic square. This street had been the location of several similar houses built around the turn of the $20^{\text {th }}$ century.
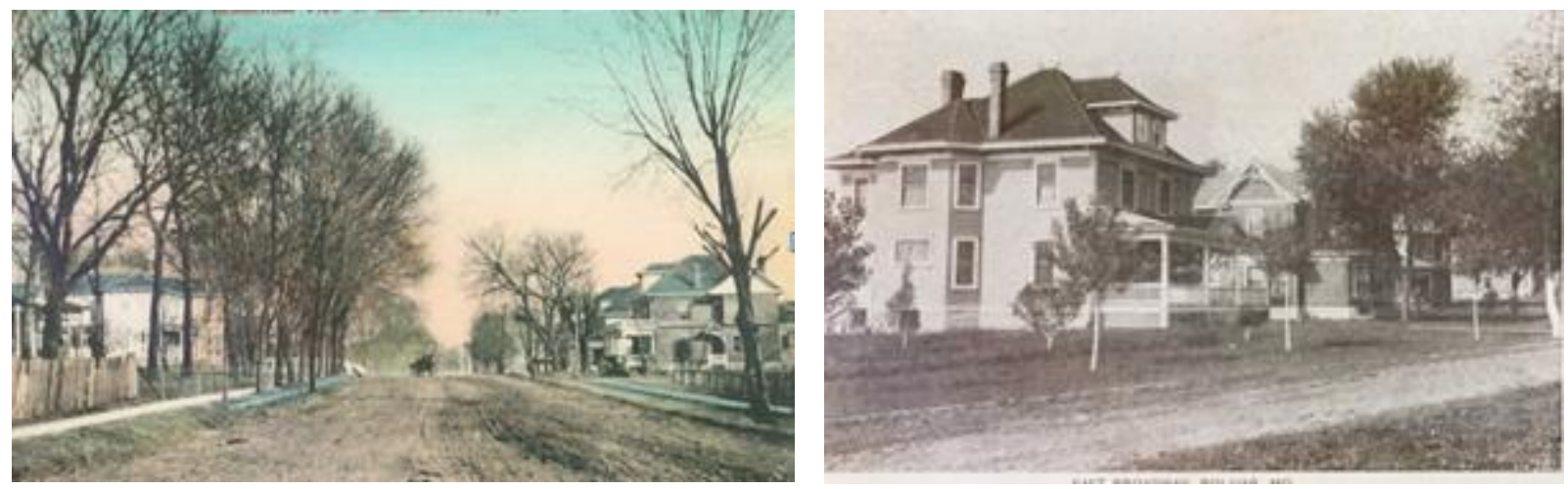

Figures 37 \& 38. Vernacular architecture, Broadway Street ca. 1900.

Like Stoneybrook, the other homes built along this street were grander in scale and ornamentation than the typical house in the area. Stoneybrook represents the vernacular architecture of the area at the time.

Located on one of the main streets, the house was built around the turn of the century. Several houses along the street still stand, however, much of this street is being taken over by businesses and the houses are being torn down or converted into commercial properties. 

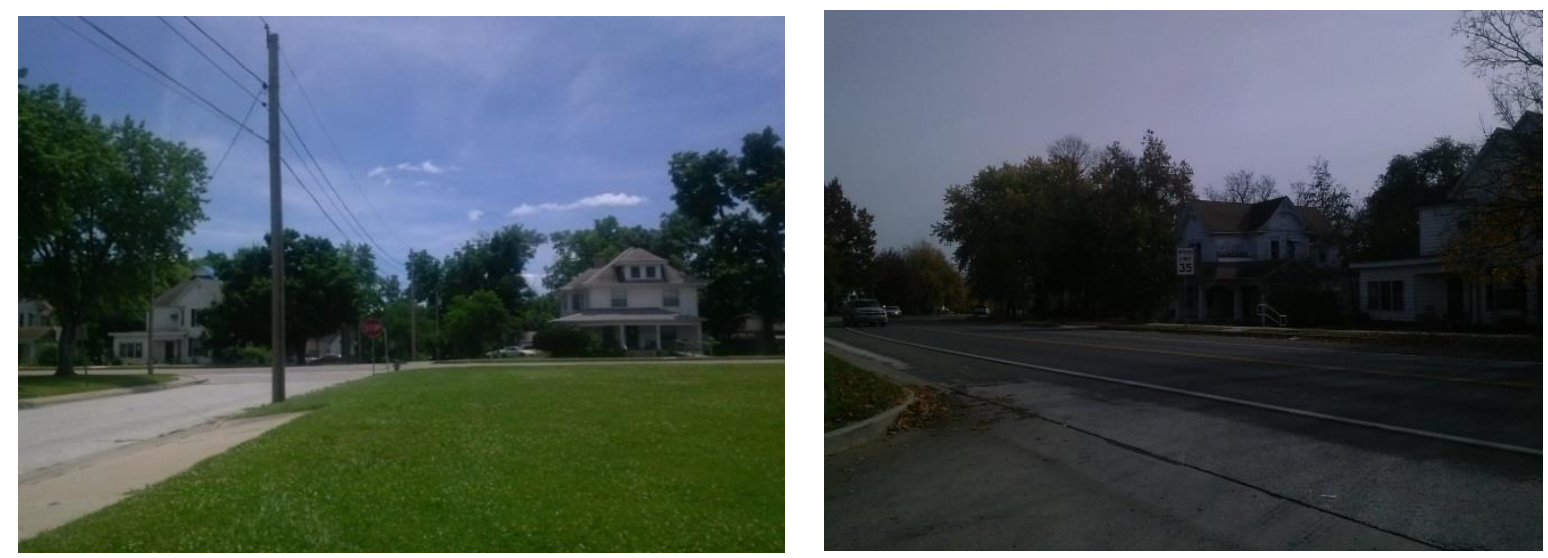

Figure39 \& 40. Broadway Street 2014

The size and the style of the house attest to the original owner's prosperity. Stoneybrook is a

Victorian Queen Anne style house. Unfortunately, the house retains very little of its historical integrity.

Stoneybrook is two-story structure with an extending front enclosed porch. The entire home is clad with aluminum siding. It has a front-gabled, steeply-pitched asphalt singled roof of irregular shape. It has cut-away bay windows which disrupt a smooth-walled appearance. The asymmetrical front façade has the remnants of the full-storied porch which once wrapped around the east side of the house.
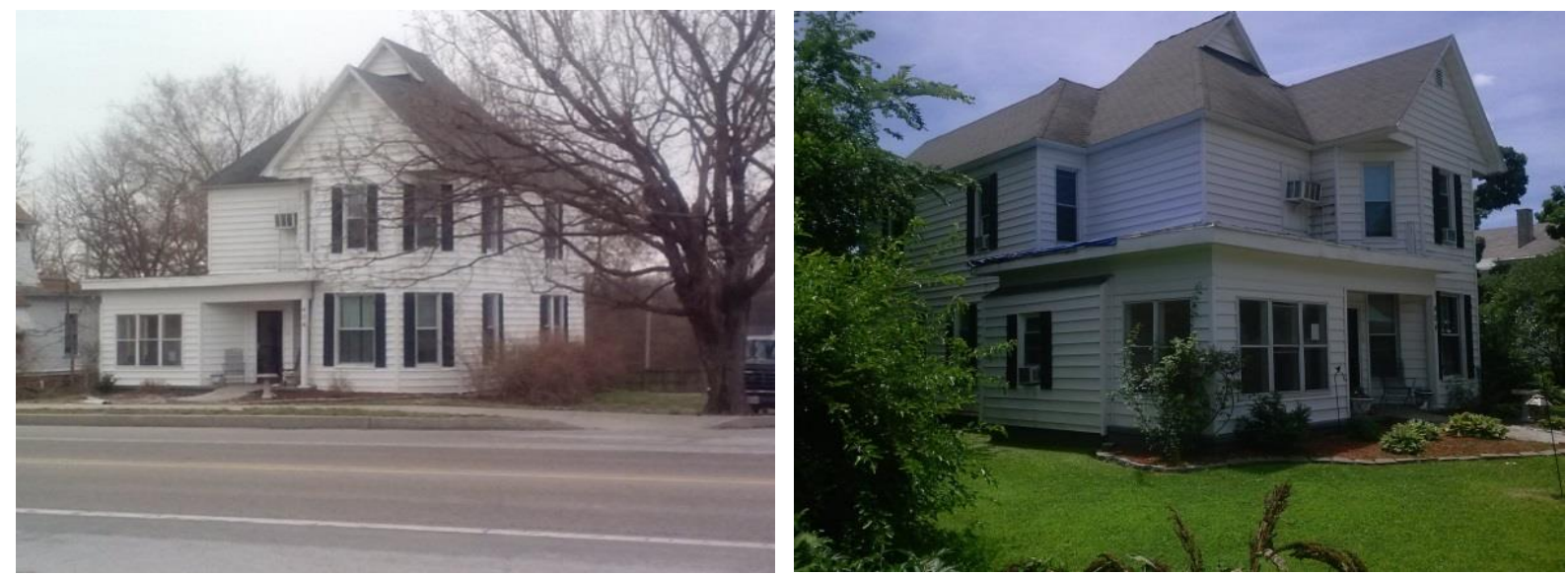

Figure $41 \& 42$. Stoneybrook, north façade 
Most residents us the main entrance at the front of the building.

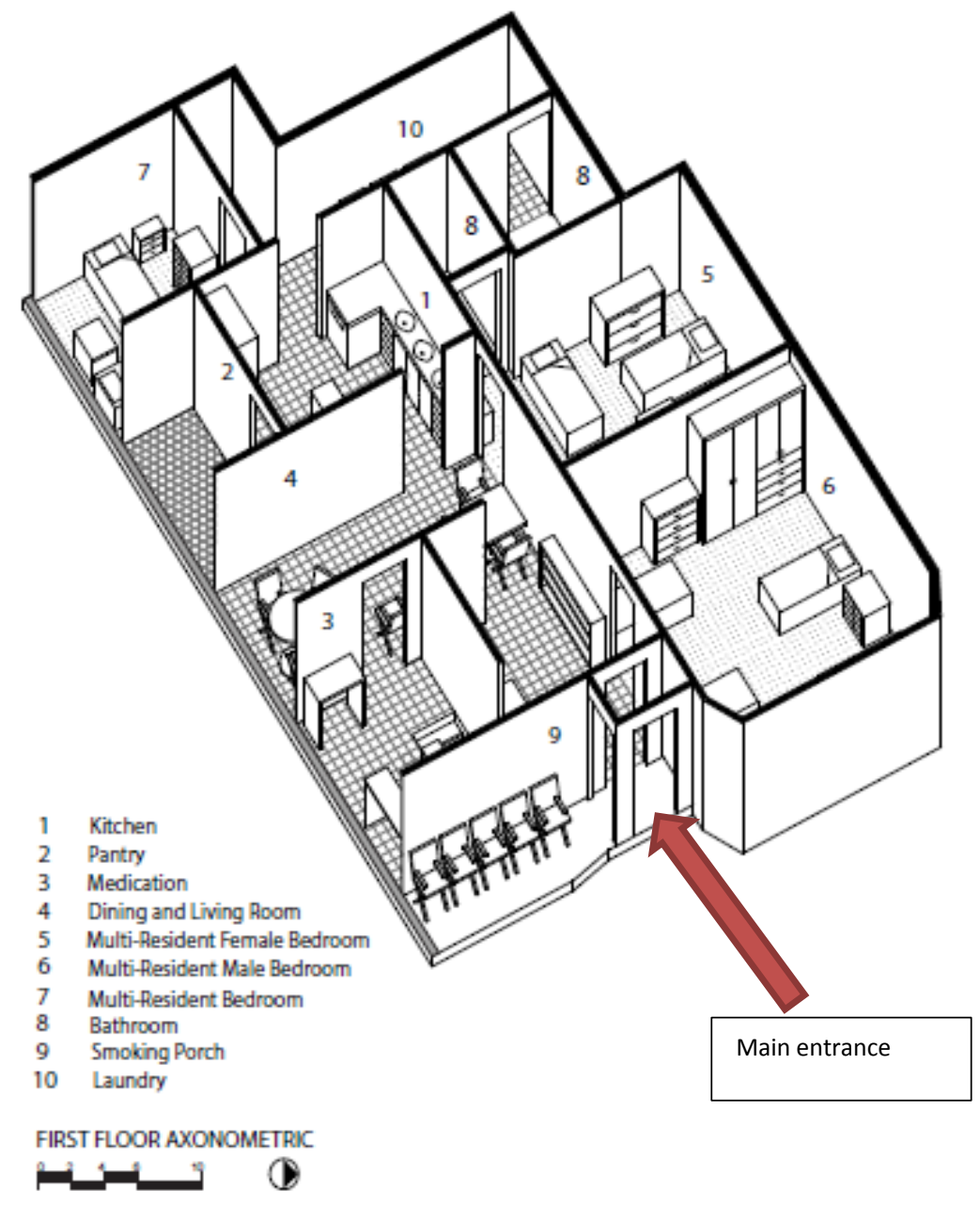

Figure 43. Stoneybrook, axon drawing, first floor, main entrance.

However, most people entering the facility use entrance at the rear of the building which provides access to the parking area. 


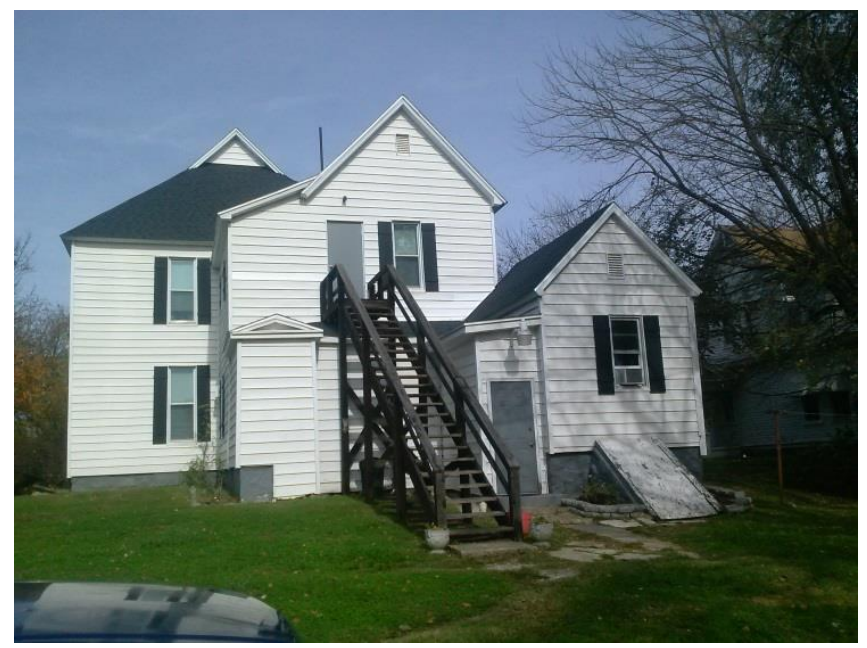

Figure 44. Stoneybrook, south façade

Directly inside the outer front door is the enclosed porch used for a smoking area for the

residents. This "smoking porch" is unheated and was so cold during an interview in March that there was ice built up on the windows and I could see my breath.

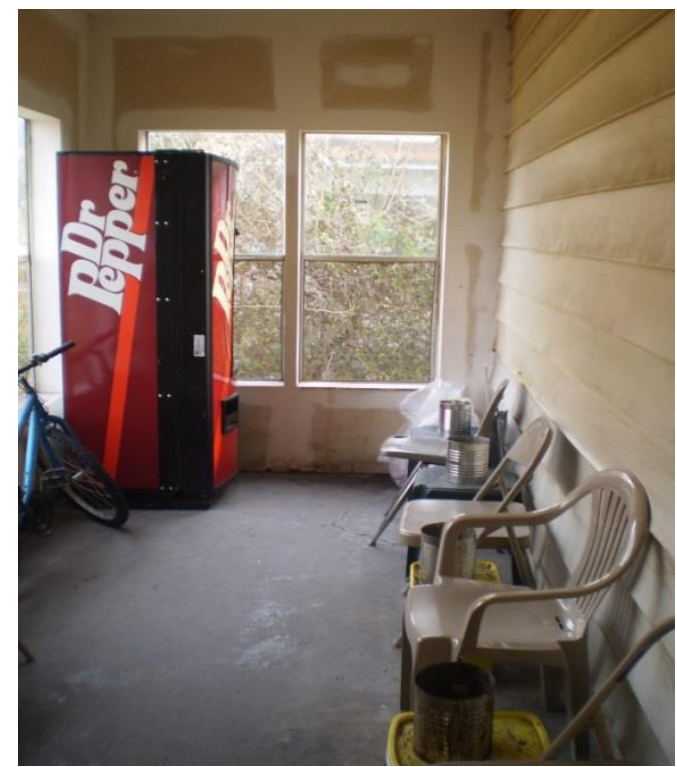

Figure 45. Stoneybrook, smoking porch.

Some residents are allowed to carry their own cigarettes and lighter however, most residents are given one cigarette an hour and a staff member must light the cigarette. Because of their tight budgets some residents will smoke cigars because they are cheaper. 
Most residents are on a limited budget ( $\$ 30.00$ a month from their Social Security checks). Although the facility might provide basic necessities like soap, shampoo, toothpaste, shaving cream, etc. anything additional must be purchased out of their monthly allowance.

The spaces within the interior of this facility strongly resemble spaces that are in many typical homes however, it is obvious minor changes have been made to the original floor plan (i.e. the enclosure of the front porch, addition of rear bedroom, and laundry area).

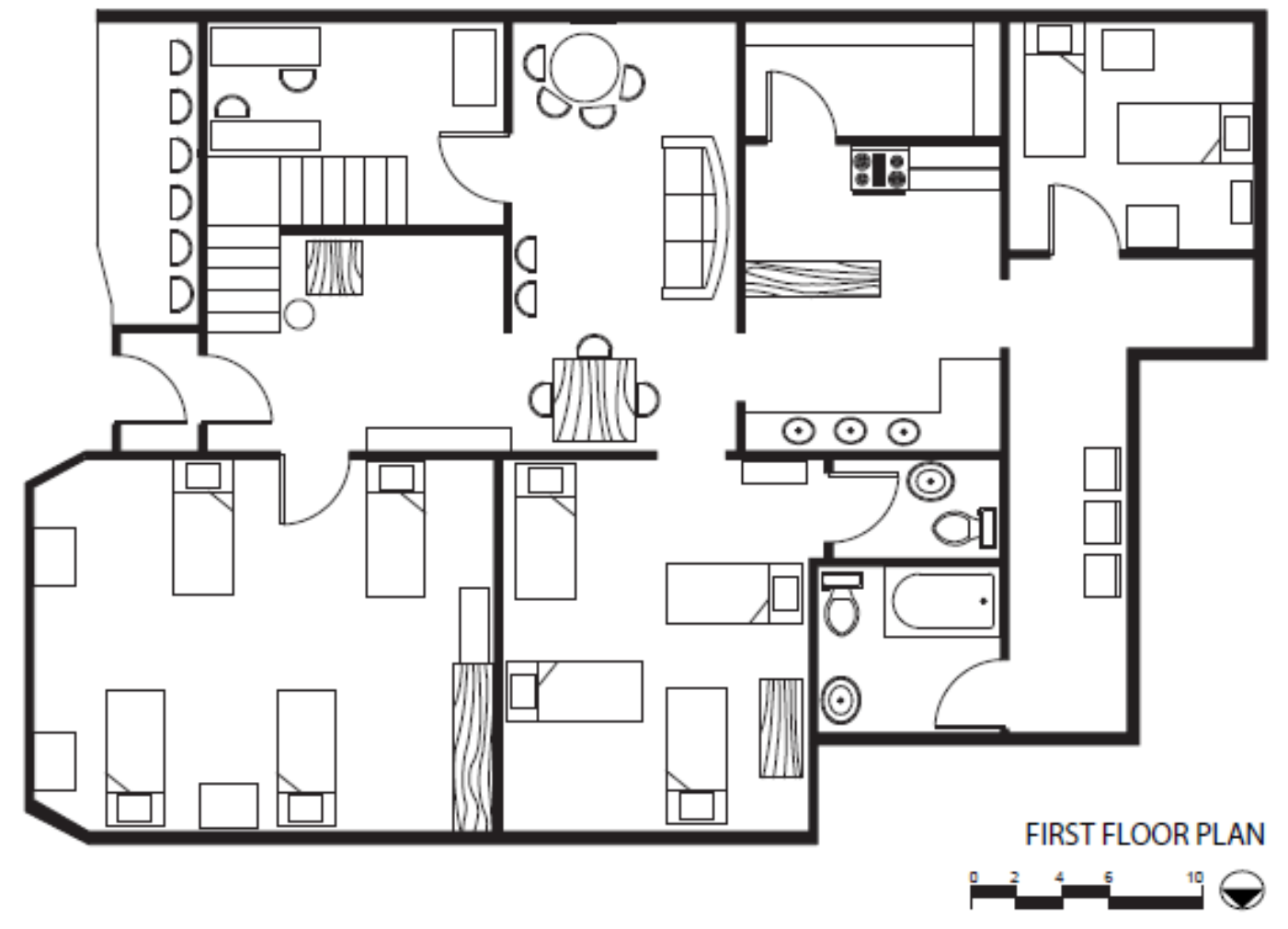

Figure 46. Stoneybrook, Floor Plan, first floor

Just past the smoking porch is the interior front door which leads to a small sitting room and the stairway leading to the second floor. The stairway balustrade and newel appear original to the house. 


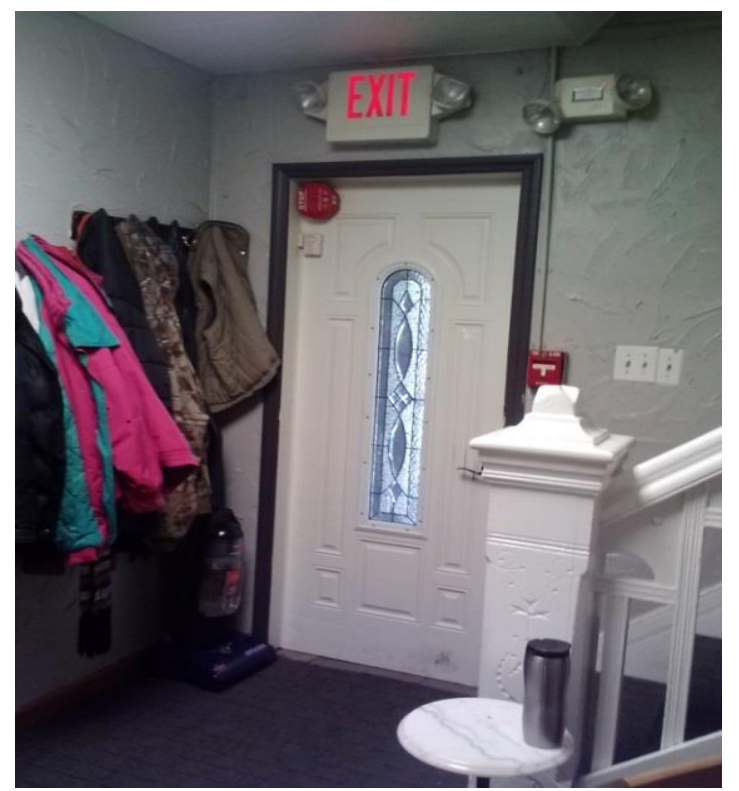

Figure 47. Stoneybrook, interior front door, view from inside the sitting room.

A door alarm is visible and other institutional features are present throughout the facility (See Figure 41). The alarm is turned on in the evening hours to alert staff if anyone tries to elope. Other institutional elements are also visible around the door.

The walls throughout the facility have a heavy textured finish and are painted a monotonous white. It is obvious that there are many coatings of paint covering every vertical surface in the facility.

Gym-room style lockers are located on the west wall of the small sitting room. These lockers contain the residents' "shower kits" and other cleaning materials for the facility. These lockers are locked at all times. Residents must request a staff member to open the locker to obtain any needed item for grooming. Also within the small sitting room is one arm chair, a small table and two lockers. 
To the right of the sitting room is the doorway to one of the bedrooms for four female residents. The bedroom is densely packed with four beds, several dressers, cabinets holding electronic equipment (i.e. television, stereo, dvd players, etc.) and other personal items. This bedroom (See Figures $42 \& 43$ ) is typical of other bedrooms in this facility.
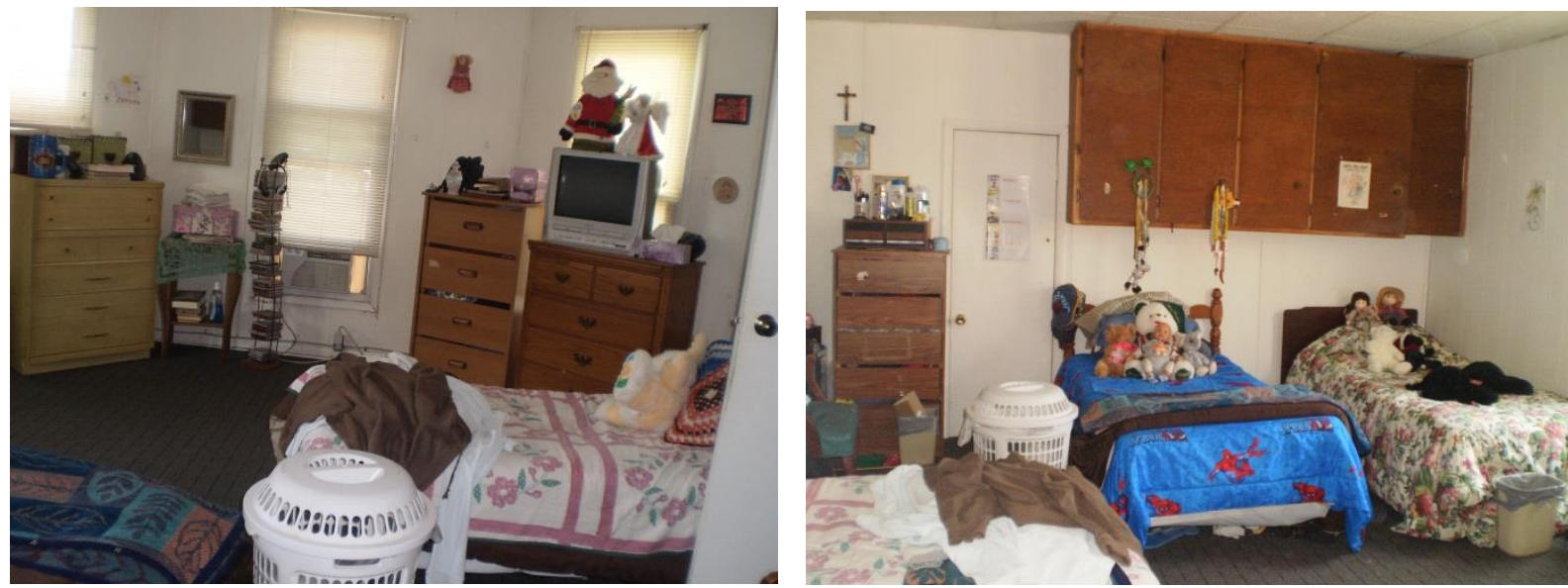

Figures 48 \& 49. Stoneybrook, female bedroom

Just beyond the sitting room is the dining/living/recreation room. The dining/living/recreation room is about $12 \times 15$ feet. It contains one sofa and two armchairs. All of the furniture in this room has institutional character-hard, nonporous surfaces and vinyl covering on the sofa and armchairs. Very limited seating often caused arguments between the residents regarding someone else "sitting in (their) spot."

A flat-screen television is mounted on the wall above a table. The television is always on throughout the day however, few residents appear interested in the program and so the television is only another source of noise.

Most body care is also done in this space. The facility is paid by Medicaid to provide assistance with showering, nail care, shaving, etc. Most of the grooming is done in this room. 
This room is also used for consuming meals. A dry-erase calendar board (visible on the photo below on the far right) lists menu items for each day. On adjacent walls are two small tables, each with three or four plastic chairs.

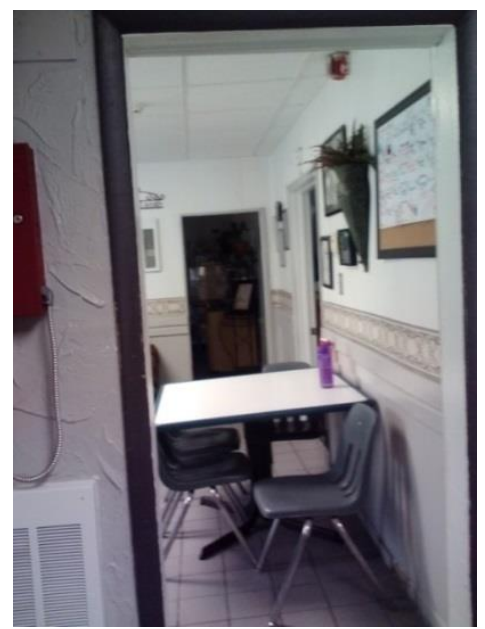

Figure 50. Stoneybrook, dining/living/recreation room

The med room/office is only accessible through the living/dining/recreation room through a door that opens at one end of the room. This space accommodates two desks, a medication cart, a file cabinet, and a table that contains a coffee maker and several cups labeled with the residents' names. A staff member explained that some residents will drink too much fluid which flushes their medications out of their system and so their fluid intakes is monitored, restricted, or controlled.

Another bedroom is located off the dining/living/recreation room. This bedroom is for four female residents and has a toilet and sink inside. Again, this room is very crowded with beds, dressers, cabinets, etc. There was some artwork on the wall but it appeared to be part of the facility decoration instead of personally meaningful pictures. 
Beyond the dining/living/recreation room is the kitchen. Staff members prepare all of the meals at this facility. The residents have access to the kitchen yet they do not participate in meal preparation. However, they are expected to rinse off their own dishes after each meal.
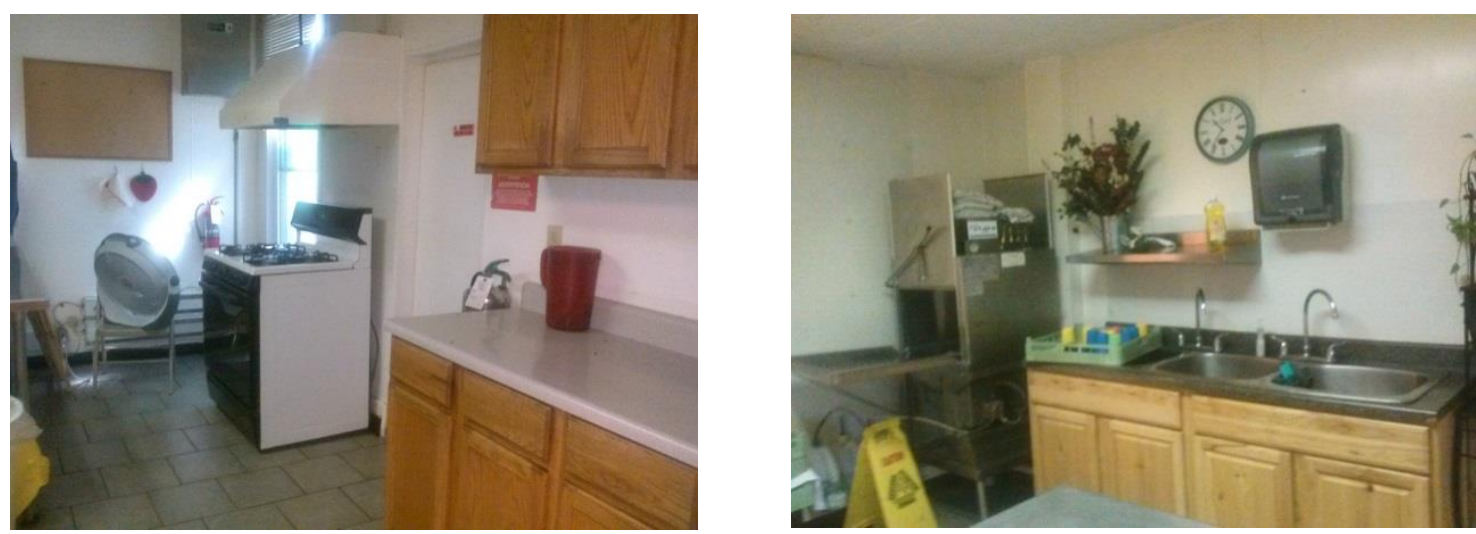

Figures $51 \& 52$. Stoneybrook, kitchen

A third bedroom, a utility room with a laundry area and a bathroom (the door is visible at the far end, to the right in Figure 47) is located beyond the kitchen near the rear door to the facility.

The bedroom appears to be a later addition to the original structure. This room accommodates two females and is more crowded with furniture and other items than the other bedrooms.

At this facility a weekly schedule is arranged for each resident who is capable of doing their own laundry. However, staff members do the majority of the residents' laundry due to the advanced age and physical impairments of the residents. 


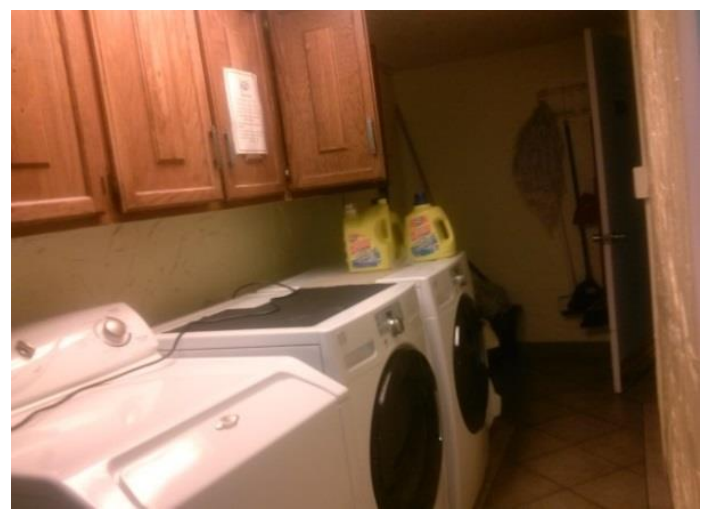

Figure 53. Stoneybrook, laundry area.

The first floor of this facility has one bathroom (door leading to the bathroom is visible in the upper right in Figure 47) is used for the ten residents on the first floor, the staff and the second floor residents during the daytime hours.

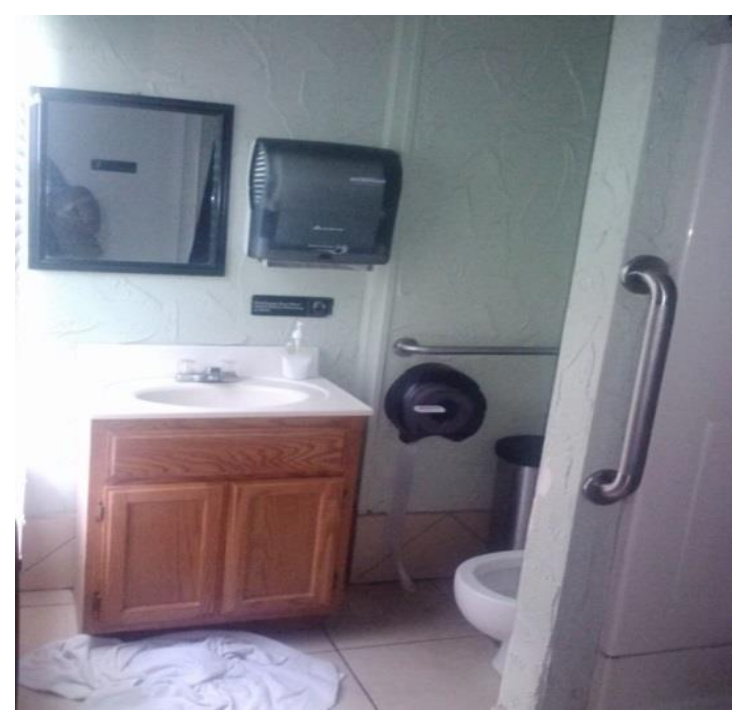

Figure 54. Stoneybrook, downstairs bathroom.

Staff members also develop a schedule for days and times for the residents' showers. A majority of the residents require at least moderate assistance with showering.

The second floor at Stoneybrook has four more bedrooms. One of the larger bedrooms accommodates four women while the other three accommodate anywhere from one to three 
males. Three bedrooms are approximately $14 \times 17$. One bedroom is a single bedroom. This bedroom is occupied by an individual with moderate impairments. He not only receives a monthly check from Social Security but he also works at the local sheltered workshop full-time. He pays the facility an additional amount for this private bedroom.
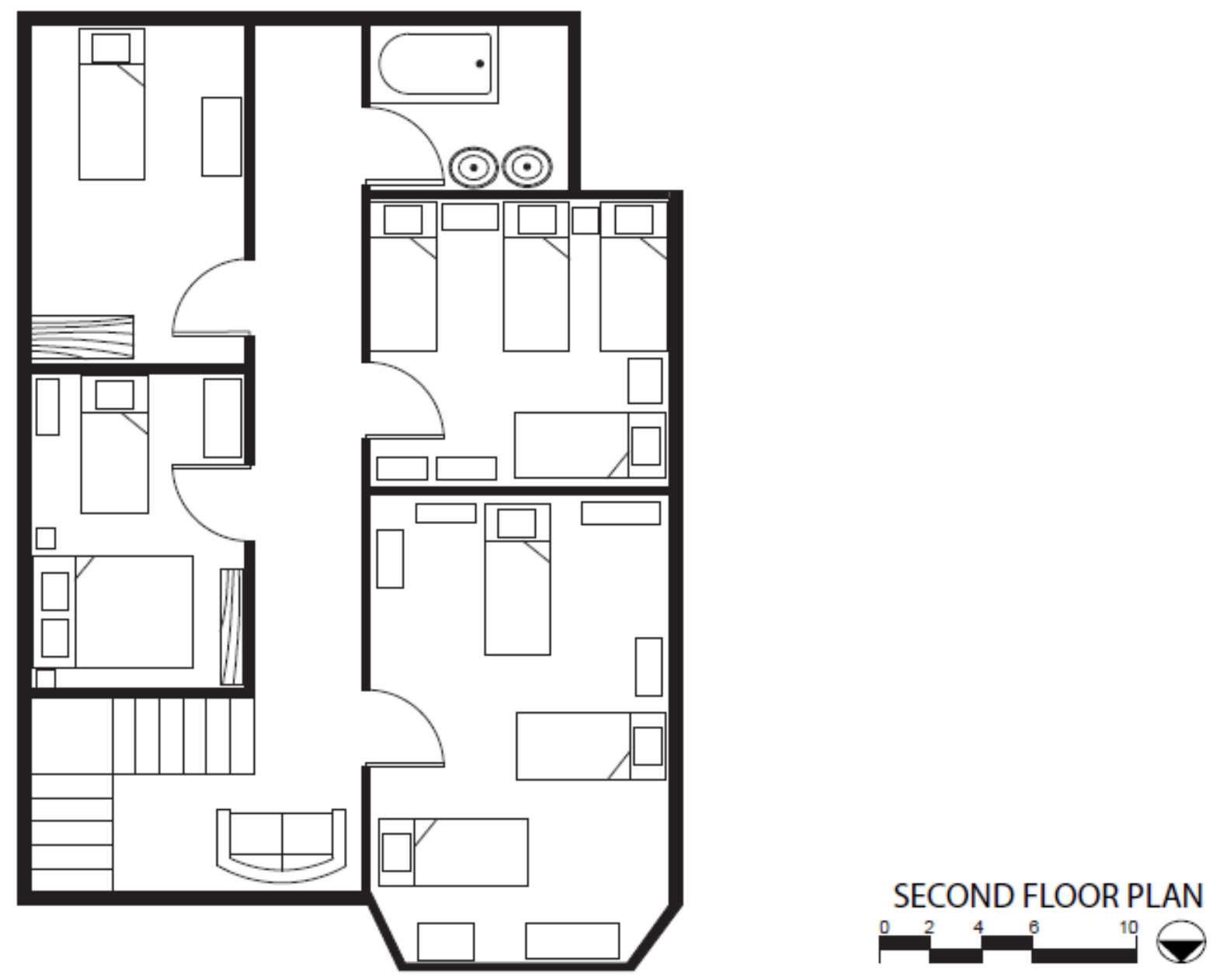

Figure 55. Stoneybrook, Floor Plan, second floor

The private bedroom on this floor is occupied by a resident that receives above the average amount of Social Security and therefore pays a higher monthly amount to the facility.

Goffman's (1961) definition of an asylum cites the example of a mental hospital, however, Residential Care Facilities also fit this description. Residents of RCFs are cut off from the wider 
society for an appreciable period of time and together lead an enclosed, formally administered round of life. This will become clearer as the residents explain their daily experiences and the other participants express their focus and concerns regarding the daily care of these residents.

\section{The People}

Sixteen individuals were interviewed for this study. All participants signed a Consent to Participate. The Consent to Participate for the residents were initially signed by their guardians, then by the residents.

Four Public Administrators were interviewed. Three were females over 40 years old and the other was a male in his early thirties. They appeared fairly homogenous regarding social and educational backgrounds. However their professional backgrounds were markedly diverse. Each put different weight on their professional and personal experiences when it came to dealing with the situations their position required.

Two government officials were interviewed. One was a licensed architect that has worked for the state for more than twenty years. He stated he knows "more about mental health design than anyone in (his) office." The other public official was a manager for the state's Department of Health and Senior Services. She has worked for the section of long-term care regulation for almost 13 years. She is the manager in the department that inspects and licenses RCF's. She has a bachelor's degree in sociology with a minor in social work.

The Facility Administrators at both facilities were interviewed. The Facility Administrator at Bridgemont has worked for her family's in-home health care business for more than 15 years. Her family's company purchased Stoneybrook in 2002 for the purpose of opening a RCF. The 
Facility Administrator at Stoneybrook worked as a Facility Administrator for the company that owned Stoneybrook prior to the time she purchased it from them in 2002.

The senior staff member at each facility was interviewed. Both staff members had a long history (more than 15 years) in health care. This staff member is responsible for a majority of the day-today operations of the facility because the Facility Administrator spends a majority of their time away from the facility managing billing and compliance issues. Also included in this section are visitors, family members, and the community. Although these individuals were not included it became obvious that their influence on the daily lives of the residents could not be denied.

Three residents from each facility were interviewed for this study. Three were males and three were females. Each resident had been living in some type of facility for at least two years, however a majority had lived in a facility for at least 10 years. Their backgrounds were mostly homogenous-five out of six residents were born and raised in rural areas in Midwest United States. The residents interviewed expressed a long history of psychological issues and personal trauma. Access to information regarding their family history was not accessed for this study, however, through their stories one can get a glimpse of family mental health issues. All six residents had Public Administrators as guardians.

\section{Public Administrators (Guardians)}

Approximately ninety percent of all residents in both facilities have guardians. A majority of the guardians are Public Administrators. A Public Administrator is an elected position for a fouryear term with their election years coinciding with national presidential elections. Public 
Administrator offices in this state are "fee offices, meaning that fees are charged for services

(usually based upon the time invested by the PA and upon the client's ability to pay). Fees must be approved by Court Order" (Greene County Public Administrators, 2013). However, all of the Public Administrators report that they are often unable to collect any fees because their wards do not have the funds to pay.

According to the website from a nearby county, the responsibilities of a Public Administrator include

Client Advocate - for housing and living arrangements, employment and day training, entitlements and benefits, religious rights and for good medical care. Further, an important aspect of advocating on behalf of the ward/protectee is the ongoing assessment of the need to continue guardian/ conservatorship. Restoring the ward's rights is known by the legal term, restoration. Surrogate Decision Making - there are two suggested principles (per the National Guardianship Association) to be considered when making Decisions for the client: Substituted Judgment - which asks the question, "What would the ward/protectee have wanted for himself?" This principle best protects the autonomy, values, belief and preferences of the ward. Principle of Best Interest - used when the guardian/ conservator is unable to determine what the ward would have done in a particular situation (which is often the case with public administrator clients who have no relatives or friends around who can give this information and the ward himself is unable to communicate his desires because of the severity of his illness). Informed Consent - regardless of which principle of decision-making is used, it is imperative that the guardian/conservator makes it using what is called informed consent which requires full disclosure of the facts. Informed consent involves using a systematic set of criteria. Further, the guardian should not make decisions "in a vacuum." Information may be needed from family members, doctors, nurses, an ethicist, the ward's minister, etc. Also, the guardian needs to determine if a court order is required. Coordinator and Monitor of Services-it is essential that the guardian/conservator develop and maintain a working knowledge of the services, service providers and facilities available in the community and to stay informed of any changes in these resources. The guardian should be in control of the plan of medical and personal care for the ward. The plan of care is developed with ward's input (when possible) by first assessing his/her needs and strengths and determining his/her goals. Then the guardian contracts with service providers to meet those needs and assists in the goals. The guardian/conservator must continually monitor the ward's progress as well as the effectiveness of those services. $(2013$, p. 1). 
When asked about their role in the everyday lives of residents of RCF many of the Public Administrators expressed ideas of protection from exploitation for their wards.

Public Administrator B explained that working with family members is one of the more challenging aspects of her job. She discussed how her clients are "almost better if they don't have family...because they've financially exploited this individual. They're the reason that someone stepped in and filed for guardianship." She discussed how her roles as a Public Administrator protects her wards from being exploited, physically abused, and mistreated by family members, friends and other community members. Another Public Administrator described her role in the lives of her wards as

an advocate and kinda mediator and buffer-alot of times among family members. And then just advocate for their healthcare needs, protecting their assets, a lot of times you're protecting them from their own family.

Public Administrator $\mathrm{C}$ felt her role was ensuring that her wards receive the community services they require. She noted, that when it came to obtaining services for her wards "guardianship with a Public Administrator is viewed very differently that guardianship with the family because families don't understand the system. And they don't know how many rights they have as that person's guardian."

A county near both facilities defines the Public Administrator's mission as working toward improving the quality of life of persons under guardianship while protecting the ward's dignity and self-respect. The ward's right of self-determination shall be observed whenever possible. The growth of the ward shall be encouraged through his/her increased participation in decision-making. The public administrator and her employees shall use the standard of informed consent when making decisions on behalf of the ward. All employees shall understand and follow the National 
Guardianship Association's Code of Ethics. Further, all must understand that the guardian/conservator is required to exercise the highest degree of trust and loyalty when making decisions for the ward/protectee. (Greene County Public Administrators, 2013, p. 1).

This does not mean that the resident was a resident in the county where the Public Administrator was appointment as their guardian. Several situations were presented by each Public Administrator in this study regarding vagrant individuals or individuals arriving at psychiatric units at the hospital in their county.

Public Administrator A recalled

two different homeless situations we've had just this year. One gentleman was frequent in the ER. Basically, he'd get drunk and go out there and say, 'I'm contemplating suicide.' which gets him a bed, meal...all his needs. But he did that in 2012 thirty-six times. (H)e'd been in an out of jail several times-public intoxication, indecent exposure, because he was homeless and after a few drinks he urinated behind a building and someone saw him.

In this case the psychiatrist at the hospital filed a petition with the court to have the county Public Administrator appointed as his guardian. The Public Administrator recalled that this case was "tricky" because when the man appeared in court he was "very coherent, very educated, very dirty, but you know, that's his choice." The homeless man took the witness stand and stated 'last time I checked I didn't know being homeless was against the law.'" The Public Administrator, while agreeing with that statement, reported that, in the end, she was appointed his guardian because "he was using the hospital as a motel, using the jail as a motel...threatening to starve himself in the county jail...saying 'I'm going to starve myself in your county jail and this is going to be bad publicity for all of you.' And he did stop eating." Another male was appointed a guardian as a condition of probation through the Department of 
Corrections after serving time in prison. Both of the preceding males are in locked facilities because they are considered elopement risks.

Sometimes a person will be appointed a guardian through the Department of Health and Senior Services. If a representative from that agency determines that an elderly or disabled individual in any way requires a guardian a petition can be filed to have one appointed.

Another Public Administrator recalled several incidents with the elderly where "their families spent all their money...They dump them in a nursing home and then...they can't stand to see them so they don't come back and they don't answer phones. Nursing homes call me and say we can't get ahold of any family." All of the Public Administrators also relayed stories about how "family dynamics are good and sometimes they work, but a lot of times they don't."

All of the Public Administrators interviewed stated they took the position when the previous Public Administrator was retiring. While they unanimously agreed there was no college degree to prepare them for this job, they all described their role as an "advocate" for their wards.

Public Administrator A is in her third term (ninth year). The population for her county is 21,159

(U.S. Census 2010). She has the highest, per capita, number of wards compared to surrounding counties due to the previously location of the state-run psychiatric facility and the Habilitation Center (for the developmentally disabled).

Public Administrator A stated that her background

is in banking and finance...(and) a title company. But one of the biggest things that I feel like prepared me for this job was taking care of my mother in her later years of life starting with dementia...downsizing from a home to an apartment, then to assisted living, then more assisted living and then finally to a nursing home. And then she got neglected in a nursing home and lost her leg so that was a very extreme, eye-opening experience....and then to the point where my sisters and I 
we're going and feeding her a meal, once a day, to make sure she was getting her nutrients and stuff like that.

Public Administrator A added

I don't have really any background in social work or anything like that. I just call it common sense...Sometimes I have to sell real estate so my background helps me...but nothing can give you the, you know, what to do in this job until you do it. You have no idea what to do in this job until you do it. I think common sense and compassion is the most you can do.

Public Administrator B has been the Public Administrator for her county since 2003. Her county has a population of 31,137 (U.S. Census, 2010) with 74 wards of the state. Also in her third term, she was born and raised in the county she serves. Prior to being elected as the Public Administrator she worked as the probate judge's clerk for six years, handling all of the guardianship cases in the court system. She believes that her background in the court system helped her the most with her current position.

Public Administrator $\mathrm{C}$ ran for the position of Public Administrator for her county when her mother-in-law was ready to retire in 2002. The neighboring county of Public Administrator A, with a population of 17,049 (U.S. Census, 2010), it has 70 wards of the state. She has a background in medical care but stated she relies on "common sense" when making decisions for her wards. She added that she treats "them as like they were my own family."

Public Administrator $D$ is the Public Administrator in the furthest county from the facilities but had five residents at Stoneybrook. His county has a population of 40,400 (2012 census). He has 126 individuals on his caseload. He spent 12 years as a caseworker in behavioral health before 
the retiring Public Administrator approached him to take over the position. He found his background in mental health one of his greatest assets.

Public Administrator D stated that a majority of his clients have a mental illness and they reside "fairly evenly between group homes, RCF's and the nursing homes." He stated a lot of referrals for guardianships come from the psychiatric unit at the local hospital. He further explained that their local hospital receives individuals from all over the state. When the individual is ready to be released he is contacted by the social worker at the hospital, letting him know the hospital has filed guardianship papers and the doctor has recommended the individual live in a facility.

When asked what kind of things he looks for when he searches for a long-term living facility he state the individual needs "to be able to follow instructions and be fairly compliant and be willing to take their medications." He discussed increased difficulty finding adequate placements for young adults because "they still have a lot of potential at that age...a lot of potential to get better or get worse." In the end, he says, "you just have to go with who's nearest and who has an opening and if that doesn't work we have to try something else."

\section{$\underline{\text { Government Officials }}$}

Official A works for the state's Office of Administration, Division of Facilities Management, Design and Construction. He began his employment with the state in 1985, shortly after receiving his Bachelor's degree in architecture. He initially worked for state's Department of Mental Health for $61 / 2$ years. He specializes in compliance with accreditation requirements and uses those accreditation requirements and relies on federal and state codes to guide the design of facilities. 
Official B is a program manager for the state's facility licensing department which "coordinates the licensing activity for all long-term care facilities and adult day-care programs." After finishing her Bachelor's degree in Sociology she ran a group home for individuals with disability for five years after graduation. She then "decided to come to work for the state because, at that time, it was more money than (she) could earn in the private sector." Although she acknowledged that there are good and bad facilities, their focus "is on environmental-fire safety, physician's orders, and residents' rights." Like the Government Official A, policy and accreditation requirements guide decision-making in her job.

\section{$\underline{\text { Facility Administrators }}$}

An Administrator for a RCF licensed with the DHSS is

a person...designated as administrator/manager who is either currently licensed as a nursing home administrator or is at least twenty-one (21) years of age, has never been convicted of an offense involving the operation of a long-term care or similar facility and who attends at least one (1) continuing education workshop within each calendar year given by or approved by the department. When used in this chapter of rules, the term manager shall mean that person who is designated by the operator to be in general administrative charge of a residential care facility. It shall be considered synonymous to "administrator" as defined in section 198.006, RSMo. and the terms administrator and manager may be used interchangeably (DHSS, Rules, 2013).

In addition to many other responsibilities, the Administrator is responsible to

assure compliance with all applicable laws and regulations. The administrator/ manager shall be fully authorized and empowered to make decisions regarding the operation of the facility and shall be held responsible for the actions of all employees. The administrator/manager's responsibilities shall include oversight of residents to assure that they receive care appropriate to their needs.

The Administrator at Bridgemont is also a family member of the owners of the facility. She also serves as the Administrator to the company' other Independent Supported Living (ISL) homes 
for the developmentally disabled. This Administrator is highly energetic and relates to all staff and residents on a personal level. Many of the residents at the RCF call her "momma" (unless she is not around, then a few residents call another, older, female resident "momma").

The Administrator at Stoneybrook has worked in facilities since her high school graduation. She initially worked for the company that owned the facility and, when the company was going to sell the facility, they encouraged her to purchase it.

Both facility Administrators split their time between facilities and their home office. The Administrator of Bridgemont spends Mondays at the facility, then only as needed. She must split her time between this facility and several others. Both Administrators explained that their duties required them to spend a majority of her time at their time doing paperwork.

The facility Administrators insured that all of their residents maintained medical and financial benefits provided by government programs and that all facility expenses were paid, staff members were properly trained, and the facility complied with state and federal regulations. Each facility Administrator had one staff member that was responsible for directly working with the residents within the facility. This staff member was highly valued by the facility Administrator.

\section{Facility Staff Members}

Staff members are present at both facilities twenty-four hours a day, seven days a week. The staff works on shifts from 7:00 a.m.-3:00 p.m., 3:00 p.m.-11:00 p.m. or 11:00 p.m.-7:00 a.m. There is one staff member on each shift except for the 7:00 a.m.-3:00 p.m., where there are two staff members. Bridgemont employs nine staff who are Certified Medical Assistants 
(CMA's), a nurse (for consulting) plus a maintenance worker (who divides his time between the corporation's other facilities).

CMA's are qualified to deliver residents' medications to them and perform other services such as taking vital signs and performing some medical treatments. The staff members work directly with the residents to carry out the objectives and goals of the RCF and are responsible for supervising the Activities of Daily Living (ADL's) of the residents. Some residents also receive physical assistance from the staff with bath and body care.

Staff members spend a majority of their time in the med room "setting up meds", completing paperwork or "charting" and sorting through various documents, including incoming facility and resident mail. When the residents require assistance with any of their various needs (receiving mail, making telephone call, obtain weekly spending money, making appointments, personal issues with other residents, or assistance with facility issues-i.e. laundry, cleaning supplies, or maintenance) they must stand in the dining room and wait for the staff member to assist them. In Bridgemont the laundry is primarily done by staff members due to the location of the laundry machines in the basement with a difficult to navigate stairwell. However, a few residents have been granted permission to use the laundry machines independently. At Stoneybrook laundry is also primarily done by staff members due to the higher degree of physical impairments of their older residents.

The staff members at both facilities are also responsible for preparing three meals per day plus snacks. Although it is "against policy" some residents at Bridgemont are permitted to assist with meal preparation and clean-up. 
At Bridgemont, Ms. R. is the most senior staff member and has been employed for 14 years with the company that owns this facility. One resident described Ms. R as "the enforcer." Her demeanor toward the residents can be somewhat abrasive and unsympathetic, at times. One male resident explained to her that his friend died unexpectedly over the weekend. When the male resident expressed a desire to go to the funeral she responded "You wanna do things but you won't get out of bed!" When a young mentally retarded male resident attempted to make conversation with her she replied "I'm not gonna answer any more of your questions today! I've got paperwork to do!" then hastily exits up the stairwell. Another young male resident was arrested for driving his employer's truck at the request of the employer. He was stopped by the local police department, arrested and taken to the county jail. After the facility Administrator appealed to the court on the residents behalf the charges were dropped. Ms. R. believes episodes such as this reinforces irresponsibility of the residents. She was opposed to this resident getting "off scott-free" and says

that is a lot of these guys problem, in my book. If you destroyed something, what happens to you? You go to jail, you pay it back, you get a felony. He has a felony but since he lives in a RCF because he has a mental illness, they don't have to pay anything back. If you go to jail you lose everything because you can't pay your bills and then what happens is they end up in places like this. And it all gets swept under the rug. I think everyone should be accountable.

Ms. S. is the main staff member at Stoneybrook. She has worked at the facility for more than 12 years. She shows compassion, patience, humor, and understanding toward even the most difficult residents at the RCF. She explained that this facility prides itself on keeping its residents long-term despite their many problematic behaviors. She added that they avoid sending their residents to the hospital but instead, attempt to work with their many care 
providers to resolve any problems. Ms. S. often takes the residents to various outings and provides much of the assistance with the daily bath and body care of the residents.

\section{$\underline{\text { Visitors }}$}

Visitors are infrequent at the RCF. Any individual entering the property is viewed with curiosity by all present. Inquiries are made to the identity and purpose of the visitor to discern if the visit is official-a state agency coming for an inspection or investigation of a hotline.

Residents may invite community members into the facility without any requests for permission from the staff. However, community members are also infrequent visitors. The only visitors I noted during the observation times was the husband of a staff member who had befriended a resident through a mutual employer. The other visitor came under different pretenses. The nature of the relationship between the male visitor and the female resident was uncertain however, it appeared the two had met through a social media website. His behavior and conversation implied that he was unaware of her current living situation or mental health diagnoses. The visitor appeared puzzled about what to do when the female resident led him behind the vending machine in the corridor and told of her plan to have him help her with an elopement. The episode of her whispering and reprimanding the male visitor for not doing the same, lasted several minutes during which he tells her "You can stay at my house if you want to" to which she replies "Can you be here at 3?" He hastily leaves. On the following day the Administrator stated there was an attempted elopement however, "she didn't get too far...not past the street." 
$\underline{\text { Family }}$

Interactions with family members can be inimical. All Public Administrators presented stories of wards being abused and neglected by family members prior to guardianship. They all agreed that their involvement arose because the family either abused or neglected its family member. All of the Public Administrators believed that when they make decisions for the individual it "works out much better." However, Public Administrator C stated she believes, that some families have good intentions-"they put them in the nursing home and they can't stand to see them so they don't come back and they don't answer phones." Administrator B explained "you have less families wanting to take care of their own...a lot of times (we're) just a dumping ground.

The Public Administrator's all reported that wards often:

have no family. Some have family that don't come but every two or three years. Some come at holidays...and they always don't have the money to go...a lot of them are paycheck to paycheck families. Not a lot of money involved. Not a lot of people that are stable...some of them hold jobs but some of them are hard pressed to make money last 'til the next paycheck.

Four of the six residents reported no family contact. One female resident said her daughters had come to see her within the past month but she "rarely gets to see them most of the time."

Another female resident at Bridgemont was recently reunited with her daughter after 25 years of estrangement. However, Ms. R. reported the daughter has not returned recently to visit the mother. Ms. R. added that at the beginning of the reunification

it was all great. The daughter was buying her all kinds of stuff, cigarettes and this and that. So when she went home last time, she was going to take her for 4 days, an extended period of time, and they didn't even make it a day. When she went to Springfield, to the city, when she would go outside and sit in the little 
yard in the subdivision, everybody made her nervous and she asked her daughter to bring her home. And the daughter was clearly upset about having to bring her back. I don't think she's taken her home or called her that much since [the resident] said she didn't like how she couldn't go outside. She came home because she couldn't go outside much.

During my observation one middle-aged male resident had a female visitor that appeared to be his mother. The female resident confronted the male resident and his mother as they were walking down the hallway toward the living room to exit the front door. The female resident hugged the woman and made several attempts to engage the visitor in conversation. The female visitor appeared very uncomfortable and the interaction with another female resident only heightened her discomfort.

Residents were able to keep in touch with family members through telephone conversations. Residents could use the landline telephone in the medication room or their own personal cell phone, if they had one. One conversation with a male resident was overheard during observation. It was obvious that he was speaking with young children. It was later learned that he is the father of three young children who live with their mother.

\section{The Community}

The Administrator of Bridgemont discussed how, before they purchased the facility, it had a bad reputation in the community. The facility Administrator discussed working with the community to improve relations. The facility Administrator reported that local churches presented the greatest problems for the facility. Although residents of the facility were welcomed at local churches, the churches were ignorant about the issues these individuals faced. Residents would portray themselves as victims of unjustly violations of freedom and as 
victims of abuse and neglect. The Administrator recalls one recent incident between a male resident who had lived at the facility for more than 10 years when he met an elderly woman he met at church. The male resident told stories of abuse and neglect at the facility. The elderly woman assisted the male resident with diverting his social security check to another location then securing him a HUD apartment. Within two months of living in the apartment the male overdosed twice and arrived at the local grocery store wearing nothing but a t-shirt. The church lady begged other church members for support and assistance but, unable to secure timely assistance, the male was sent to an in-patient psychiatric facility and was not permitted to return to the RCF or the community. Ms. R. at Bridgemont tells of another more recent incident with the male resident who

goes to church and he tells them people that the only thing we feed him is peanut butter and jelly. You could have spaghetti, you could have seven different things on the menu and he will refuse everything and says he doesn't like it and ask if he can have a peanut butter and jelly sandwich so I'm like yeah, 'I'll fix it for you' cause that's the alternative if you don't like the food. So they'll have something to eat. Then he goes to church and says all we feed him is peanut butter and jelly.

The facility Administrator at Bridgemont explained that she works with community members and says "we've even went and spoke in front of the church."

The facility not only had to struggle to regain acceptance in the community but also with the agencies providing funding and support. When considering the effects of her efforts over the past 14 years she says

we have acceptance. In 1999, No. Because this place, it was under a 35 page ordeal, when we took over from the previous people that had it." And there was all kinds of issues. But we didn't know that when we took over. There was only 15 people here. So then we got it to capacity and then we got the Certificate of 
Need. But it took years to get a good reputation because it didn't have one. There was a lot of mental strain.

Their efforts have paid off. They are well respected among Public Administrators and are considered a first choice for placement of a ward when if there is an opening.

Stoneybrook experienced less difficulty with their community. This was probably due to the larger size of the community and other several other similar facilities in the community. The staff members also keep a "close eye" on their residents while out in the community. The facility Administrator recalled several events in the past where they received calls from various businesses about their residents stealing from them. Both facility Administrators recall times where they had to go bail out their residents from jail.

The facility Administrator at Stoneybrook also stated that their residents attend several churches throughout the community. One church that the residents attend frequently is a small nondenominational church. The facility Administrator believed the incentive for their attendance is that, after the service, the pastor buys the residents' lunch at McDonalds. The Administrator acknowledged that she knows the residents attend there only for the meal but considers it harmless. And, she stated, she has had only one resident who was asked not to return to that church (because he was heckling the preacher).

\section{$\underline{\text { Residents }}$}

While some American families may have the financial and social resources to care for their mentally ill family member, many individuals with a mental illness are not as lucky. These individuals will eventually come to the attention of the legal system-usually because of issues 
revolving around bizarre behavior and homelessness. For these individuals, care and treatment usually involves the appointment of a guardian and living in some type of facility.

The residents in Bridgemont were a case-mix of individuals. The residents had diagnoses of a variety of mental illnesses, developmental disabilities, traumatic brain injuries, cerebral palsy, etc.

R.C. is a forty-four year-old female resident in Bridgemont. She grew up in Maine with a twin sister and two brothers. She recalls a tormented childhood of abuse and neglect. She moved to Texas when she was 18 years old, two years after her twin sister moved out of the home. She has not had any contact with any family members since she left in 1987 and when asked if she wanted to reestablish contact she replied "It's too late. I left when I was 18 and I've had no contact with them all this time."

When asked about whether she wonders if her family of origin is looking for her, she says, "they're not my family now since I'm adopted." R.C. was adopted at the age of thirty-two by a couple who "wanted a child together so (she) paid for the adoption and it went through." She had met the couple during R.C.'s employment as a clerk at a psychiatric hospital unit and had known them for five years at the time she was adopted by them. She moved into their home and they lived as a family unit until, she states: "my therapist was drugging me up pretty good and my father was drunk one night and decided to rape me...My adopted mom didn't believe me. She kicked me out." When asked if she continues to have contact with her adoptive parents she says "they don't have anything to do with me." 


\section{R.C.'s guardian reported the following}

She was adopted...(T)he adopted mother tells me that the adopted father (and R.C.) had an inappropriate relationship. As far as (R.C.) says, it comes from the father, and of course the adopted mother says it came from R.C....it takes two to tango. So I just believe it was everybody's fault, you know. She was married...She's been all over the United States. She actually worked at one time as a clerk for [The in-patient acute psychiatric unit at the local hospital]. And now she becomes a patient over there.

Her inability to cope with this situation caused her to have "a nervous breakdown after (she) had (her) gallbladder removed and the doctor messed up and caused a bowel leak and (she) nearly died." Then, she states, she got "tired and the abuse and getting stomped on ...finally got the nerve to o.d [overdose]....and that's what brought me into a group home."

She lived in one group home after another for the next couple of years, staying for only a few months at each, prior to coming to this facility about four years ago.

R.C. shares a room with two female roommates. She says one roommate "has seizures and she forgets a lot of things. And when she gets into one of her moods she gets difficult to live with." She has problems with the other roommate because "her space is a dive." In her room she has a tv, computer, and a Kindle Fire hd that her guardian has purchased for her over the years.

She describes the rules of the RCF as "being too strict" and says "like one rule is there's no going back to bed after 8 o'clock meds in the morning. She found this rule difficult to follow because "sometimes you're tired because your 8 o'clock meds make you tired."

She has also experienced a difficult time with rules regarding relationships within the RCF. When asked what are some of the rules that are broken at the RCF she replied "no sex." 
She has had three intimate relationships since moving to this facility even though "you can't have boyfriends and girlfriends here." She recalled a time when she

was dating someone here and they broke us up. He lived upstairs and I lived downstairs and staff came into my room and told me I was banned from going upstairs and that I was banned from being around him and I couldn't talk to him and couldn't be near him.

She discussed how, "in a place like this you get close to people and you get feelings for people and it's so hard...not to feel for somebody...we live in such a tight, tight community here that it's hard not to develop feelings for each other." In spite of disagreements with some of the rules, R.C. considers her interactions with others to be positive.

She described ADL's as “daily living skills...I don't know what the A stands for. You know, take a shower." She says "sometimes I get lazy and stuff and don't take a shower and they give me reminders and stuff." When asked about how staff would know if she took a shower she says "there's a camera to see if we go take a shower."

She described this facility as "a homey place. We're more of a family here. It's more family based." She calls the facility Administrator "momma" and says "it's like we're her kids and she adopted us." When asked what type of things makes this facility a homey place she recalls efforts by the staff members and the facility Administrator to

give us special dinners during the holidays. Momma makes out our birthday list for our birthdays and she asks us to write down one thing we want for Christmas and she goes out and plays Santa and we each get one thing for Christmas on Christmas Day. They stuff our stockings and we have a stocking party and they decorate for Halloween and Thanksgiving.

Her community interaction involves "going to the library and that's about it." 
Her goal is to move into her own apartment in a local community however, she says, her symptoms from schizophrenia, anxiety and pica [an eating disorder characterized by an appetite for substances largely non-nutritive] have prevented her from achieving this goal. She says her medications are helpful but she feels her pica is like an addiction that she struggles with on a daily basis and her "voices...never go away."

Another resident at Bridgemont, H.F., was a 34 year-old female and has lived at this facility for almost two years. H.F. appeared very eager to participate in this study. When introduced she quickly accepted the earliest interview time available. Even still, H.F. was very guarded in her answers and only divulged information that presented her as a competent individual. She discussed how she was self-sufficient because she "was able to cook for myself... able to go do my own laundry...bought my own food with my own money."

She reported that she was born and raised in Oregon. She was held back in school for two years "because of a hearing disability." She revealed an early history of psychological issues while talking with a male resident in the recreation room at the RCF when she yelled "What choice do I have in it? What choice does a 7 year-old girl have about taking medication?"

Her guardian provided the following information

she knows everything. She thinks she has a medical degree. She doesn't. She has three children. They live with her ex-husband even though one of them is not his, but he still has custody. Actually, I'm not sure if they're divorced, I don't know. She has a lot of health issues, she thinks. She's had knee surgery...There's been a lot of issues through the years. She's not appropriate with them...One instance was they lived, the husband travels a lot, he left them with friends or people, whatever.....and they went to pick her (H.F.) up and took her home to visit for the weekend. And they called and said (H.F.) can't come over any more, she can't stay overnight...They said...she (H.F) had her cellphone and her middle daughter, who was 10 or 12, was playing with it and there was a picture of (H.F.) masturbating on it. (H.F.) likes men. 
She's very high functioning to talk to. I think she has a pretty high I.Q. She can tell you about her meds, her illness, all that kind of stuff. She wants to live out on her own. She thinks she's going to move into an apartment soon. She was selling her meds when I got her. She was homeless. She had been living with some guy here in town. She tries to manipulate the doctor to get what she wants. She likes her meds. She grew up in Oregon. She was living in Adrian. She got thrown out of HUD housing before I got her.

When asked how she ended up in this area she stated "I married an asshole." She recalled living in Oregon when her infant "son passed away...ended up choking on his vomit. He was seven weeks when he passed." She explained that after feeding the infant she fell asleep with the infant in the bed with her. While she was asleep the infant rolled over asphyxiated on his vomit. She recalled her mother-in-law, who lived in the Midwest, flew the infant to this area for burial and after that she, her husband, and two young daughters moved here also. She had another daughter after moving here. She reported seeing her three daughters within the past month but stated she "rarely gets to see them most of the time."

She described the situation that led to her guardianship as "a money situation." She was living on her own until she was 30 years old then "had some problems...living at friends' house and then they broke into a convenience store. And I had no money to get my scripts." She recalled getting a guardian because she “couldn't manage (her) money. If you have no money you can't manage money." She was approved for Social Security Disability a few months after she was appointed a guardian.

H.F. stated she lived in a nursing home for about 16 months. She stated she liked living at the nursing home because "they fed us better" and she had her own room with her own bathroom and shower. She stated she does not like living at this facility because "there's not much 
conversation. If you want intelligent conversation you really can't talk to a whole lot of people." At the nursing home she stated she had a few people she could talk to...because they were older and they actually have their sense about them...but here there are too many people that have issues." Her guardian stated that she was pressured by H.F.'s caseworker to try a transitional apartment program through DMH.

Her guardian recalled the time she placed H.F. in a "transitional apartment where they have oversight for meds but the residents were supposed to keep their room clean...and there was two kitchens, dining room and living room and they had to take care of it." The transitional apartments are in "an institutional looking building" on the side of the Department of Mental Health office. The residents were also required to attend meetings and work with their case managers on budgeting and daily living activities (DLA's). The guardian stated this arrangement “didn't even last three months and she got kicked out. She took part of her money and went out and bought booze and some of them were young." H.F. contributed the failure of the transitional apartment program to her roommate's underage drinking. After the failure at the transitional apartment in 2012 her guardian moved her to this RCF.

At this RCF she has been in charge of the resident coffee fund. H.F. states

I know how to totally budget. I am the only one in charge of certain aspects like coffee money and stuff like that...I'm the only one that's held responsible to hold the key. I'm in charge of the coffee money but I know that I can do that and manage it because I'm the one that volunteered to do it but it's like nobody can manage it.

During observation H.F. remained highly active. She continually moved from one space to another, interacting with many residents throughout the day. Her interactions often led to 
confrontations, accusations and emotional outbursts. When asked if she has friends in the community she responded "No, I don't like going out into the community because I don't like associating with a lot of people."

When asked about her goals she stated “I don't really want to stick around here much. After I get my own guardianship back I don't plan on sticking around here." Her goal is to "get my life back. I want my girls back. I want a life. I don't want to be here." She says that her "anxiety" is standing in the way of achieving her goal despite taking "the highest dose of Buspar that I can be on."

D.A. is a 53 year-old under guardianship with Public Administrator C. D.A. also lives in Bridgemont. He appeared very subdued throughout the observation and interview and appeared to be Developmentally Delayed/overmedicated. Throughout the interview D.A. experienced excessive delays in response time, difficulty providing accurate information regarding dates and times, went into a catatonic state and drooled on himself throughout the interview. When formally introduced he appeared bewildered so numerous explanations were given using the simplest language possible.

His guardian described D.A. as:

His hair is buzzed, it's black. He's got a beard...kinda bigger, taller guy...doesn't like to shower...talks to himself a lot. The goal of moving out is always his goal. But we're never gonna get there unless a miracle happens. Just 'cause he's not gonna get up. He can't get up and shower and shave...He's got tons of potential... all the potential in the world. If we can just get him to do, you know, the things we need him to do...on a regular basis and not have to wake him up 50 times in the morning. You know you just have to babysit him so much. 
Later, his guardian added "D.A. sent me the sweetest card this past summer, spring. Out-of-theblue. He's never sent me anything."

As an adult he moved into an apartment in the town he grew up in. He received services from several agencies. Since he was already diagnosed as developmentally disabled he receives additional case management services from the area's "Regional Center" that services individuals with a developmental disorder. In his own apartment the case manager worked with other private and public agencies to provide services such as psychiatric care and other medical care, transportation, medication administration and in-home care.

His health care plan provided in-home services that was "supposed to come in and help cooking, cleaning and shopping but all they did was sit on their butt." D.A. reported that he "fired them cause they weren't doin their job and I didn't like them." He reports he got evicted from this apartment because he "got picked on there a lot, everybody was calling the cops on me all the time."

Finding himself on the brink of homelessness, his case manager from the Regional Center helped him find an RCF in a nearby metropolitan area about 50 miles from his home community. He lived there for about six months until he" got kicked out of there." He then went to live at a nursing home because "he had no choice in the matter...I had very few days to find a place to live so it was either that or live on the streets." After living at the nursing home for several months he then went to live at Bridgemont in 1996 but only stayed for "a little while" before moving again to an another RCF. His residency there lasted "one week and one day until (he) almost died from an allergic reaction to medication." When he got out of the 
hospital he went to live in another RCF (Stoneybrook). He stayed there briefly until his "dad got really sick [and he] was getting ready to lose (his) guardianship anyway" so he moved into the nursing home where his father resided. After guardianship was approved in 2002, his guardian placed him at Bridgemont where he has resided since. Prior to having a guardian he moved freely from one facility to another but it was usually because he was evicted from the facility. He was not able to secure tenure at any facility due to his behavioral problems.

When asked about family involvement he stated that both of his parents are deceased and the only other family member is a brother and his wife and their children in the state of Washington. He reported having little contact with them. He attends a community church but did not have any other ties to the community. The only "visitors" he receives at the facility are his guardian, case manager, and other professional staff.

When asked what he most liked about living at this facility he said "the friendly staff" even though "I get mad at them...they get on to me about sleeping too much." His goal is to live in his own apartment in the larger metropolitan city because he does not like the local hospital. He understands that his independence requires him to "get my act together...start obeying the rules...start being med compliant...start doing my hygiene."

Currently his case manager works with his guardian and the RCF staff to help him secure stable housing and maintain eligibility for federal and state assistance programs. In addition, he receives Community Integration $(\mathrm{Cl})$. $\mathrm{Cl}$ provides D.A. with an individual who meets with him a couple times a month to "go out to eat, go fishing...a bunch of this and that." He also attends the Psychosocial Rehabilitation (PSR) activities though the local CMHC. 
All residents interviewed at Stoneybrook have the same guardian (Public Administrator D). Their guardian stated he had "files" on all of his wards but was unfamiliar with their contents and therefore provided no background information.

E.C. is a female in her 70's and lives at Stoneybrook. When I asked E.C. her age she stated "Well they say I'm 70 but I don't think I am. I think I'm in my early 60's. I don't think I'm 70 . I was 50 when I came here." She stated she grew up in a rural town about 150 miles from this facility. She reports growing up with three sisters and one brother. She has never married or had children but continues to have relationship with her brother and one sister and says "sometimes they come see me. I'm so glad when they come see me. They give me money. I get twenty-five dollars a month from my brother."

She recalls her employment as limited to a fast food restaurant in high school then six months at a sewing factory right after high school. When she was asked how she came to live in boarding homes she initially stated she could not remember. Shortly thereafter she recalled “Nothing happened. Oh yeah, I remember. I hate to tell you. I stabbed my dad...If I hadn't done that to dad I still would be free." She reported her father did not die from the wound and was unable to recall details of the incident but explained "the voices" told her to do it and she "wasn't in (her) right mind."

She recalled living in a cabin on her family's property. She stated she "fixed it up all by myself, put curtains up, blinds up and other things. It was cute. My brother came up there and I said 'why do I have to go live in a boarding home? And I said 'Oh, no, I don't want to'." She reported that she has lived in "a nursing home and five or six boarding homes....ever since I was 
40...I've been in places- awful." She stated she did not know why she was moved around and did not know why she was moved to this facility. The primary staff member and the facility Administrator stated that E.C. is very difficult to get along with. They reported she often provokes other residents to fight with her and has been known to physically attack other residents. When asked how she has been able to stay at this facility for so long E.C. explained that this facility did not hospitalize her when she would get into a fight. When asked about her roommates E.C. replied "they don't like me...my roommate has got it in for me."

E.C. had extreme difficulty staying on topic. When she discussed hating going to the hospital I asked why she thought the hospital was awful. She responded "The nurse was always treating me mean. What time is it? I want coffee."

D.T. is a 52 year-old male that has been living at Stoneybrook for five years. He appeared quite older than his age and had difficulty communicating due to a markedly enlarged tongue. He reported he has lived in one other facility prior to moving here. When asked about how he came to live her he replied "I don't know."

Ms. S. at Stoneybrook stated that D.T. has gradually, over the past couple of years, lost the use of his arms, some loss of the use of his legs, and some speech abilities. The doctors initially thought it was MS [Multiple Sclerosis] but the tests were inconclusive. His arms dangle at his sides and he shuffles slowly. He stated the problem were a result of neck surgery.

The facility Administrator stated they have made some minor changes to accommodate his disability. The facility replaced many door knobs to door levers and moved his bedroom to 
downstairs and near the front door. In addition, the staff members provide extensive assistance with eating and bath and body care.

D.T. reported very few social interaction outside of the facility because he "can't go anywhere without staff." When asked about his family D.T. replied "My family's dead. Went up to heaven."

D.T. reported he generally likes living at this RCF. He says he doesn't like his room because there are "all guys" and wishes he shared his room with females. He shares his room with three other male residents. When asked why he continues living in facilities he stated "I don't know." D.T. became agitated twenty minutes into the interview and the interview ended.

J.A. is a 67 year-old male resident and has lived at Stoneybrook for eight years. He stated he has lived in "two or three" facilities prior to this one. When I first approached J.A. another female joined the interview. She immediately explained that they have been "engaged" for five years and they both extended their hands to show they were wearing wedding rings. She went on to explain that their guardians will not permit them to get married. J.A. further explained that he and his fiancé would like to get married but will not be able to unless her guardian retires or loses her position in the next election. When asked if they would go live in a house on their own J.A. stated "No. We're not able to take care of ourselves...(she's) not able to do nothing and I'm not either." J.A. stated neither one of them are able to cook a meal or go shopping adding "neither one of us is able to walk around in a big store."

When asked about his family J.A. stated that before he was born his parents lived in logging camps where his father drove a log wagon with a team of mules. Right after high school he 
worked on a ferry boat on a nearby river. He got married and had four children before the couple divorced.

After J.A. got divorced he "travelled around a lot." When asked how he supported himself he stated "when I was travelling I worked all kinds of jobs. When I was in Houston I worked as a security guard and I was a manager in a wholesale wallpaper distributor at a warehouse. I was an armed security guard in a lot of difference places." From Houston he travelled to Florida and worked at Disney World for a short time. He lived in his van throughout his travels. However, J.A. always returned to his home town.

He stated he has lived in "two or three" facilities prior to this one. When asked about how he came to live in a facility J.A. stated he had been living with another male in his home town who had been drinking a lot and got him to start drinking. He stated "I was drinking real heavy and I asked about what to do and I was told to go into a psych unit for detoxification. I went into one and somebody came in and asked me if I wanted to live in a place like this and I said 'yes'. While I was in one the manager took me to court and got me a guardian." When asked what his diagnoses are D.A. reported “major depression. There was two or three more. I just can't remember."

J.A. believes he could not live outside of a facility due to the pain he experiences in his neck. He reports he has "had an MRI and other tests" and they showed the discs in his neck are badly deteriorated. He reported he was given pain medication and when asked about what other medications he takes J.A. responded "I don't know what all I take-a whole handful of pills...morning and night." 
When asked how he likes living in this facility he reported "not very much...there's 37 rules."

He stated he and his fiancé “can't even hold hands. There's no physical contact. That means I can't kiss her or hold hands even though we've been engaged for five years." When asked about what would happen if they broke the rules J.A. stated

You can't go into each other's room. That's a big no, no. If she got caught in my room or I got caught in her room we'd both be restricted for a couple months apiece which means you don't go anyplace...except to see the doctor and you wouldn't be able to get sodas when they have sodas in there and no visitors and no phone calls.

When asked what he does like about this facility he reported "I like the food."

When asked about anything he likes about the building in particular he said "I wouldn't say there's anything I really like. I can tell you what I don't like-there's not enough bathrooms...Also the dining room is kinda small." When asked if he liked one of his previous placements he referred to a facility he lived in prior to this. J.A. stated

It was brick, about 2 years old. That was an absolute mansion. Two people to a big room. A bathroom to each room. A front room with a chandelier with a fireplace in it. Wall to wall carpet. A dining room with fancy tables. Only two rules- don't go into the kitchen and don't smoke inside the building. They have a smoke room with heating and air conditioning and a TV. And if you want to set in there all night. And they have hot coffee any time you want it, day or night. They have lemonade and tea dispensers-any time, day or night, just go in and help yourself.

(J.A. is referring to an example of a design used for newly constructed facilities discussed in Chapter Three). When asked why he left this facility he stated "Oh, I did something I shouldn't have. I think I was cutting on myself. I got kicked out." 


\section{Public Policy}

Title VIII of the Civil Rights Act of 1968 and the amendments over the following twenty years should have protected individuals with disabilities. However, this has not been the case. One Public Administrator explained that "there's no place for the mentally ill population to go to. You're getting this population group right now that is $20^{\prime} s, 30$ 's, 40 's that have this mental illness but there's no facilities to go into to get help...there's no housing for them." And even in the facilities that are available, it is difficult for individuals with difficult behaviors to secure stable housing.

One Public Administrator discussed how current governmental practices has affected the housing issues they face. She reported that in her second year in office the Department of Mental Health $(\mathrm{DMH})$ began closing the nearby state-run facility for the developmentally disabled:

In 2012 is when they (DMH) started saying it's gonna happen, they said it'll be done by 2012. There are no patients living on the campus here locally. Now they did, we had a choice when they were put out into the community where we wanted them to go...We fought tooth and nail not to get this because I think there's a huge majority that can live in the community with good support without any problems. But there's those few that we've tried... When they were at the $\mathrm{Hab}$ Center there was so much oversight than there is living in the individual homes...But there are just some of them that are so fragile that it's really scary unless you know those people taking care of them. You know these positions are not high paying position... But when you get into these private providers...they try to do the best they can...it's harder for them to keep good employees.

This has left many individuals vulnerable to exploitation, poor living conditions and lowered expectations for regarding living environments for individuals with a mental illness. 
When asked about these closures and the lack of housing resources for individuals with a

mental illness Government Official A stated "the push is to get as many clients into the community as possible." When asked if he thought more people are being kept in facilities that do not need to be there he stated

I think so. And the other thing is a lot of them have died off. They've been in there for a long time. There are new ones that come in but I think they try to have something new to come into. They are all shrinking. (A nearby state-run psychiatric hospital] used to be very big because they used to put clients into these big three story monstrosity buildings. They had 31 groups homes and then they had two up north that we renovated into apartment and group homes. Those have been torn down and then all the big Kirkbride-type buildings with the steps going up and you can't get into the building-they're being torn down. It you went out there it's quite different because the big buildings are gone.

While many facilities for the mentally ill are closing due to dilapidated buildings and high

maintenance costs, they are not being replaced. In addition, Government Official A admitted that the closures are for financial reason. When asked about the closure of most state-run psychiatric facilities he stated

it's also the expense. It takes a large support staff. Not only the caregiver staff for 24-hour care so you're talking about three people per client just for care and then you have the dietary staff and maintenance staff and janitorial and stuff. The facilities are getting smaller.

In addition, the government has increasingly shifted the responsibility of their housing needs to private organizations. As one Public Administrator put it “DMH doesn't want to own buildings and stuff...or be responsible for upkeep and things like that. They don't want the bricks and mortar." She added, the state does not

want the responsibility any more. They've privatized all the placements... Everything is going privatized. Well maybe that's great for them but for those private people-they don't have to take my clients. So when you've had some- 
body in 5 or 6 RCF's, where do you go with them? They don't want the responsibility of anything going wrong with a lawsuit.

When the government began closing facilities they made no provision for the construction of new ones. Public Administrator B discussed how the city she lived in had five newly built RCF's. After further discussion she stated that the buildings were originally built as nursing homes and are now being used as RCFs. When asked if they had the appearance of a nursing home she stated

Yeah, kinda, in a sense. I mean it's a room the size of this office (about $8 \times 14$ ) and you have two people living in it. And they go down to the cafeteria and get their meals and go back to their room or they've got a couple big dining setting areas.

When Public Administrator D was asked about what he looks for in a facility he stated that he likes a place where

the staff communicates well as far as telling us when something is going on. They kinda take care of things and you don't have to micromanage them to make sure they're taking care of things. All of them are state inspected so that takes a little guess-work out of deciding if that's a good place for this person. If the state decides it's a good place.

When further pressed about whether he considers any architectural elements in his decision-

making he stated

A few years ago the state went in and required them all to put sprinklers in so that's one of the first things I notice....safety, and if they have a yard and, at the more secure facilities, if they have fence around it. And how safe the neighborhood is-Are there bars on the windows? Do they need to have bars to keep the people in or keep the people out? Just generally, if they're in a safe neighborhood. And if this person like to wander around, how close are they to other things like stores. And if they have an alcohol problem, how close are they to a liquor store.

Public Administrator B stated “I don't look at the building as a rule. I know buildings are really well worn with mentally ill patients. They are not taken care of. No matter how you try they're 
not the prettiest buildings." All of the Public Administrators expressed dilemma of having to choose between a nice place to live and good caregiving.

All of the Public Administrators expressed the need for more government involvement in the care for the mentally ill. Public Administrator C discussed her involvement with local and state representatives. She expressed the need for the county, state, and federal departments (DHSS, DMH and HUD) to work together to develop more housing units with on-site services. Public Administrator $\mathrm{B}$ described working with $\mathrm{DMH}$, and the state-run psychiatric facility, to develop

some kind of test program...that we could have some medication management for a certain set of apartments, but maybe not 24 hours...(so) some of my mentally ill clients, if we could get just that little bit of oversight we could keep them in their apartments. I would be so much cheaper...It's so cost effective to pay a med tech to give somebody meds to keep them out of the $\$ 100,000$ a year behavior ward stay.

However, to date, no such program has been implemented.

When discussing imminent closure and rebuilding of the state-run psychiatric hospital Government Official A stated "it's a big institutional building that they portray in movies like One Flew Over the Cuckoo's Nest or something like that. It's just not conducive to proper programming for these clients." He said of that facility "the environment right now is not very therapeutic and we're trying to have a facility that is more therapeutic.

Theories regarding mental illness also affect the design of facilities. When asked what architectural features he considers important when building environments for disabled individuals Government Official A made a clear differentiation between an individual who has a mental illness and those with a development disability: 
If a person has disabilities, generally we want those clients, we want those residents, to have their residence in groups or a homey atmosphere. Security is normally not an issue as it is for a psychiatric facility because these people have a hard time getting around by themselves. Some can get around pretty well. The way we call facilities that take care of people with developmental disabilities are Habilitation Centers. They're not 'Rehabilitation Centers' because they're just born that way. So the object is to make their life as comfortable as possible-enjoy life as much as they can in their situation. And anytime we have something going on with a facility-a construction project-it's always, client number one. Because the client's go out and they're curious and they try get inside the construction fencing so we try to make sure everyone is safe. So a Habilitation Center generally has a group setting.

Government Official A demonstrates the impact of Foucault's criticism of imposing a whole range of regimés and categories on people. He also makes a clear distinction between the mentally ill and the developmentally disabled. This distinction, he understands, is one of etiology and prognosis. His understanding is that individuals are not born with a mental illness because it usually manifests itself in early adulthood and that the medical profession has developed effective treatment for mental illness. Therefore, he justifies the goal of designing living environments for the developmentally disabled is "homey", "comfortable" and "enjoyable" while the goal for the mentally ill is "security."

When asked to elaborate on how one design can accommodate a case-mix of individuals Government Official A stated

one new psychiatric concept is you have a bedroom where the client sleeps. If the client feels withdrawn then the client can stay in the bedroom. Then the bath facility is in the bedroom or down the hall. And then that hallway is under one security deal. And then you have spaces near there where the clients can be cluttered with other patients, like a tv lounge or a day room or they come together for therapy. But there may be some psychiatric patients who you don't want to be with anybody so they have to have one-on-one therapy. Dining, it used to be in a big hall and everybody went to the big hall and then they went back to their room but now they're finding that it's easier to manage if you have smaller dining room. There 
are psychiatric patients who don't want to leave their room. So it's kinda called the ward-neighborhood-community concept. So you might have three pods in an area each pod with 25 beds, so like 75. And each pod area has its own neighborhood area, like a day room or whatever. Another thing that is really helpful is to have the offices of the caretakers on the wing. Don't have them so far away. And then there might be a community that services three pods and you have walking down the hall to get to that area. It might be like a hair salon or a chapel. So it's kinds like a shopping mall-you go down there with all these services then it gets tighter and tighter to the private space. It's very important for the psychiatric patient to have private spaces.

Public Policy can also greatly affect how the built environment is designed through building codes and regulations. Government Official A explained that

the big thing about DD design is you want the place where the client sleeps as homey as possible. So if you go into the room you will see a standard bedroom set that the family brings from the house-just a standard bedroom set. We don't have to worry about suicide. Now if there is a case where someone is trying to kill himself then that person will be in a difference environment. But most of them are very homey, they can hang up posters on the wall, their favorite football players. Some of them are quite nice, they try to put stuff up...these homes are flagship group homes, they are awesome group homes.

In contrast to a DD design, Government Official A notes a psychiatric facility

has gotta be secure-to protect them from others and protect us from them. And there's a balance there you have to watch out for. You just can't have a bunch of frilly things in a bedroom in a psychiatric hospital because they might eat them or they might hang from them...each bedroom will have windows with security glass and locked. That's the big difference too is DD you cannot lock the windows. In a DD facility the windows have to be able to be opened to get some body out. In a psychiatric facility, the I-2 [building code] allows you to lock the windows. They normally don't lock the doors and allow the client to go back and forth into the hallway.

In addition, Government Official A exemplified the perpetuation of the theory behind the panopticon in current design theory:

anytime you have a turn in a hallway, because you try to have a person in the central nurses' station looking down the hallway and making sure that no one's taking someone's pills or meeting up with an ex-client or whatever. We still have buildings that have turns, dark areas in the hallway that we need to modernize... 
Government Official B is a program manager for the state's facility licensing department which "coordinates the licensing activity for all long-term care facilities and adult day-care programs." She reported there are about 471 licensed RCF's in the state. Her unit inspects these facilities for licensure on an annual basis. She stated the focus of their inspections is

Environmental-fire safety, physicians orders, and residents rights. You have some that are really innovative and are really connected with behavioral health centers and some that are not. The variation depends on regional variances as well. What resources do they have available? In rural areas they may not have those services readily available. Sometimes it just that some are more internally motivated that others to provide those extra services. It just kinda depends. They are required to have an activity program that meets the needs of the residents.

In addition, they look at,

the cleanliness....if there is dirt on the floors and gouges in the wall... 'What does it smell like?' Then determining what is the source of the smell. Is it a smoke smell because they allow smoking in the facility and they don't have adequate ventilation? Is it a body odor smell because the residents need assistance with bathing? Is it a food smell?-which is good....Just constantly observing-what's going on? Are there broken tiles on the floor and haven't been repaired and they're not able to easily clean? Are there gouges in the wall? Is the wallpaper peeling off the walls? Are there water marks on the ceiling to show that there are leaks that haven't been taken care of?

She noted that all of long-term care is currently going through a movement called the "culture change movement...(which is) moving the culture of facilities and what the facility looks like to more home-like and to create a home-like environment and be more therapeutic. She believes the change was provoked by the

Aging in Place component in assisted living. It's extremely, extremely, hard to communicate with families regarding the fact that once their loved one is physically or mentally not able to make that path to safety they will have to discharge them. They could live there for 8 or 9 years, be happy with the facility, happy with the staff, they love being there, and the family is comfortable. Then the individual declines to the point where they are not able to stay there anymore-that's tough for families. 
The Aging in Place philosophy would require the facility to adapt to the need of their residents as the residents' needs change over time-especially into old age where they may have more physical health needs. However, Government Official A noted that, while some facilities have adopted this Aging in Place philosophy but they would need to meet additional, stringent licensing requirements.

In addition, while social policies such as Normalization and Social Role Valorization should have benefitted the residents of RCFs, many aspects of these social policies were never realized for the residents of the RCFs. The Normalization principle and his human management implications are often misconstrued or misapplied. Each of the Public Administrators and Public Official A interviewed used the term "normal" several times. However, when inquiries were made about what the word "normal" meant to them they often discussed their wanting their wards, as one Public Administrator put it

to have a good life...I know they're never going to be, per se, normal, but likeable... When people are going to like you and not hate you...and the better you do the more privileges you get...you get to go to the part or get to go fishing...the more you can go home or could go to work...go to the whatever...it's that the rewards that they can get.

Here, participation in activities like going home or going to work is considered a reward for good behavior. In addition, the burden is placed on the individual with a mental illness to conform their behavior to the norms of society instead of the opposite.

Bridgemont's Mission Statement also reflects ideas regarding Normalization and Social Role Valorization:

it is our belief that in a Democratic Society, we must assist each individual in realizing his or her own worth and should lead him or her toward becoming the 
most worth and productive member of society possible, operating with the least restrictions. It is our responsibility to assist an individual in choosing and maintaining a living environment that will foster and accelerate their intellectual, physical, social and career development.

However, many of these aspects were never realized for the residents of this RCF. As H.F. put it "I want my life back...I want a life...I don't want to be here."

One Public Administrator discussed the opportunity for some residents to work in the community and earn money. She believed this contributed to their quality of life-"it's not the best quality of life, but at least it's some quality."

As with the Normalization principle, the Social Role Valorization (SRV) principle is often misunderstood and misapplied. Most of the individuals interviewed (except the residents) implied that having a job or participating in community activities is a privilege for good behavior. One Public Administrator discussed her efforts to find employment opportunities in her community for her wards. She stated the developmentally disabled, we can get them a few odd jobs-a lot of them volunteer at thrift stores and hang clothes up. They don't get paid but they may earn a quarter-credit or something like a free blouse. But it's really hard to find work

for them." Another Public Administrator discussed one of her wards working:

so if they're doing well and they're thinkin' they might want to work, well then I'll find a facility closer to a workshop so they can go to work if they're doing really well where they're at...some of them don't want to work a lot but I like them to have a reason to get out of bed.

Again, according to the SRV principle, the burden should be placed upon society to create socially valued roles for all members of society. Instead, individuals with disabilities are expected to conform to the standards of the rest of society. One male with a mental illness and 
mental retardation discussed working for a small kitchen appliance factory for two weeks

before

they fired me because they said that I was too slow on the assembly line.

They said the only thing they liked about me was 'redo work' but they didn't have enough redo work to keep me busy everyday so they fired me. They said I wasn't really facts enough on the assembly line.

A majority of the work that the mentally ill and developmentally disabled are able to secure are through sponsored programs. These sheltered workshops' are supported through state and federal funding. There are very few programs like this available, but more important, they do not incorporate the disabled individual into a workplace with other members of society. Here, again, the individuals are segregated from society in their workplace.

Public Policy also affects how the social environment of the RCF is organized (whether it is highly structured or restrictive). If the policies restrict the residents behaviors by limiting their participation in a variety of daily living activities and the amount of control the resident has over his environment he will become increasingly helpless. As discussed previously, symptoms of Learned Helplessness were evident in the residents' statements.

A portion of the lack of control in the lives of the residents is perpetuated by the programme of the facility. As Markus notes

order is based on stable categories of people, objects and activities, together with a set of rules...which govern their interactions. They establish diurnal, weekly and season timetables and shifts; and they specify the duration and repetition of events. The rules are, equally strongly, built into space and its management. They define the location of persons and things, the control the paths of movement and the degree of choice as well as the visual paths, they define programmed encounters and place on those occurring by chance. Time and space are joined in rules which govern the opening times of specific spaces. In short the building and its management determine who does what, where, with whom, when and observed by whom (1993, p. 97). 
As one resident confirmed-"the staff does our meds...they cook our meals...they do our laundry...they clean our rooms....they talk to us when we need talking to....and they remind me to do my daily ADL's." This leaves little responsibility on the part of the resident to retain their ability to manage their daily lives to the fullest extent possible. It extracts control over their environment from the residents as they do not take part in caring for themselves but are encouraged to let others do it for them.

Both of the RCFs in this study presented typical RCFs in the area at the time of this study. Despite structural differences of the two facilities, both facilities had institutional elements and allowed little space for personalization, privacy and independence.

The residents' daily lives were regimented by public policy which governs the daily operations of the facility. The individuals interviewed-Public Administrators, government officials, facility administrators, and facility staff members all expressed the influence of public policy regarding the design and daily operator of the facility.

The residents' reactions to the regimented life and lack of control over their lives resulted in complacency with the dismal redundancy, degradation, unnecessary dependence and promotion of safety and security over individual needs. 


\section{CHAPTER FIVE \\ Discussion}

Data obtained from interviews, observations, building analysis, and analysis of public policy revealed that Residential Care Facilities have all the characteristic of a total institution described by Goffman: "a place of residence and work where a large number of like-situated individuals, cut off from the wider society for an appreciable period of time, together lead an enclosed, formally administered round of life" (Goffman, 1961).

As a result, the environment in which they live does little to promote feelings of competency and controllability which are considered a "central motivational force underlying much of human behavior (Parmelee \& Lawton, 1990, p. 466). The people in their lives, public policy, and the built environment create obstacles for them instead of providing them with the support they need to live a "good life." And lastly, public policy dictates the sacrifice of safety and security over individual needs.

\section{Daily Rounds}

The residents of RCFs described their daily activities and scheduled and regimented. The residents expressed little control over their daily activities such as eating, bath and body care and recreational activities. When R.C., at Bridgemont, was asked how she spends her day she said she begins by

getting up at 5:00 and doing my blood sugar and insulin. I get up and go into the office and do my own blood sugar and then I go back to bed until around 8 . Then we get up at 8 and we take our 8 o'clock morning meds. Then I go in and make my bed and straighten up my room. And then I wander around the hallways and talk to my friends and try to find things to do until 11 o'clock meds and then lunchtime is about 11 o'clock. Then we take our meds at 12 and then usually, I take a rest 
until 2. And then I get a 2 o'clock med and then I usually rest from 2 to 4 . Then I take a 4 o'clock med and 5 o'clock blood sugar and 5 o'clock meds and five-thirty dinner. Then I usually take down time. My down times comes as reading or relaxing or listening to music. It's the same thing day after day.

R.C. relinquished control of her daily life to the rules and routines of the RCF. Her activities are organized around frequent medication times and inflexible meal times and menus.

When another resident, H.F. at Bridgemont, was asked about her daily activities she stated I get woke up or I come down. I get a six o'clock pill. I have hygymotos which is that my immune system attack my thyroid which causes nodule and goiter on my thyroid which makes it hypo and without my thyroid pill it would shut down my thyroid eventually. Even with it, it will eventually shut down but it will slow down the process. But right now my pituitary gland in over producing, making my thyroid working harder. But I went to the doctor earlier today because I got a lump in my groin that I gotta have that removed Friday. He removed my gallbladder. Then I had to go have a stent put in because I had a stone in my gallbladder. They removed the stone then put a stent in. Then they put me on a different pills to help with the spasms Hopefully that will help because l've been having a lot of pain under where the stent in.

Although this female resident experienced issues with tangential thinking throughout the interview, she expressed her daily preoccupation with physical health ailments. With little else to stimulate her mind she focused on her physical health issues throughout the day.

A majority of the residents' days are limited to pacing throughout the facility, smoking, watching television and waiting for meal/medication times. Several times a day residents can be seen lining up or gathering around the office/med room door at both facilities. When I asked a resident at Bridgemont why the long line was forming outside the office/med room door she replied that medication time was drawing near and she wanted to be first in line. 
Relying on another person to provide for your basic needs is difficult for any adult. However, for the residents of the RCFs in this study, they are required to depend on inflexible schedules and predetermined menus.

\section{Eating}

Most American adults have many choices about what they eat, with who they eat, when they eat with, and where they eat. However, for individuals living in a RCF, daily activities such as eating, bathing, grooming and recreation are highly regimented.

At Bridgemont, the main staff member, Ms. R. fills out a monthly calendar with the menu and does the grocery shopping. She says the task can get tricky because there may be individuals who have specific dietary needs like a low cholesterol, low sodium or low fat diet. She state that the facility tries to meet all of their dietary needs but "sometimes it's just too much and we have to serve what we got." She does not post a menu so the residents are unaware what they will be served on any given occasion. She boasts "home-cooked meals", however, this description is vague and obscure. The meals are served on cafeteria style trays that are slid through the opening in the steel divider (See Figure 27).

The narrow dining area at Bridgemont was originally designed as a sunroom during additions in the 1980's. The area is now enclosed and with fast-foot type booths lined up along the wall. This space is heavily used throughout the day for a wide variety of activities. 


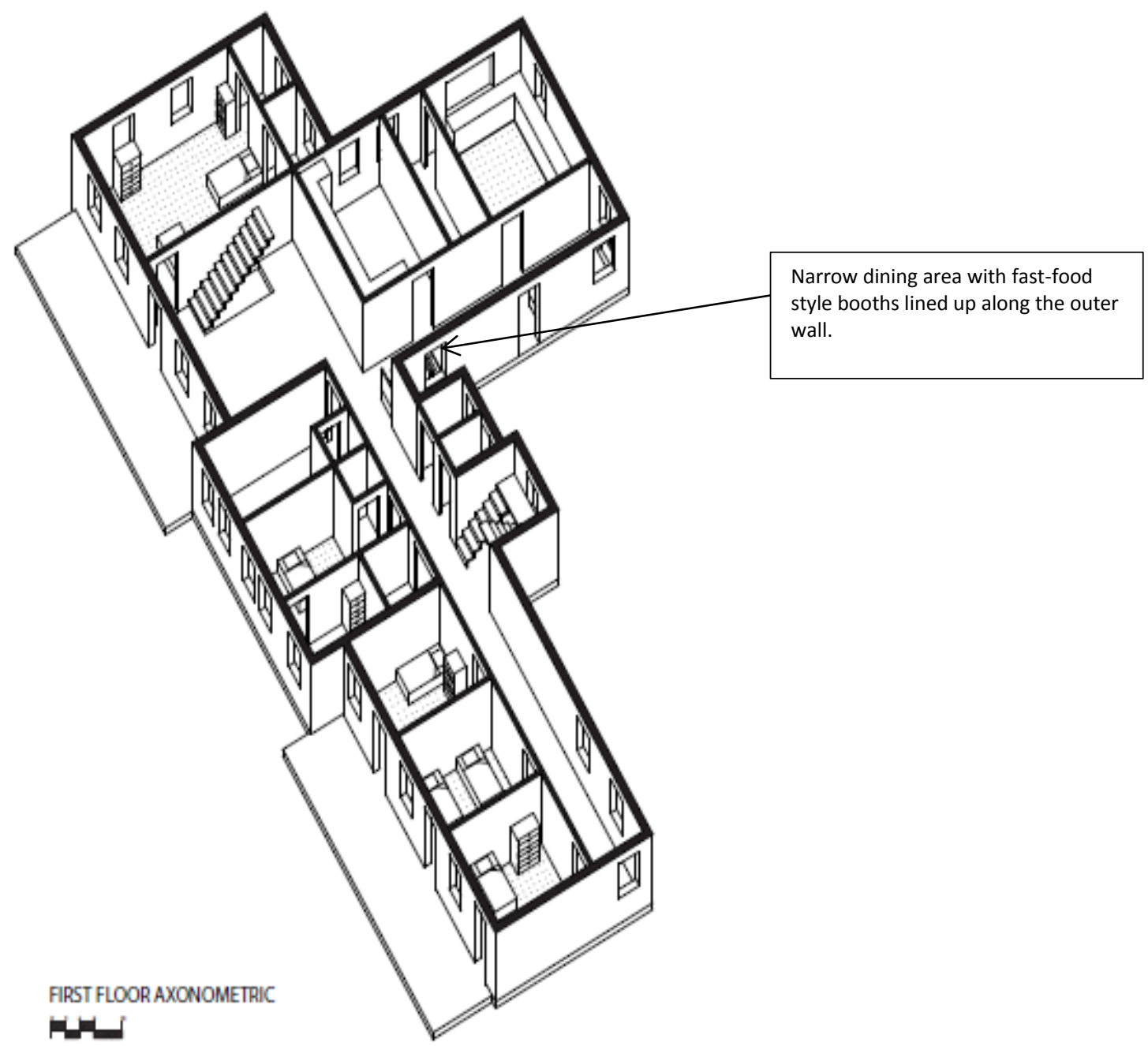

Figure 56. Bridgemont axon drawing, dining area.

There is not enough seating for all residents to eat at the same time. Because of this residents will form a line up to thirty minutes prior to any meal to ensure they get sufficient portions, the food is fresh and at the right temperature, and they are not forced to sit next to another resident with very undesirable eating habits.

At Bridgemont all meals are served at a specific time-breakfast at 7:00 a.m., lunch at 12:30 p.m., and dinner at 5:30 p.m. When those times arrive the residents must line up and wait to 
be served and the line extends through the dining area. They wait in line to receive a tray of food to be passed through the steel barrier (Figure 50). They demonstrate an irritable passivity that comes with being forced into a situation where they have committed no crime yet are treated like inmates in a prison.

At Stoneybrook the monthly menu is also completed by the senior staff member, Ms. S. She posts the facility menu (along with any scheduled activities) on a dry erase board inside the living/dining/activity room (visible in Figure 50). She also does the grocery shopping for the facility. At Bridgemont, another staff member usually prepares the meals throughout the day.

The mealtimes are also a highly structured activity at this facility. They are served at specific times to avoid any conflict with medication times. Eating at this facility involves all residents leaving the living/dining/activity room and lining along the wall in the small sitting room.

Stoneybrook has two tables where eating is done. Each table seats four residents at a time (See Figure 50). Therefore the other twelve residents must wait in the line until the first group of residents finishes eating. 


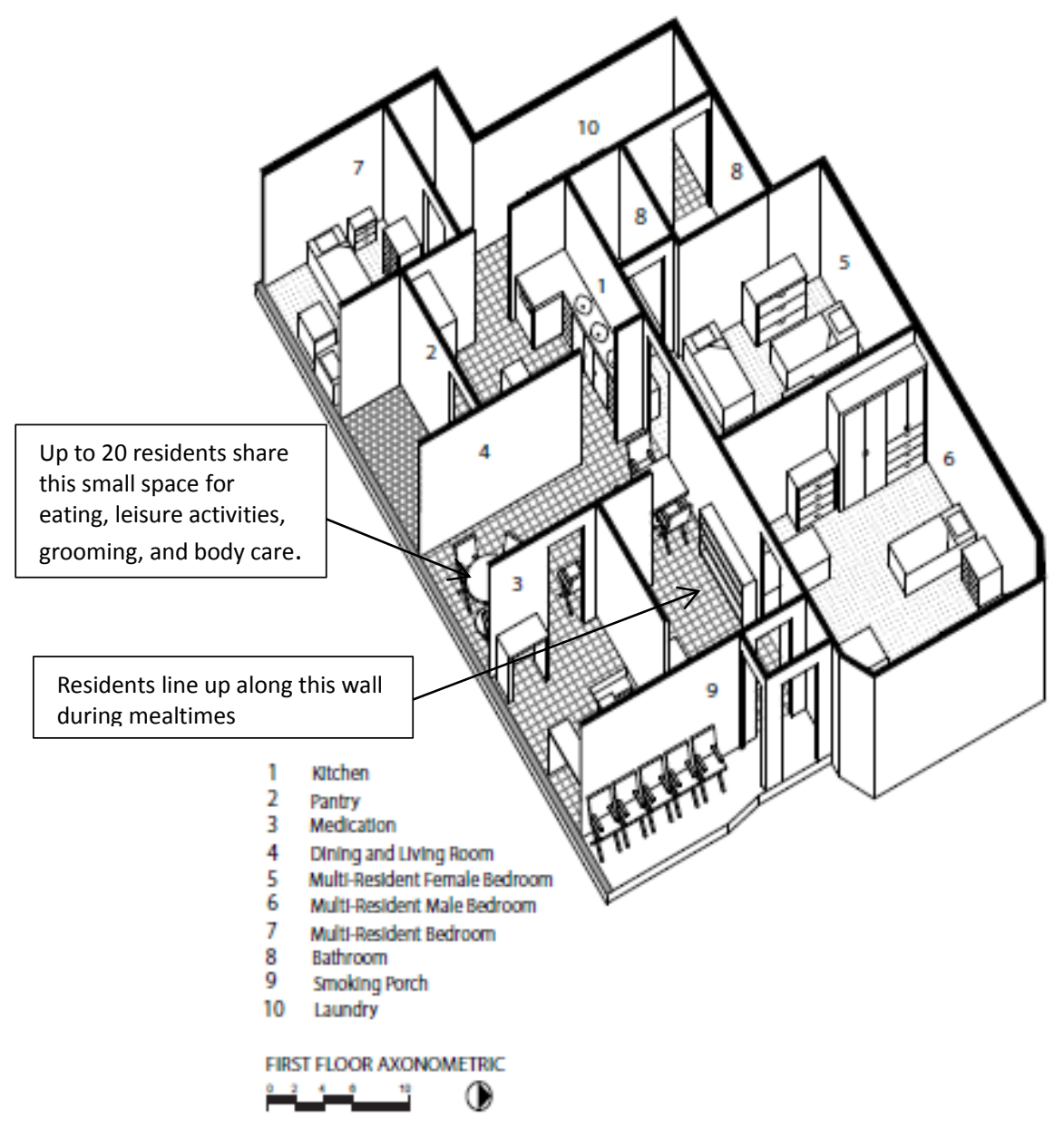

Figure 57. Stoneybrook axon drawing, dining area.

The order in which the residents line up is based on a variety of factors. Some residents prefer to eat first despite the fact that the other residents will be standing in the line, watching to ensure that the meal is consumed as quickly as possible because they are anxiously waiting for their turn. Another factor is the ability of the resident to create enough of a disturbance that they could move to their desired place in line. The entire eating process can be disrupted by any one of the residents who, at any given time, realize the absurdity of their situation and are unable to endure standing in a line three times a day to eat. 


\section{Bath and Body Care}

Both facilities receive funds from Medicaid to provide assistance with bath and body care for a majority of their clients. Bath and body care include showering, shaving, nail care, perineal care, and oral care. These services are provided by the facility staff members and documented in the residents' charts. Bath and body care is also highly regimented. A schedule is also developed for these activities as well. Residents are assisted with showering at least twice per week.

Residents at Stoneridge who require assistance receive bath and body care in the shower room on the first floor.

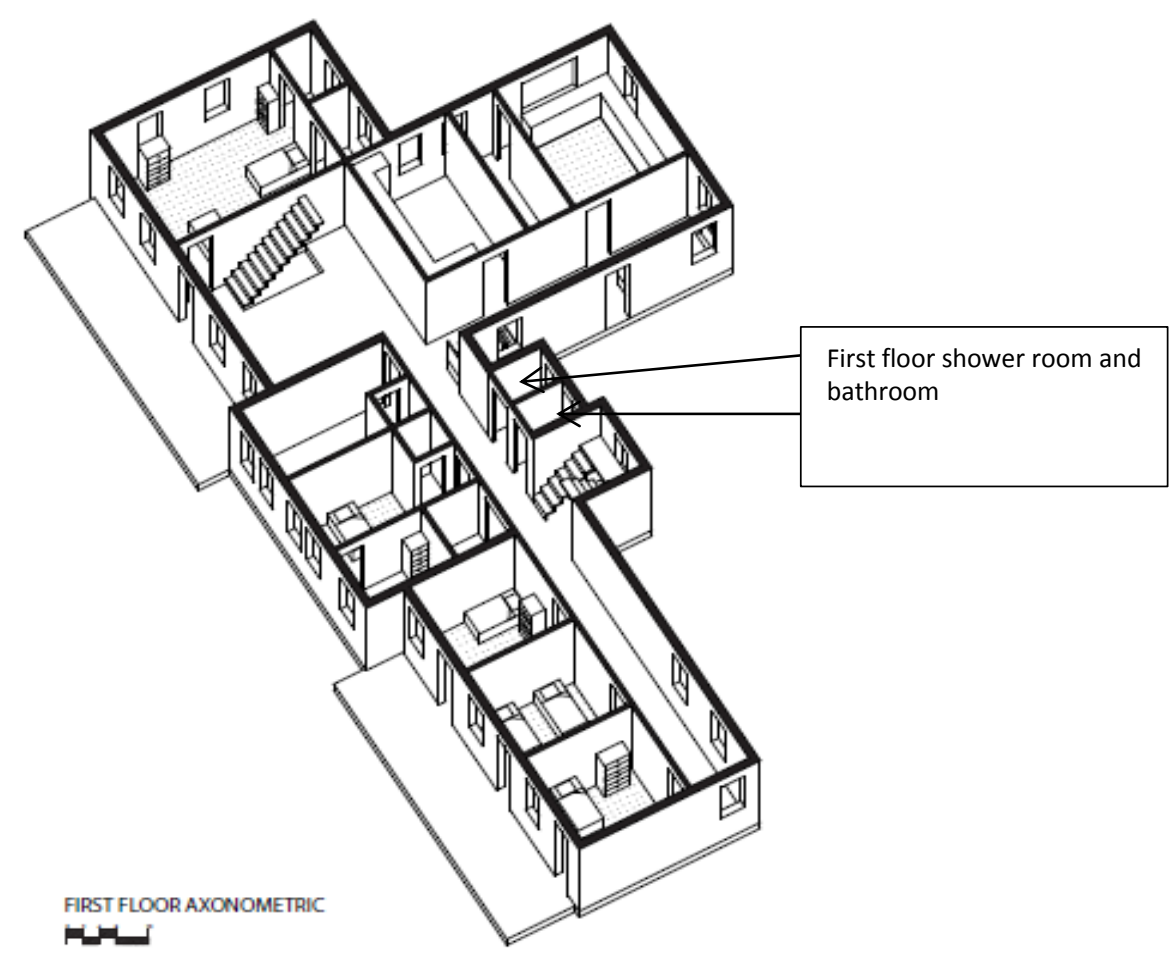

Figure 58. Bridgemont, axon drawing, first floor shower room and bathroom. 
During my observations a female staff member was assisting a female resident with a shower.

This shower room opens onto the first floor corridor which maintains a steady flow of traffic throughout the day. During the process the staff member left the shower room on two occasions. On each occasion she opened the door exposing the naked female resident to everyone in the corridor.

Residents at Stoneybrook are assisted with showering in the bathroom located on the first floor (See Figure 54).

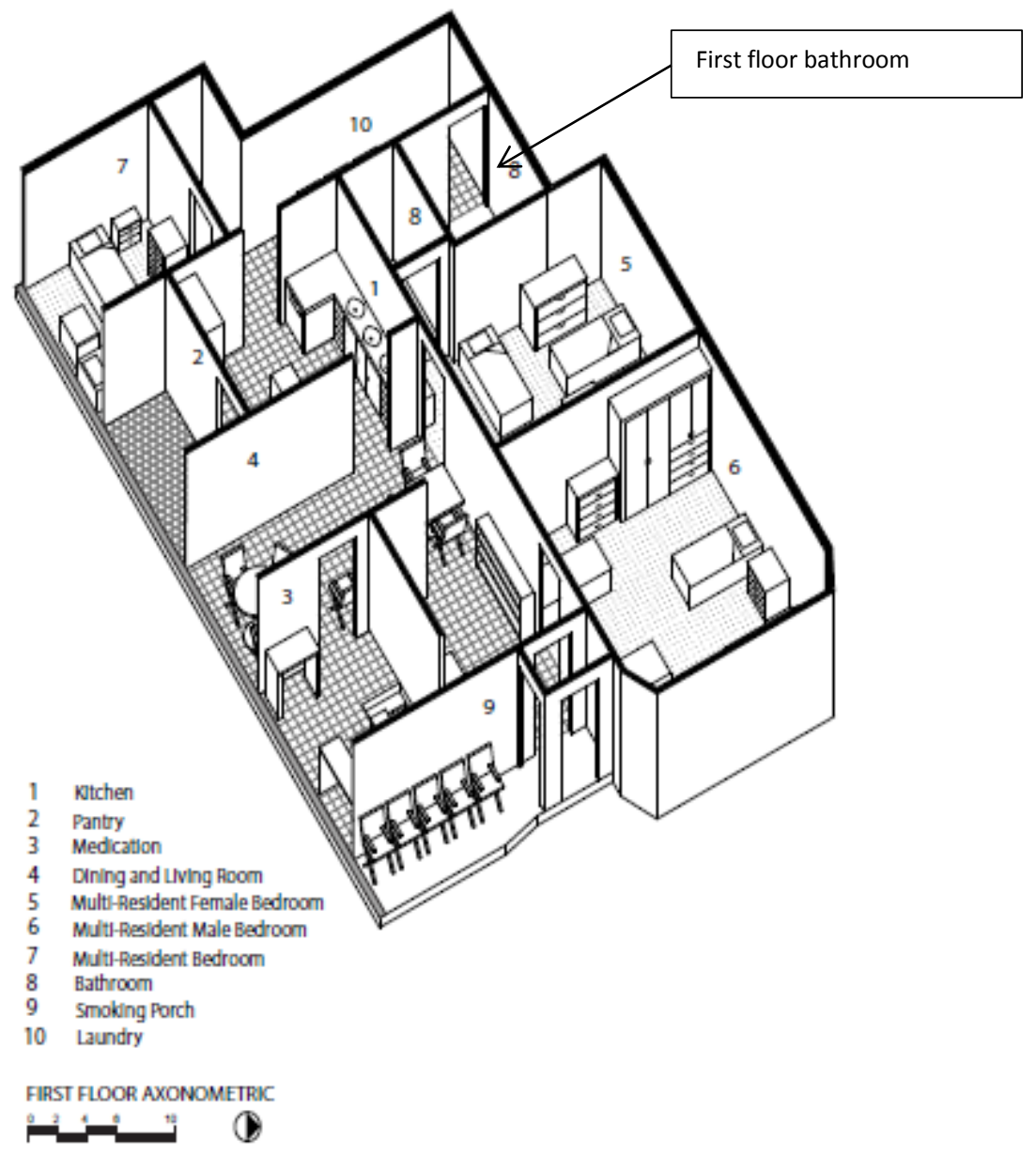

Figure 59. Stoneybrook axon drawing, first floor bathroom. 
Other body care such as trimming clients' fingernails and toenails is done in the living/dining/activity room at Stoneybrook.

At both facilities in this study the residents must stand in line to eat, to receive medications (up to four times a day), to get mail or their spending money, to make a phone call, to discuss a personal issue with a staff, to obtain bathing or showering supplies. All of these activities require lining up.

Ordinary adults have the experience of standing in a line at any given point during a day. We may stand in line at a grocery store, a bank, or a fast-food restaurant. We endure the situation but consider it an occasional inconvenience. If we were required to do this to the extent residents at the RCFs had to do it we would quickly realize the absurdity and refuse to endure such treatment. However, for the residents in this study it is all part of their daily round of life in a RCF.

When another resident, H.F. at Bridgemont, was asked about her daily activities she stated I get woke up or I come down. I get a six o'clock pill. I have hygymotos which is that my immune system attack my thyroid which causes nodule and goiter on my thyroid which makes it hypo and without my thyroid pill it would shut down my thyroid eventually. Even with it, it will eventually shut down but it will slow down the process. But right now my pituitary gland in over producing, making my thyroid working harder. But I went to the doctor earlier today because I got a lump in my groin that I gotta have that removed Friday. He removed my gallbladder. Then I had to go have a stent put in because I had a stone in my gallbladder. They removed the stone then put a stent in. Then they put me on a different pills to help with the spasms Hopefully that will help because I've been having a lot of pain under where the stent in.

Although this female resident experienced issues with tangential thinking throughout the interview, she expressed her daily preoccupation with physical health ailments. With little else to stimulate her mind she focused on her physical health issues throughout the day. 
A majority of the residents' days are limited to pacing throughout the facility, smoking, watching television and waiting for meal/medication times. Several times a day residents can be seen lining up or gathering around the office/med room door at both facilities. When I asked a resident at Bridgemont why the long line was forming outside the office/med room door she replied that medication time was drawing near and she wanted to be first in line.

One Public Administrator explained that

in a RCF the residents "have no quality of life...They get up, they take their meds, they go eat breakfast, they go back, they flop down in bed, they watch tv, they get up for lunch. There's nothing...(they're) never gonna learn anything in those places except to get up and go get a meal and go back to his room and sit...wouldn't you love that? It would be so depressing.

Although the residents discussed attempts to improve their situations they were constantly reminded of their failures by the RCF staff members, Public Administrators and the facility Administrator. D.A. was continually reminded of his hygiene failures, H.F. of her past poor financial decisions, and the Ms. R. at Bridgemont responded to one resident's request to attend the funeral of a community member with "You wanna do things but you won't get out of bed." The Public Administrators were also openly pessimistic about their wards ever being independent of guardianship or living on their own. In response, the residents developed various behaviors that allowed them to cope with this reality. A majority of the residents entirely gave up (R.C., E.C., D.T., and J.A.), others tried to prove themselves competent (H.F.) while others attempted to gain control over any portion of their life (D.A.). A majority of the residents interviewed in this study expressed a generalized sense of a lack of control over their environment and themselves and have become profoundly passive in their efforts to escape their situation. The residents described their continued residence at a facility 
as inescapable and independent of their efforts to escape similar to the traits of Learned Helplessness described by Seligman, Walker \& Rosenthan (2000). They saw themselves as stuck in a situation without any control and believed any actions they took would not make a difference. They understood that the outcome of their lives was not contingent on their behavior but was in the hands of other decision makers. Their expectation that future responding would be futile undermined their motivation to respond and produced difficulty in seeing that outcomes are contingent upon responding. They respond by relinquishing control and suffer from profound passivity described by Seligman, Walker \& Rosenthan (2000).

In addition, Parmelee \& Lawton (1990) propose "satisfaction of autonomy needs is presumed to produce a positive state of emotional activation that eventuates in a sense of self as an effective causal agent. Frustration of such need may lead to mediate boredom and eventually to apathy and reduced self-efficacy (1990, p. 468).

\section{Ostracism}

Since the beginning, asylums were built on were built on the outskirts of communities because

of the fear of contagion. Despite the location of the two RCFs in this study (within towns) the residents continue to suffer from exclusion from society.

Individuals benefit from social interactions within their community. This interaction gives us a sense of belonging and value. Through social interactions we form and maintain emotionally significant relationships. However, for the residents of the RCFs in this study, they refrained from interactions with the community. All residents interviewed in this study openly expressed avoiding social situations in the community. One resident stated "I don't like going out into the 
community because I don't like associating with a lot of people." Another resident described only going out into the community with a staff member to do Community Integration activities. The third said she goes "to the library and that's about it."

For these residents, social situations cause anxiety by increasing the chronic feeling of the worst sort of insecurity described by Goffman (1961). Interactions with community members force them to confront their deficiencies which led to their current situation. By avoiding, or severely limiting, contact with community members they are able to sustain their interpretation of their character and social identity. They are able to uphold this impression of their self, due to limited contact with community members that may contradict their belief about themselves. The residents of the RCF refrain from interacting within the community and isolate themselves within the facility. However, they are continually reminded of their failures by the RCF staff members, their guardians, and the community.

Unaccepted as full-fledged members of society and continually reminded of their failures, the residents make efforts to form a group identity within the RCF. Members developed a lingo understood by all participants. They used agreed upon terms such as "passing meds", "med room" and the "sign out." Members also participate in following agreed upon implicit and explicit rules and reminding others of their obligations to follow these rules. These activities reinforce their group solidarity by providing them with feelings of belonging, identification and emotional attachment while shielding them from the rejection of society

Several residents reacted to their stigmatization and rejection by attributing their current situation to only minor failings with which other normal human beings struggle. In an effort to 
create and manage an image of integrated self, the residents developed ways in which their interactions seem meaningful and reasonable (Goffman, 1961). Some residents offered unsolicited information regarding their educational or employment backgrounds, familial involvement, and current involvement in activities, knowledge regarding various medical diagnoses and medications, and therapeutic interventions.

D.A. perceived his inability to secure stable housing, meet his medical and social issues as an inability that the average person experiences. R.C. continues to focus on securing appropriate familial relationships and H.F. attempts to prove her ability to manage her finances by managing the residents' coffee fund.

Residents of RCFs also questioned whether their membership in the RCF world was even justified. Several explained how they were clearly more capable of providing for themselves, that their capabilities have been overlooked, they have been wrongly accused, or their intentions misunderstood. H.F. minimized her behavior and presented situations that, at the very least, shed a neutral light on her. She portrayed herself as very competent and knowledgeable in everything from child care, insect control and extermination, money management and medical terminology. J.A. discussed his work history and his travels throughout Southeast United States. Despite the fact that he was homeless for several years he felt competent in his ability to care for himself. He attributes his assignment of a guardian to his roommate's heavy drinking and coercing him to drink with him. 
For many residents going to the doctor is one of the only interactions they have outside of the facility. In addition, the residents look forward to doctor visits because it provides them time away from the facility and satisfies their need for attention.

One of the major criticisms of Maslow's hierarchy of needs is that he placed sexual desire in the physiological needs category. Along with food and breathing which must be satisfied before a person considers "higher" levels of motivation. The position of sexual in this category, however, is appropriate.

The residents of both RCFs clearly expressed the need for an intimate relationship. As R.C. put it "In a place like this you get close to people and you get feelings for people and it's so hard. It's hard not to feel for somebody. I've had three boyfriends in here...and all three have been busted up...But we live in such a tight, tight community here that it's hard not to develop feeling for each other and so it hard." She discussed her most current relationship: "he lived upstairs and I lived downstairs and (Ms. R.) came into my room and told me I was banned from going upstairs and that I was banned from being around him and I couldn't talk to him and couldn't be near him...It hurt 'cause we really got close. I've still got a picture of him and some mementoes."

H.F.'s guardian stated that she is no longer able to visit her three daughters at her ex-husband's home because on one occasion her daughter viewed a video on H.F's cellphone of H.F. masturbating. Her guardian states "she likes men." Meanwhile, she attempts to secure an intimate relationship by luring a male from the community into the facility to arrange an elopement. 
J.A. explains that he and another resident have been engaged for five years however their guardians have refused to allow them to marry. He adds "we can't even hold hands. There's no physical contact...That means I can't kiss her or nothing like that. Can't kiss her or hold hands even though we've been engaged for five years."

The residents in this study are fully aware of the steps taken to ostracize them from the community and are fully aware of tensions between being inside the facility and going outside of it. Inside, they feel acceptance. Outside, they are reduced from a whole and usual person to a tainted, discounted one. As a result they chose to spend a majority of their time within the facility.

\section{Built Environment's Contribution}

All of the residents interviewed described living in the RCF as "too hectic" and "stressful." The symptoms of stressful reactions described by Chorpita \& Barlow (1998) were evident in the residents' statements and behaviors. During the interviews and observations the residents expressed stress symptoms of "anxious apprehension, narrowed attention, and reduced autonomic reactivity...anxiety and mood disorders" (Chorpita \& Barlow, 1998, p. 4).

Although Psychology restricts environmental stress to social forces (i.e. interpersonal interactions and personal characteristics), Environment \& Behavior research broadens this category to include physical aspects of the environment. Environment \& Behavior research defines stress as person-environment demands that tax or exceed the individual's ability to adapt. 
It is estimated that people spend more than $90 \%$ of their lives within buildings (Evans and McCoy, 1998). This is especially true for the residents in this study. The world within the facility designated the level of face-to-face encounters members must engage in. The boundaries of the RCF-it's walls, outside grounds, property lines, and community, etc. force upon the residents and staff the level of contact that will be required to participate in on a daily basis. Several residents could only minimize the level of contact by attempting to isolate themselves in their bedrooms and/or sleeping excessively.

Evans \& McCoy (1998) describe dimensions of the designed environment that potentially could affect human health by altering stress levels. My study identified several elements in the physical environment of the RCF that overlapped with the taxonomy developed by Evans \& McCoy (1998) and caused stress for the residents-crowding, and the after effect, noise (Stimulation), lack of stimulus shelter (Restorative), and absent or vague behavior settings (Affordances).

Overstimulation can come from a variety of environmental sources and cause a myriad of behavioral effects. Wachs \& Evans (2009) found that higher levels of residential density and chaos were inversely related to performance tasks. Density measures are quantitative assessments of the number of persons per spatial unit. It might be expected that as density increases experientially there is an increase in noise (Heft, 1984 as cited in Wohlwill \& Heft, 1991). Noise "can be studied as a type of environmental stimulus in terms of its impact on behavioral functioning, well-being, etc., that is a standard problem for psychological research conforming to the $B=f(E)$ paradigm" (Wohlwill, 1984, p. 146). Wohlwill concluded that the 
problem of noise as an environmental issue serves as an aversive stimulus and interferes with optimal behavioral functioning (1984). Exposure to noise has been empirically linked to both auditory and non-auditory effects. Non-auditory effects of noise include physiological detriments (increased heart rate or blood pressure), low motivation, and poor cognitive or attentional performance (Evans \& Lepore, 1993; Evans, 2001).

In Bridgemont there were more than one hundred interactions recorded over a two hour period during observations. Despite the large amount of square footage in this facility a majority of the activity takes place within two areas-the living room and dining area. However, there never appeared to be any sustained activity in any space. Residents would wander into the living room, briefly interact with another resident then move into another space-either exiting the front door or into another interior space. The constant movement of people, conversations, doors slamming, music blaring, staff calling out from the medication room to various residents, and sounds from the television programs blaring all created a level of noise that it was even difficult to focus on any one interaction during observation times.

The density and resulting noise exceeds the capacity of this space and the environmental quality decreases (Wohlwill, 1984). Since residents limited their daily activities to the facility (especially in inclement weather) they continue to experience the detrimental effects of overcrowding and the resulting noise. This increases their stress level and they suffer the behavioral and physiological consequences. 
Most American adults have the ability to establish some control in their environment. They do this by establishing territorial boundaries. Within these boundaries individuals are able to establish a sense of control over themselves and the space they inhabit.

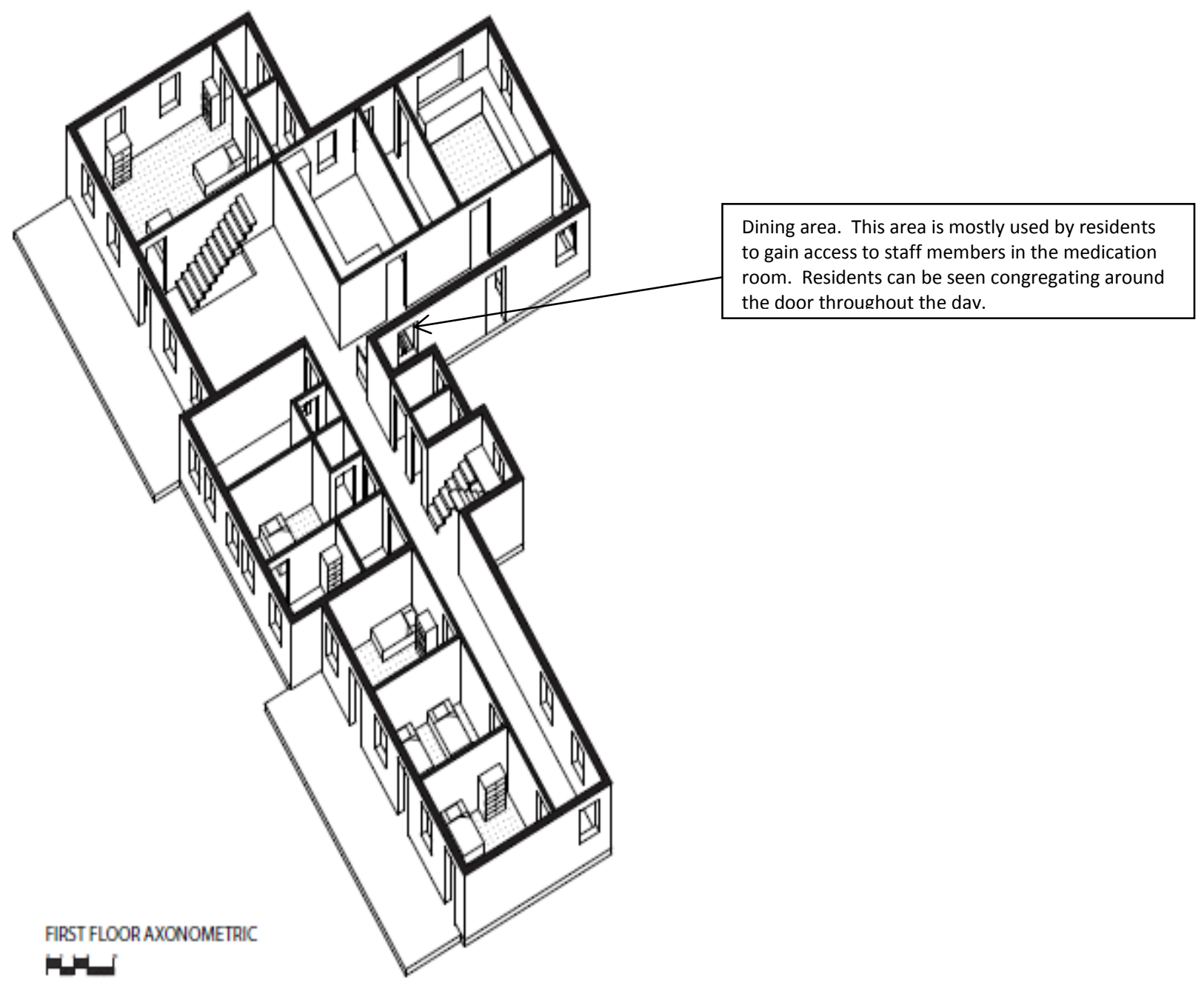

Figure 60. Bridgemont,axon drawing, first floor dining area.

In Stoneybrook the residents are confined to one room in the facility which functions as the living room, dining room, and activity room. 
The residents remained overstimulated by the constant activity in a restricted space and the resulting noise. With very few other spaces to occupy and their coping skills already compromised by their mental illness, they remained unable to deter aversive stimulus which interfered with optimal behavioral functioning.

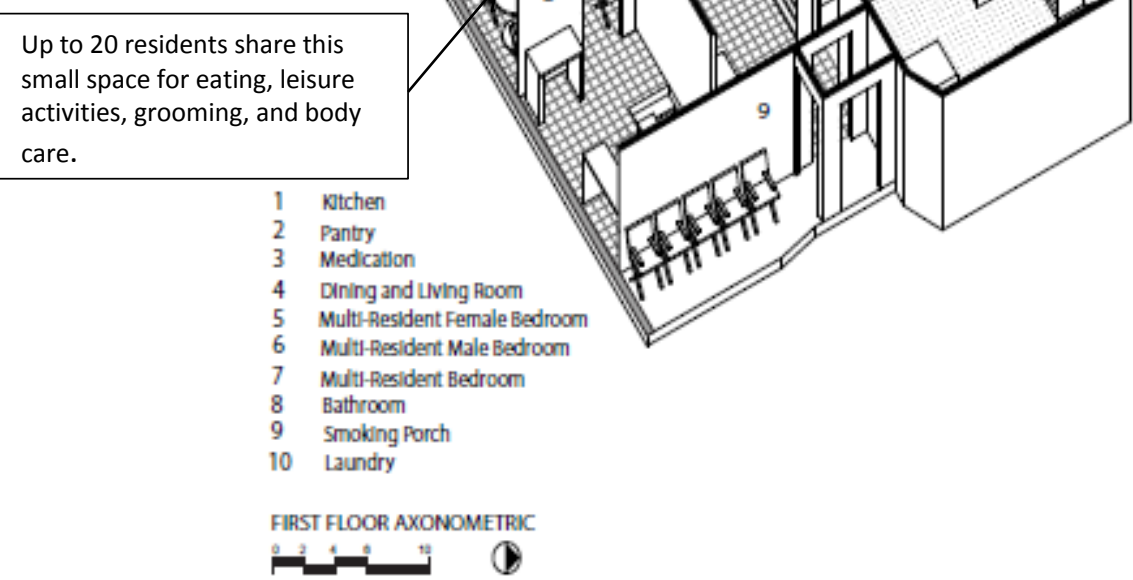

Figure 61. Stoneybrook, first floor

Evans \& McCoy assert "restorative qualities define the potential of design elements to function therapeutically, reducing cognitive fatigue and other sources of stress...and provide resources that can attenuate stress" (1998, p. 91). Restorative elements allow an individual to alter the 
balance between stress and personal resources by providing rest and recovery from a hectic environment. Elements that provide individuals with some degree of isolation and privacy, known as stimulus shelters, offset some stressful impacts of high levels of stimulation.

The residents of both RCFs in this study expressed a lack of privacy or a place to go that provides them with a stimulus shelter. In an effort to manage the barrage of activity one resident described spending about 20 hours a day in her room. But this gave her little relief due to her two roommates and her bedroom directly inside the front door which "slams all day long." In each of the two study sites there was one private bedroom. All other residents share a bedroom with up to three other residents.

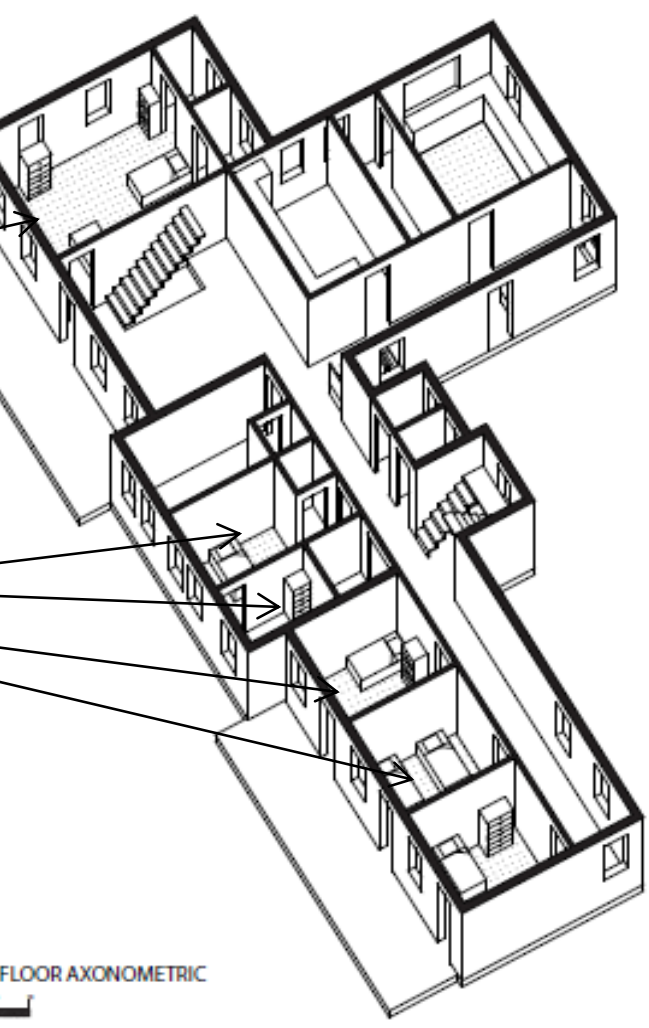

Figure 62. Bridgemont, axon drawing second floor. 
Neither of the two facilities in this study provided the residents resources for rest and recovery from their hectic living conditions. The residents had no place to go that provided them with a quiet place and shield them from the barrage of activity within the facility. Without a stimulus shelter the residents are confined to a stressful environment and remain helpless in changing their situation.

Evans \& McCoy (1998) contend that purposive actions require legible interiors and Julia Robinson adds that, like clothing, the features of the architectural setting become cues for the expected behavior, as well as props to support it (2007). Psychologist Donald Norman adds "when a building user cannot see what or how something in the space functions or when confronted with cues about purpose or use which are vague or in conflict, human reactions are likely to encompass frustration, annoyance, and, on occasion, even hostility or helplessness" (1989, p. 42). Ambiguities or misinformation about functional meaning of interior elements can result in stress due to disorientation caused by vague or missing cues or use of too many competing cues. Clearly legible behavior specific spaces are necessary so that the residents can move from one space to another with a clear intention about the behavioral expectations of that space. When the legibility of a space is clearly defined the users can behave according to the expectations of the space. When they are able to do this is it gives them a sense of accomplishment and competence. Spaces that provide a clearly discernable function and provide feedback to the residents regarding its purpose are very limited or absent in the RCFs in this study. 
In Bridgemont the dining area is directly behind the living room. Residents use this area not only for consuming meals but also for reading, coloring, craft projects and visiting with other residents. However, the appeal of this area appears to be the presence of the "med room" within the dining area. Residents congregate in the dining area throughout the day to wait for medications or speak with staff members.

The set-up of the dining/living/med room is similar in Stoneybrook. With private spaces absent in both facilities and all areas are shared by at least one other resident residents are forced to display all behavior publicly. Most grooming and body care are done in the living/dining/recreation space. Additionally, the medication room/office is only accessible through this room through a door that opens at one end of the room.

In both facilities the two most frequently used spaces (living/dining rooms) are so multifunctional that they lose any functional purpose. Instead these spaces become ambiguous because of the conflicting cues they present. Residents are not sure which behaviors to engage in when they enter the space. At both facilities residents can be seen entering a space, standing in the doorway for several moments observing the current behavior in the space. In their attempts to understand the present behavior of other residents occupying the space they then attempt to act in accordance with others. However, there is such a variety of activities taking place in any space that it would be hard to discern which behavior should be engaged in at any particular time. 
This space is used for watching television, leisure activities, consuming meals, receiving medication and body care and grooming .

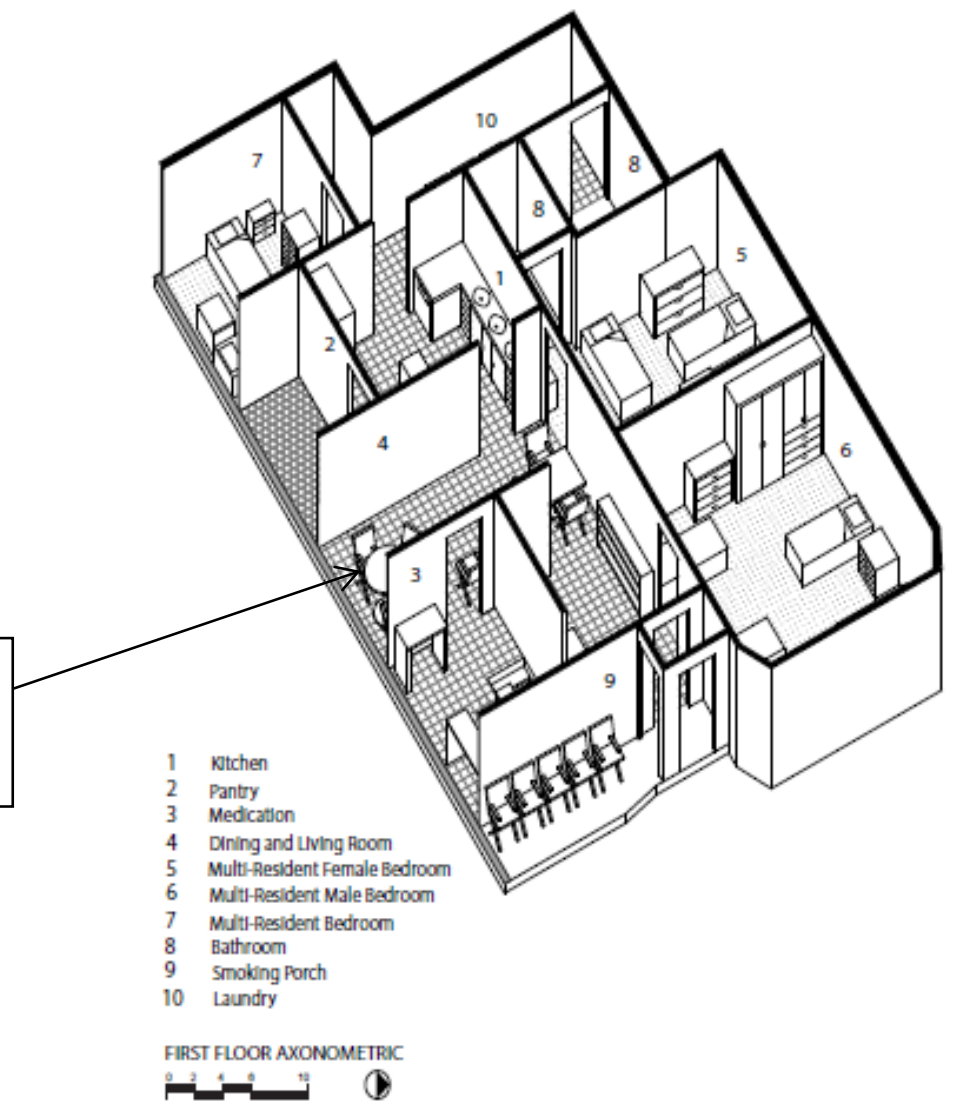

Figure 63. Stoneybrook, axon drawing, first floor

Throughout the day residents at both facilities can been seen attempting to engage in a wide variety of activities within one space. The combination of the medication room within the dining room creates conflicting cues about the behavioral responses of the dining and living room areas. The residents are provided with mixed cues about the expected behavior in the setting at any given time. Without being able to predict what type of behavior is expected the resident experiences frustration because he or she cannot determine what sort of behavior is appropriate in the specific setting. The meaning of the living room is lost and the residents have difficulty making sense out of it. The result is conflicting signals about the purpose which heighten the residents' stress level. In addition, the lack of competency the residents feel 
about their ability to predict expected behavior and behave accordingly contributes to their expressed feelings of being stuck in a situation they have no control over.

Caring for themselves and their environment is not encouraged by either facility. When asked, the staff members reported "it's against policy" to allow the residents to work in the facility. In spite of this, the Administrator at Bridgemont stated she allows the residents to perform small household tasks, such as sweeping, mopping, or helping in the kitchen around mealtime. During observation times, two residents were observed participating in facility cleaning activities. On one occasion a female was observed with a mop and bucket in the long corridor of Bridgemont. She made several announcements to other residents about her ability to help with the cleaning and sought approval from the staff members several throughout the short period. The Administrator at Bridgemont sated she has also allowed residents to run errands around town for her in exchange for a small reward (i.e. a soda from the convenience store) and the Administrator at Facility Number conceded that she has given money to residents for doing lawn care.

When Bridgemont was purchased by the current owners in 2001, the new owners' philosophy is "to promote an individual home environment in all areas of human concern through support, understanding, and opportunity." The organization's brochure further notes that their management and staff

are dedicated to enhancing individual self-esteem and providing opportunities for each individual in areas such as: physical and mental growth, community integration, participating and membership, daily habilitative programming and like skills, and promoting responsibility and independence. 
However, the residents did not benefit from these "opportunities." When H.F. was asked about whether this RCF has helped her develop some skills she stated

No, they don't. They don't give you the skills. If you got the skills that's different. But if you don't then you're kinda screwed. I learned to cook when I was seven. I started cleaning, my dad drilled stuff in my head when I was growing up. I watched my mom cook. I taught myself to cook for the majority...And for one, I'm OCD [Obsessive Compulsive Disorder] so when I clean I'm gonna get the things clean because things have been drilled into my head which haven't been drilled in other people's head. I know how to do laundry to a perfectionist degree that other people don't get...I figured out how to use the washer so when I want to do my whites I can bleach them just right. Fill up the washer machine and put the bleach in it and then put my whites in then pause it and let them soak after the water fills up.

Although this resident is able to participate in a small portion of caring for herself, most of the residents have become complacent in allowing the staff members of the facility to care for all of their needs. R.C. stated "the staff does our meds...they cook our meals...they do our laundry...they clean our rooms, they talk to us when we need talking to...and they remind me to do my ADL's." As their residency continues they become more complacent with allowing others to meet their basic needs, less able to complete activities of daily living independently, and become more dependent.

Through the voices of the participants, assessment of the physical attributes of the built environment, and analysis of public policy I was able to understand why these individuals have very little chance of ever living a good life. In an effort to fulfill basic psychological needs individuals living in a RCF must suffer humiliation and degradation. Their daily lives are filled shame and rejection by a society that refuses to integrate them. In addition, public policy is flawed. It dictates the practices that deprive these individuals of opportunities in become independent and lead a meaningful life. The building they depend on for asylum (an inviolable 
place of refuge and protection) exacerbates their conditions and even causes new, adverse conditions. They are stuck in a situation that is detrimental to their mental and physical health yet have no power to change it.

\section{Conclusions}

Dante Alighieri wrote in Inferno "we to the place have come, where I have told thee...Thou shalt behold the people dolorous...who have forgone the good of intellect" $(1400$ 's/2006). The mentally ill are dolorous and for good reason. They are trapped within the walls of the RCF, left to struggle together with more environmental demands that could peaceably be absorbed. Like the characters in tragicomic play, they must remain together-each one inescapable from one another. It would be inaccurate to say that the absurdity of their situation never occurs to them. Several factors in their lives prevent them from imagining some change that would remove the absurdity.

Although there is a conspicuous discrepancy between their aspirations and the reality of their situation, they have difficulty seeing it. Unable to survey their situation, they cannot begin to question their seemingly inescapable situation and are forced to painfully re-enact their daily existence. Their senses are dulled by heavy doses of medication and they are trapped in a prison of their own complacency. Even more absurd than the complacency in which the residents of the RCFs accepted their situation is the absurdity of a society which allows this situation to be perpetuated.

We, as a society, fail to accept them as full-fledged members of society and they are denied rights and liberties of other members of society. We fear those different from us and consider 
them a threat so we banish them to live on the fringe of society and we refuse to incorporate them into the fabric of society because we find no economic value for them.

Rejected by society they look for a place of refuge. However, when they retreat into the place they must call "home" it does not provide them with shelter form the storms of life. Instead, the places they must live exacerbates their conditions and suffer the detrimental effects of their environment.

Although Irving Goffman's seminal work regarding institutional settings (1961 \& 1963, see also, Rothman, 1971 \& Spivack, 1984) has done well to inform society of the detrimental effects of institutional living, current living environments of the mentally ill have largely been ignored. Canter \& Canter note "it is surprising that there is a such a paucity of information about the design of therapeutic environments derived from effective research processes...it is almost as if in the need to get on with doing something useful little resources are available for evaluating and studying what is being done" $(1979$, p. 23$)$. Meanwhile the mentally ill will continue to suffer and society, as a whole, will bear the ultimate economic and social price. Individuals with a mental illness continue to live in environments that rob them of the autonomy and selfdetermination. Designers place equal, if not greater, emphasis on security and the primary need over autonomy and independence, personalization, and control over space.

Today's American society is considered to be one of the most advanced in history. I question whether this is true when millions of Americans are stripped of their Constitutional Rights and are forced to live in atrocious environments where the average American could never tolerate. Even if we do not take into consideration Christian beliefs such as “...Inasmuch as ye have done 
it unto one of the least of these my brethren, ye have done it unto me" (Matt 25:40 KJV), the medical profession's Hippocratic Oath which states "With regard to healing the sick, I will devise and order for them the best diet...and I will take care that they suffer no hurt or damage" (late $5^{\text {th }}$ century BC) or Oath of Office of the President of the United States to "the best of my ability, preserve, protect and defend the Constitution of the United States" (U.S. Constitution, Article Two, Section One, Clause 8, 1787) we cannot even be considered a sane society when we allow this situation to perpetuate.

What has resulted from the closure of the large state-run asylums are facilities that mimic their predecessors. Residential Care Facilities have all of the institutional elements proposed by Goffman. Instead of RCFs providing the mentally ill with a better quality of life, residency in a RCF rob the residents of any chance of living independently. Significant elements of asylums of the $19^{\text {th }}$ century continue to exist in current living environments for individuals with a mental illness. Instead of developing a new philosophy of care for these individuals we have only mimicked pre-existing philosophies.

\section{Transinstitutionalization}

In historical perspective, we have returned to the nineteenth century practices of treatment of the mentally ill by putting large numbers of mentally ill back into prisons. Jails and prisons treat more people with a serious mental illness than hospitals and are considered the asylums of the $21^{\text {st }}$ century (See Appendix A). What has actually occurred in the United States is not deinstitutionalization but transinstitutionalization. 
In 1939 a British researcher named Lionel Penrose advanced the theory that a relatively stable number of persons are confined in any industrialized society. Using prison and mental hospital census data from 18 European countries, he demonstrated an inverse relationship between prison and mental hospital populations. Coining the term "transinstitutionalization," he postulated that if one of these forms of confinement is reduced, the other would increase. This is also true within the United States

However, RCFs should be included in the definition. This study has shown that RCFs do not promote the social values of Normalization and Social Role Valorization upon which the program of deinstitutionalization was founded. Current practices within the RCF, dictated by social policy, prevent the residents from pursuing a good quality of life. Instead, RCFs are actually detrimental to the therapeutic needs of these individuals-they are barely better than the prisons that house a majority of individuals with a mental illness.

\section{Implications for Research}

This study lends itself to many practical implications. Individuals with a mental illness do not belong in prisons. This is both costly and inhumane. Until society creates public policy that recognizes studies such as this, society will continue to suffer both economically and humanely.

Mental health expert E. Fuller Torrey notes that

any state can solve this problem if it has the political will by using assisted outpatient treatment and mental health courts and by holding mental health officials responsible for outcomes. The federal government can solve this problem by conducting surveys to compare the states; attaching the existing federal block grants to better results; and fixing the federal funding system by abolishing the "institutions for mental diseases" (IMD) Medicaid restriction (2005). 
In addition, public policy must also consider research such as this when considering the policies that determine practices in Residential Care Facilities. The inclusion of Environment and Behavior research such as this can shed light on the practical implications of the built environment's effect on human health.

It is a challenge to break free from pre-existing philosophies of care and treatment and come up with something revolutionary. Short of a Copernican Revolution in the way we treat these individuals we will continue to misplace precious economic resources and create an environment that perpetuates inhumane practices. 


\section{More Mentally III Persons Are in Jails and Prisons Than Hospitals: A Survey of the States}

\begin{tabular}{|c|c|c|c|c|c|}
\hline State & $\begin{array}{l}\text { Total number of } \\
\text { prisoners in jails } \\
\text { and } \\
\text { state prisons, } \\
\text { June } 30,2005 \\
\text { State Ranking }\end{array}$ & $\begin{array}{l}\text { Estimated } \\
\text { number of } \\
\text { prisoners } \\
\text { seriously } \\
\text { mentally ill } \\
(16 \% \text { of } \\
\text { total) }\end{array}$ & $\begin{array}{l}\text { Number of } \\
\text { patients in } \\
\text { state, private, } \\
\text { and } \\
\text { psychiatric } \\
\text { units in } \\
\text { general } \\
\text { hospitals, } \\
2004\end{array}$ & $\begin{array}{l}\text { Odds of a } \\
\text { seriously } \\
\text { mentally ill } \\
\text { person } \\
\text { being in jail } \\
\text { or prison } \\
\text { compared to } \\
\text { in } \\
\text { hospital }\end{array}$ & $\begin{array}{l}\text { State Ranking } \\
\text { based on } \\
\text { per capita } \\
\text { expenditures } \\
\text { by state mental } \\
\text { health } \\
\text { authority, FY } \\
2002 \\
\text { (lowest no. } \\
\text { spends most) }\end{array}$ \\
\hline Alabama & 40,561 & 6,490 & 1,609 & 4.0 to 1 & 35 \\
\hline Alaska & 4,678 & 748 & 206 & 3.6 to 1 & 20 \\
\hline Arizona & 47,974 & 7,676 & 827 & 9.3 to 1 & 14 \\
\hline Arkansas & 18,693 & 2,991 & 920 & 3.3 to 1 & 50 \\
\hline California & 246,317 & 39,411 & 10,295 & 3.8 to 1 & 13 \\
\hline Colorado & 33,955 & 5,433 & 1,325 & 4.1 to 1 & 31 \\
\hline Connecticut & 19,087 & 3,054 & 1,571 & 1.9 to 1 & 5 \\
\hline Delaware & 6,916 & 1,107 & 372 & 3.0 to 1 & 21 \\
\hline Florida & 148,521 & 23,763 & 4,826 & 4.9 to 1 & 45 \\
\hline Georgia & 92,647 & 14,824 & 2,921 & 5.1 to 1 & 43 \\
\hline Hawaii & 5,705 & 913 & 311 & 2.9 to 1 & 3 \\
\hline Idaho & 11,206 & 1,793 & 394 & 4.6 to 1 & 47 \\
\hline Illinois & 64,735 & 10,358 & 3,841 & 2.7 to 1 & 30 \\
\hline Indiana & 39,959 & 6,393 & 2,413 & 2.6 to 1 & 27 \\
\hline lowa & 12,215 & 1,954 & 744 & 2.6 to 1 & 39 \\
\hline Kansas & 15,972 & 2,556 & 732 & 3.5 to 1 & 25 \\
\hline Kentucky & 30,034 & 4,805 & 1,638 & 2.9 to 1 & 40 \\
\hline Louisiana & 51,458 & 8,233 & 1,807 & 4.6 to 1 & 42 \\
\hline Maine & 3,608 & 577 & 463 & 1.2 to 1 & 9 \\
\hline Maryland & 35,601 & 5,696 & 2,211 & 2.6 to 1 & 6 \\
\hline Massachusetts & 22,778 & 3,644 & 2,979 & 1.2 to 1 & 12 \\
\hline Michigan & 67,132 & 10,741 & 2,496 & 4.3 to 1 & 16 \\
\hline
\end{tabular}




\begin{tabular}{|l|l|l|l|l|l|}
\hline Minnesota & 15,422 & 2,468 & 1,982 & 1.2 to 1 & 11 \\
\hline Mississippi & 27,902 & 4,464 & 2,484 & 1.8 to 1 & 18 \\
\hline Missouri & 41,461 & 6,634 & 2,441 & 2.7 to 1 & 28 \\
\hline Montana & 4,923 & 788 & 256 & 3.1 to 1 & 7 \\
\hline Nebraska & 7,406 & 1,185 & 688 & 1.7 to 1 & 38 \\
\hline Nevada & 18,265 & 2,922 & 298 & 9.8 to 1 & 37 \\
\hline New & 4,184 & 669 & 337 & 2.0 to 1 & 10 \\
\hline Hampshire & & & & & \\
\hline New Jersey & 46,411 & 7,426 & 4,606 & 1.6 to 1 & 8 \\
\hline New Mexico & 15,081 & 2,413 & 732 & 3.3 to 1 & 49 \\
\hline New York & 92,769 & 14,843 & 12,142 & 1.2 to 1 & 1 \\
\hline North Carolina & 53,854 & 8,617 & 2,443 & 3.5 to 1 & 41 \\
\hline North Dakota & 2,288 & 366 & 365 & 1.0 to 1 & 23 \\
\hline Ohio & 64,123 & 10,260 & 2,536 & 4.0 to 1 & 34 \\
\hline Oklahoma & 32,593 & 5,215 & 1,463 & 3.6 to 1 & 46 \\
\hline Oregon & 19,318 & 3,091 & 1,026 & 3.0 to 1 & 36 \\
\hline Pennsylvania & 75,507 & 12,081 & 6,128 & 2.0 to 1 & 2 \\
\hline Rhode Island & 3,364 & 538 & 363 & 1.5 to 1 & 26 \\
\hline South Carolina & 35,298 & 5,648 & 1,113 & 5.1 to 1 & 33 \\
\hline South Dakota & 4,827 & 772 & 319 & 2.4 to 1 & \\
\hline Tennessee & 43,678 & 6,988 & 2,221 & 3.1 to 1 & 22 \\
\hline Texas & 223,195 & 35,711 & 4,579 & 7.8 to 1 & 48 \\
\hline Utah & 11,514 & 1,842 & 462 & 4.0 to 1 & 29 \\
\hline Vermont & 1,975 & 316 & 177 & 1.8 to 1 & 4 \\
\hline Virginia & 57,444 & 9,191 & 2,548 & 3.6 to 1 & 32 \\
\hline Washington & 29,225 & 4,676 & 1,521 & 3.1 to 1 & 15 \\
\hline
\end{tabular}




\begin{tabular}{|l|l|l|l|l|l|}
\hline West Virginia & 8,043 & 1,287 & 609 & 2.1 to 1 & 44 \\
\hline Wisconsin & 36,154 & 5,785 & 1,500 & 3.9 to 1 & 17 \\
\hline Wyoming & 3,515 & 562 & 199 & 2.8 to 1 & 24 \\
\hline
\end{tabular}

by

E. Fuller Torrey, M.D.

Executive Director, Stanley Medical Research Institute, and Board Member, Treatment Advocacy Center

Sheriff Aaron D. Kennard (retired), M.P.A.

Executive Director, National Sheriffs' Association

Sheriff Don Eslinger,

Seminole County (Fla.) Sheriff's Office, and Board Member, Treatment Advocacy Center

Richard Lamb, M.D.,

Professor of Psychiatry, University of Southern California Keck School of Medicine, and Board Member, Treatment Advocacy Center

James Pavle Executive Director, Treatment Advocacy Center

May 2010 


\section{References}

Alighieri, D. (1400/2006). Divine Comedy. New York: Chartwell Books, Inc.

Beam, A. (2001). Gracefully Insane. U.S.: Public Affairs.

Bing (2014a). Pennsylvania Hospital. Downloaded at: http://www.bing.com/images/ search?q=pennsylvania+hospital+photos\&qpvt=pennsylvania+hospital+photos\&FORM=I QFRML\#a.

Bing (2014b). Patterson General Hospital. Downloaded at: http://www.bing.com/search? q=paterson\%20hospital\%20photos\&pc=cosp\&ptag=AFC1692AFF9844FB583F\&form=CO NBNT\&conlogo=CT3210127.

Burrell Behavioral Health Brochure (2014). Downloaded at: http://www.burrellcenter.com/.

Burrell Behavioral Health (2014). Services. Downloaded at: http://www.burrellcenter.com/ services-2/ adult-services/

Canter, D. \& Canter, S.(Eds.) (1979). Designing for Therapeutic Environments. New York: John Wiley \& Sons, Ltd.

Centers for Medicare and Medicaid Services. (2013) Community Mental Health Centers. Downloaded at: http://www.cms.gov/Medicare/Provider-Enrollment-andCertification/CertificationandComplianc/ CommunityHealthCenters.html.

Charmaz, K. (2006). Constructing Grounded Theory: A practical guide through qualitative analysis. Los Angeles: Sage Publications, Inc.

Chorpita, B. \& Barlow, D. (1998) The Development of Anxiety: The role of control in early environment. Psychological Bulletin, 124 (1),3-21.

Community Mental Health Act: Kennedy's vision never realized (2014). Downloaded at: http://www.wjla.com/articles/2013/10/community-mental-health-act-kennedy-svision-never-realized-95665.html.

Cresswell, J. (2009). Research Design: Qualitative, quantitative, and mixed methods approaches. Los Angeles, Sage Publications, Inc.

Ericsson, K. (1985). The Principle of Normalization: History and experiences in Scandinavian countries. Presentation, ILSMH Congress, Hamburg, 1985. 
Evans, G. \& McCoy, J. (1998). When Buildings Don't Work: The role of architecture in human health. Journal of Environmental Psychology, 18.

Fairfield State Hospital (2013). Downloaded at http://www.fairfieldstatehospital.com/ index2.html.

Flyvbjerg, B. (2011). Case Study. In Denzin, N. \& Lincoln, Y. (Eds.) The Sage Handbook of Qualitative Research. Los Angeles: Sage Publications, Inc.

Foucault, M. (1977). Discipline \& Punish: The birth of the prison. New York: Vantage Books.

Goffman, E. (1961). Asylums: Essays on the social situation of mental patients and other inmates. New York: Anchor Books.

Greene County Public Administrator (2013). Mission Statement. Downloaded at: http://www.greenecountymo.org/public_administrator/.

Gubrium, J. (1997). Living and Dying at Murray Manor. USA: First University Press of Virginia.

Lawton, M. (1998). Environment \& Aging: Theory revisited. In Scheidt, R. \& Windley, P. (Eds.) Environment and Aging Theory: A focus on housing. Westport, CT: Greenwood Press.

McAlester, V. \& McAlester, L. (2009). The Field Guide to American Houses. New York: Alfred A. Knopf.

Missouri Department of Elementary and Secondary Education (2013). Educational Services Provided to Students with Severe Disabilities. Downloaded at: http://dese.mo.gov/ se/ep/documents/ DESEREPORT.pdf.

Missouri Department of Health and Senior Services (2013a). Alphabetical Listing of Long Term Care Facilities. Downloaded at: http://health.mo.gov/cgi-bin/nhomes.pl.

Missouri Department of Health and Senior Services (2013b). Level of Licensure for Long Term Care Facilities. Downloaded at: http://health.mo.gov/safety/showmelongtermcare/ Ivloflic.php.

Missouri Department of Health and Senior Services (2013c). Rules of Department of Health and Senior Services: Division 30-Division of Regulation and Licensure, Chapter 86-Residential Care Facilities and Assisted Living Facilities. Downloaded at: http://www.sos.mo.gov/ adrules /csr/current/ 19csr/19c30-86.pdf.

Missouri Department of Health and Senior Services (2013d). Senior and Disability Services: Frequently Asked Questions. Downloaded at: http://health.mo.gov/seniors/ nursinghomes/faqs.php. 
Missouri Department of Mental Health (2013). Legal and Advocacy Nursing Home Reform Act Revised 5-3-11. Downloaded at: http://dmh.mo.gov/docs/dd/L8-NursingHome ReformAct5-3-11.pdf.

National Alliance for the Mentally III. (2014). Downloaded at: http://www.nami.org/.

Nelson, W. \& Shriner, C. (1920). A History of Paterson. Downloaded at: http://www.paterson history .com/.

Norman, D. (1973). The Psychology of Everyday Things. New York: Basic.

Olmstead vs. L.C.: (2014). Downloaded at: http://en.wikipedia.org/wiki/OImstead_v._L.C.

Osburn, J. (1998). An Overview of Social Role Valorization Theory. The International Social Role Valorization Journal/La revue internationale de la Valorisation des roles sociaux, 3(1), 7-12.

Parmelee, P. \& Lawton, M. (1990). The Design of Special Environments for the Aged. In Handbook of Psychology of Aging (Third Edition). New York: Academic Press, Inc.

Pennsylvania Hospital (2014a). About Us. Downloaded at: http://www.pennmedicine.org/ pahosp/about-us/.

Pennsylvania Hospital (2014b). Historic Tours. Downloaded at http://www.pennmedicine.org/ pahosp/about-us/history/historic-tours.html

Richards, L. \& Morse, J. (2013). README FIRST FOR A USER'S GUIDE TO Qualitative Methods, Third Edition. Los Angeles: Sage Publications.

Saldaña, J. (2013). The Coding Manual for Qualitative Researchers. Los Angeles: Sage Publications, Inc.

Schwarz, B. (1996). Nursing Home Design: Consequences for employing the medical model. New York: Garland Publishing, Inc.

Szasz, T. (2007). Coercion as Cure: A Critical History of Psychiatry. New Brunswick, New Jersey: Transaction Publishers.

Taylor, J. (2010). The Most Famous and Notorious Insane Asylums in History. Downloaded at: www.asylum.com/2010/02/famous-notorious-abandoned-haunted-insane-asylums/.

Torrey, E. (2005). More Mentally III Persons Are in Jails and Prisons Than Hospitals: A Survey of the States. Downloaded at: http://mentalillnesspolicy.org/NGRI/jails-vs-hospitals. html\#.VNJmR81ZG1k.email. 
Wohlwill, J. (1984). Psychology and the Environmental Disciplines. In Bornstein, M. (Ed.). Psychology and Its Allied Disciplines: Psychology and the social sciences. New Jersey: Lawrence Earlbaum Associates, Inc.

Yanni, C. (2007). The Architecture of Madness: Insane asylums in the United States. Minneapolis: Minnesota University Press. 


\section{VITA}

Renee Desneige Christensen was born March 7, 1964. She moved to California the following year and attended several public schools in southern California. She graduated from Yuba City High School in 1982 then joined the United States Navy. After her discharge in 1986 she lived in Boston Massachusetts and briefly attended Northeastern University and Boston College. She then moved to Missouri and finished her B.A. in Psychology at Drury University in Springfield, Missouri in 1994. She then went on to receive a MEd in Human Services from Drury University in 2000. In 2014 she received a MS degree and a PhD in Architectural Studies from the University of Missouri-Columbia 